BUL--2.132-REV.

DE84 002574
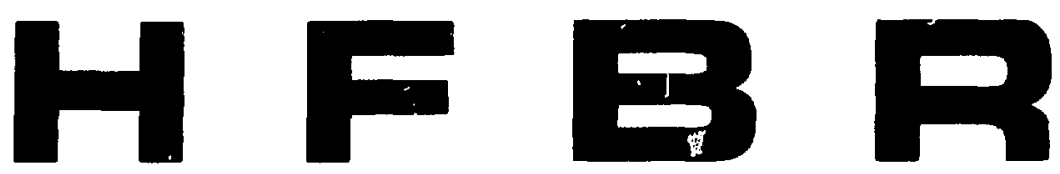

\title{
HANDBOOK
}

\section{AUEUST 1983}

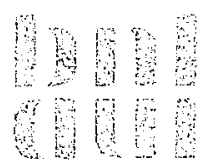

INFORMAL REPDRT

BROOKHAVEN NATIONAL LABORATGRY UPTON, LONG ISLAND, NEW YORK 11973

ASSOCIATED UNIVERSITIES, INC. UNOEA CONTRACT NO DE-ACO2-76CHOOO1E WITH THE

UNITED STATES DEPARTMENT OF ENEREY

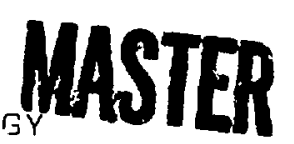




\section{PRHFACE}

This manual is intended primarily to acquatint outside users and new Broukhaven staft member: with the rescarch facilities avalableat the HFlBR. In addition to describing the beam lines and major in:- ruments. genrat information is also provided on the reactor and on services avalable at the latboratory. We are indebted to members of the usergercups in the Brookhaven I lepartment of Physies. (hemistry and Biology for providing the information from which the manual was assembled. We would also like (o acknowledge in particular. the valuable assistance of $F$ 'l. Langdon for coordinating the preparat ion of figures fur the experiment al facilities.

\section{The Editors}

S. Shapiro, 1).C. Rurer. and $H$. Kuper

\section{DISCLAIMER}

This report was prepared as an account of work sponsored by an agency of the United States Government. Neither the United States Government nor any agency thereof, nor any of their employces, makes any warranty, express or implied, or assumes any legal liability or responsibility for the accuracy, completeness, or usefulness of any information, apparatus, product, or process disclosed, or represints that its use would not infringe privately owned rights. Reference herein to any specific commercial product, process, or service by trade name, trademark, manufacturer, or otherwise does not neces:arily constitute or imply its endorsement, recommendation, or favoring by the United States Government or any agency thereof. The views and opinions of authors expressed harein do not neccssarily state or reflect those of the United States Government or any agency thereof. 


\section{CONTENTS}

Preface $\ldots \ldots \ldots \ldots \ldots \ldots \ldots \ldots \ldots \ldots \ldots \ldots \ldots \ldots \ldots \ldots \ldots \ldots \ldots$ iii

I. The High Flux Beam Research Reactor $\ldots \ldots \ldots \ldots \ldots \ldots \ldots$, I

General Description of the Reactor .................. 1

The Confinement Building $\ldots \ldots \ldots \ldots \ldots \ldots \ldots \ldots \ldots, 7$

Beam Tube Design ............................ 9

Cold Neutron Moderator............................ 12

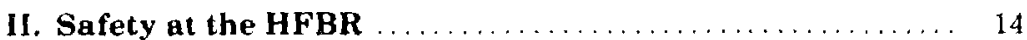

Use of the Confinement Building ..................... 14

Actions in Case of HFBR Emergencies . ................. 15

Safety Requirements for Experiments . . . . . . . . . . . . . 16

111. HFBR User Policy $\ldots \ldots \ldots \ldots \ldots \ldots \ldots \ldots \ldots \ldots \ldots \ldots$

IV. Experimental Beam Facilities .................... 20

H1-A Spectrometer (Nuclear Physics) .................. 21

H1-B Spectrometer (Nuclear Physics) . . . ............ 22

H2 Tristan (Nuclear Physics) ...................... 24

H2 Fast Chopper (Nuclear Physics) ................... 26

H3.A Spectrometer for Protein Crystallography .......... 28

H3-B Duuble-Axis Spectrometer

(Small Angle Scattering and Diffraction) ............. 28

H4-M Triple-Axis Spectrometer

(Inelastic Scattering) ........................... 30

H4-S Double-Axis Spectrometer

(Diffraction and Small Angle Scattering) $\ldots \ldots \ldots \ldots \ldots \ldots, 32$

H5 Triple-Axis Spectrometer

(Inelastic Scattering) ........................... 34

H6-M Triple-Axis Spectrometer

(Diffraction) $\ldots \ldots \ldots \ldots \ldots \ldots \ldots \ldots \ldots \ldots \ldots \ldots, 36$

H6-S Double-Axis Spectrometer

(Diffraction) $\ldots \ldots \ldots \ldots \ldots \ldots \ldots \ldots \ldots \ldots \ldots \ldots \ldots \ldots \ldots \ldots, 38$ 


\section{CONTENTS (cont.)}

H7 Triple-Axis Spectrometer

(Inelastic Scattering) .......................... 40

H8 Triple-Axis Spectrometer

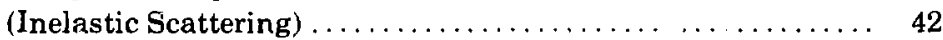

H9-A Triple-Axis Spectrometer

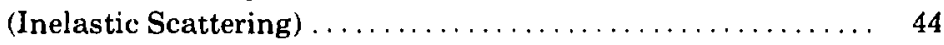

H9-B Double-Axis Spectrometer

(Small Angle Scattering - Biological Stucture) $\ldots \ldots \ldots \ldots, 46$

Ancillary Equipment .......................... 48

Computer Control System (RECF) $\ldots \ldots \ldots \ldots \ldots \ldots \ldots \ldots \ldots, 48$

V. Irradiation of Samples at the HFBR $\ldots \ldots \ldots \ldots \ldots \ldots \ldots, 49$

VI. General Information for Visitors $\ldots \ldots \ldots \ldots \ldots \ldots \ldots, \quad 52$

The Laboratory and Its Organization ................. 52

Appointments ............................... 52

Transportation .................................. 55

Housing .................................. 57

Food Service $\ldots \ldots \ldots \ldots \ldots \ldots \ldots \ldots \ldots \ldots \ldots \ldots \ldots \ldots, \quad 58$

Other Services and Amenities $\ldots \ldots \ldots \ldots \ldots \ldots \ldots \ldots \ldots, 58$

Directory $\ldots \ldots \ldots \ldots \ldots \ldots \ldots \ldots \ldots \ldots \ldots \ldots \ldots \ldots \ldots \ldots, 63$

\section{Appendices}

A. Physical Constants and Conversion Factors $\ldots \ldots \ldots \ldots \ldots \ldots, 65$

B. Wavelength, Frequency, Energy Relationships ........... 66

C. Radiation Inits $\ldots \ldots \ldots \ldots \ldots \ldots \ldots \ldots \ldots \ldots \ldots \ldots \ldots \ldots \ldots \ldots$

D. Coherent Neutron Scattering Amplitudes .............. 68

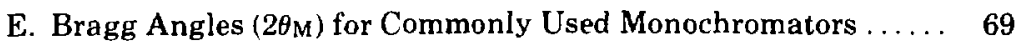

F. Gamma-Ray Attenuation ........................ 73 


\section{The High Flux Beam Research Reactor}

Since their discovery by Sir James Chad wick in 1932, neutrons have been studied not only in themselves, but have provided an extremely powerful tool for studying matter on the nuclear, atomic, and molecular levels as well. Neutrons have been used as probes by nuclear and solid state physicists, chemists, and most recently, by biologists. As techniques for using neutrons have developed in these various disciplines, there has been an accumpanying need for higher levels of neutron flux in order to carry out more complex and sophisticated experiments. The Brookhaven High Flux Beam Reactor (HFBR) was designed to meet this need, providing a total flux of $2.4 \times 10^{15}$ neutrons $/ \mathrm{cm}^{2}$-sec at a power of 60 megawatts.

The HFBR first achieved criticality on October 31, 1965, approximately four years after construction began, and became available for general experimental use at full power several months later. The initial construction cost of the HFBR was $\$ 12.5$ million, and its current annual operating cost is approximately $\$ 6.1$ million (including associated overhead cost distributions).

\section{GENERAL DESCRIPTION OF THE REACTOR}

The HFBR uses highly enriched U-235 fuel and a heavy water moderator to sustain a controlled nuclear reaction. The core consists of 28 elements, each containing 18 curved fuel plates (of the Materials Testing Reactor Type). In each plate $\mathrm{U}_{3} \mathrm{O}_{8}$ powder is mixed with aluminum powder to form a cermet core, which is encased in alumi- 
num cladding. The cladding acts as a barrier or containment for the highly radioactive isotopes formed as fission products during the chain reaction.

The fuel elements are placed in a roughly cylindrical arrangement inside a spherical-shaped aluminum reactor vessel. The core is approximately $5.3 \mathrm{~cm}$ high and $18 \mathrm{~cm}$ in diameter, has an active volume of about 97 liters and contains a maximum of 9.8 kilograms of U-235. The $\mathrm{D}_{2} \mathrm{O}$ moderator is pumped downward through the spaces between the fuel element plates at a pressure of $1.4 \times 10^{6}$ pascals, carrying away the 60 megawatts of thermal energy developed in the core during normal reactor operation. The $\mathrm{D}_{2} \mathrm{O}$ is circulated through a pair of heat exchangers where the heat is transferred to an $\mathrm{H}_{2} \mathrm{O}$ secondary loop which dissipates the heat into the air through a set of cooling towers.

Outside the reactor vessel is a water-cooled thermal shield of steel and lead $23 \mathrm{~cm}$ thick. This secondary vessel protects the surrounding outer shield from excessive heating by radiation from the reactor and provides containment to keep the core covered with heavy water in the event of a leak in the reactor vessel. An outer shield, known as the biological shield, protects the reactor operators and experimenters from the radiation produced in the reactor. The biological shield, which has a minimum thickness of 2.4 meters, is a mixture of heavy concrete and steel punchings.

In contrast to most reactors, which are designed to minimize the escape of neutrons from the core, the HFBR has been expressly designed to maximize the number of neutrons available in external beams. This is accomplished through the choice of coolant material and core configuration. Heavy water, rather than light water, has been selected as the coolant and moderator in this reactor. The volume of $\mathrm{D}_{2} \mathrm{O}$ flowing through the core to cool the fuel elements does not provide sufficient moderation to thermalize all the neutrons 


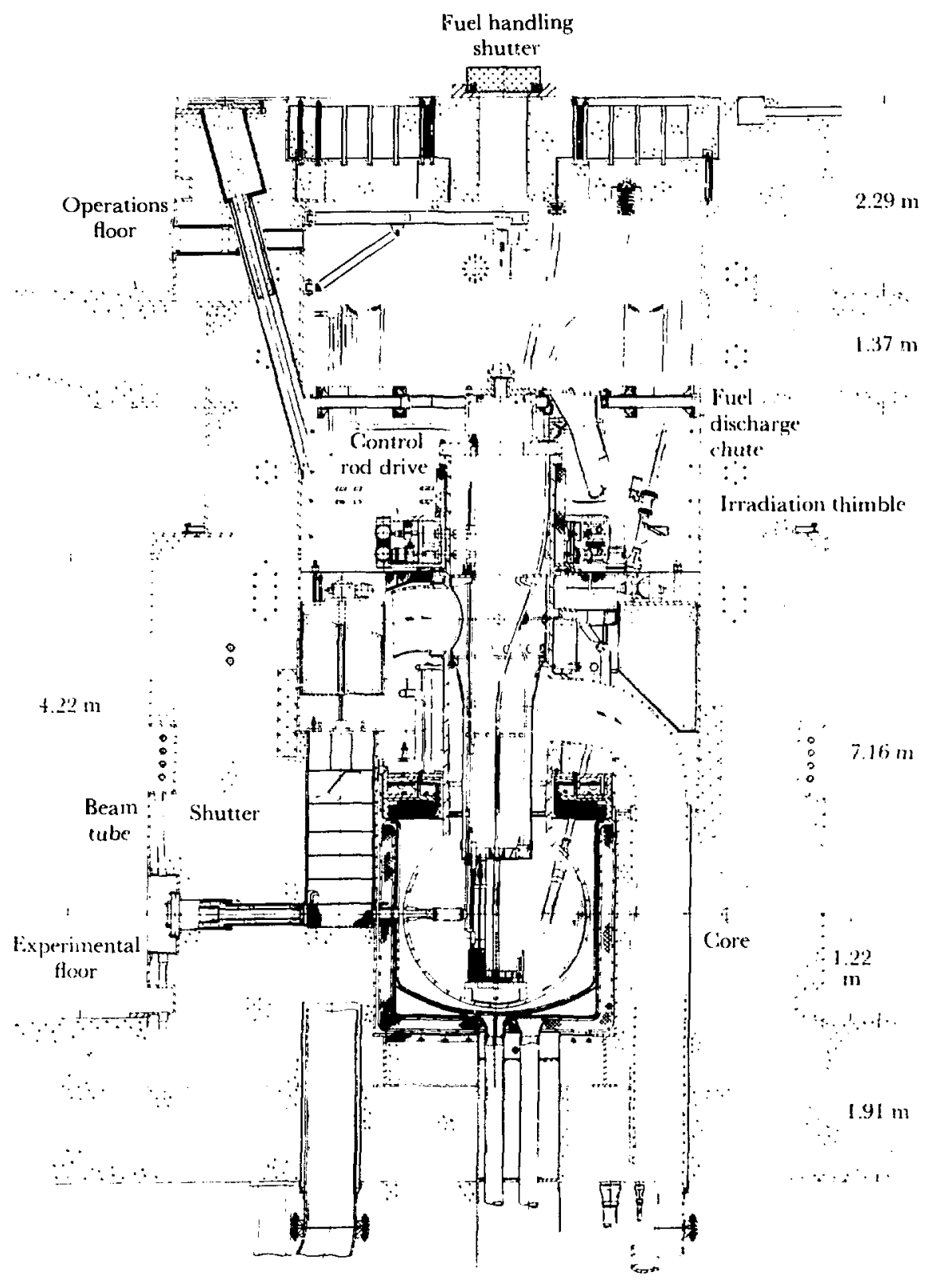

Elevation of the reactor vessel and shielding, showing a typical bean tube, shutter, and thimble. 
within the core. A large number of fast and epithermal neutrons thus escape from the region of the fuel and are subsequently moderated in the large volume of $\mathrm{D}_{2} \mathrm{O}$ reflector surrounding the core. Some of the resulting thermal neutrons are reflected back into the core where they help tc sustain the nuclear chain reaction. This choice of materials and configuration results in a unique neutron distribution in which the useful thermal neutron population peaks in the reflector, where the neutrons are directly accessible to the beam tubes. The higher energy neutrons, which are normally not desirable in the beams, are greatest in population within the core. Power density is peaked at the periphery rather than at the center of the core as in most other reactors.

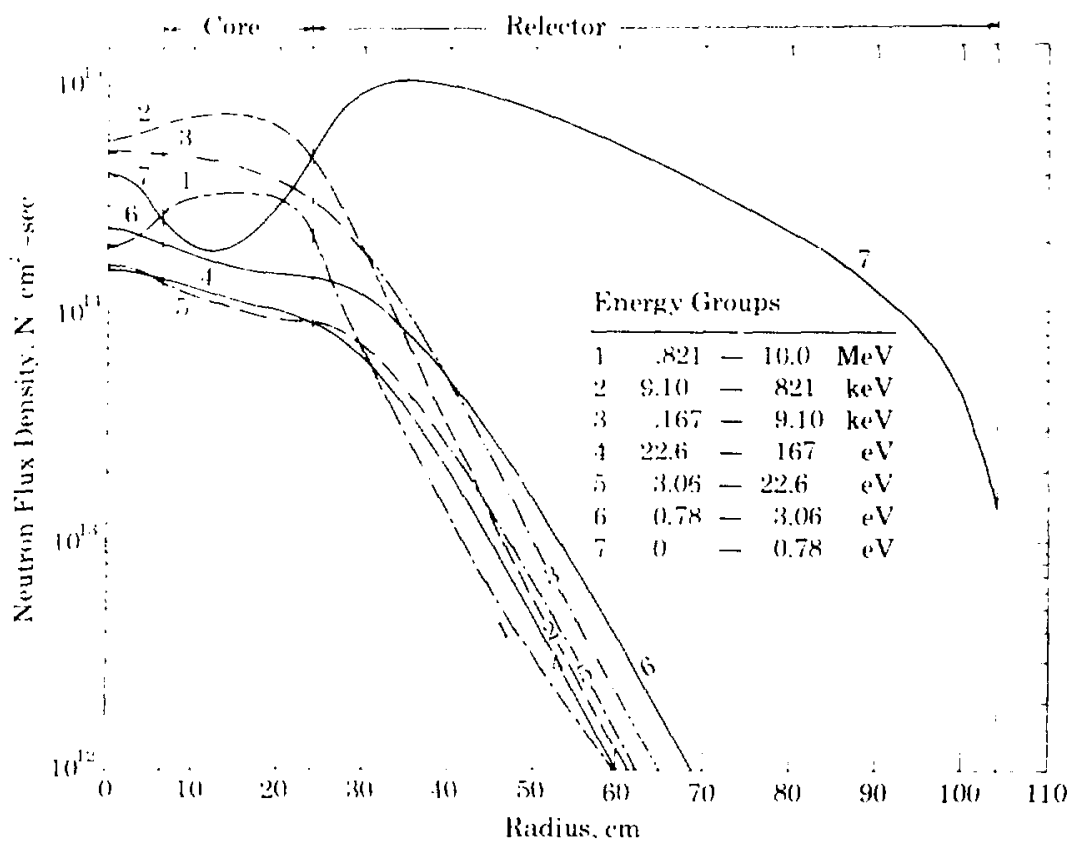

Calculated neutron fux distributions as a function of radial distance from the center of the core. 
Sixteen control rods containing dysprosium and europium oxides act as neutron "poisons" to absorb thermal neutrons and control the rate at which the nuclear reaction takes place. These rods are located just cutside the core and are arranged into two groups, a main bank which can be raised above the core, and an auxiliary bank which can be lowered below the core. Shutdown of the chain reactinn is accomplished by masking the core from the return of thermal neutrons from the reflector by covering the sides of the core with the control rod blades. During normal operation, the neutron flux is maintained constant at the core midplane by withdrawing the control rods approximately symmetrically from the top and bottom of the core as fuel burnup progresses.

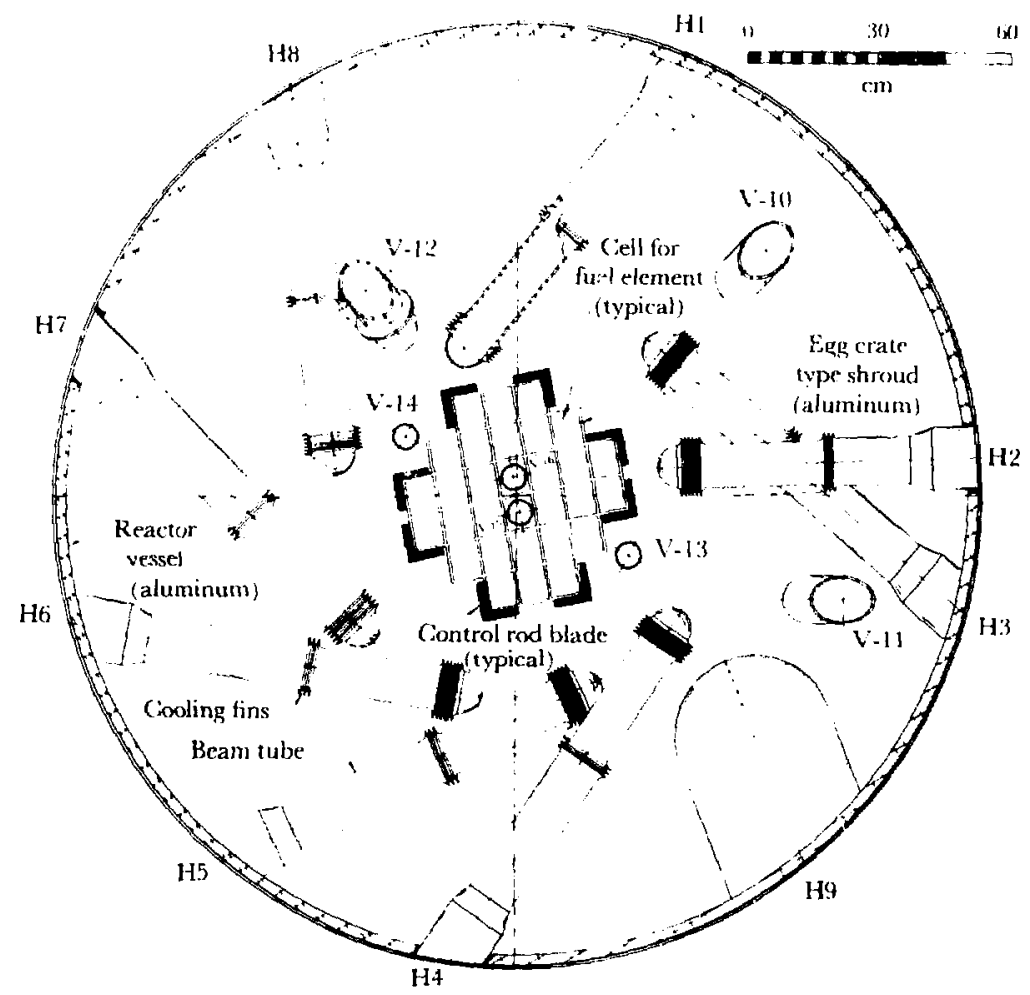

Plan view of the location of the experimental beam tubes and irradiation facilities within the reactor ve sel. 


\section{HFBR Statistics}

Reactor power

Total fast neutron flux, fuel region

Maximum thermal ilux, reflector

Active core volume

Active height of core

Diameter of core (equivalent cylinder)

Number of fuel elements in core

Dimensions of fuel element

Cross section (fuel plates)

Jength of 2 outer plates

Length of 18 inner fuel plates

Total length of fuel element

Uranium-235 content of fuel element

Total uranium-235 loading

Reactor coolant

Total coolant flow rate

Maximum operating coolant pressure

Maximum operating inlet coolant temperature

Maximum temperature at fuel elenient surface

Number of control rods

Dimensions of control rod cross section

(rods are right angle shape)

Length of main rods

Length of auxiliary rods

Neutron absorber in rods

Diameter of spherical portion of reactor vessel

Diameter of neck of reactor

Thickness of thermal shield (lead and steel)

Minimum thickness of biological shield (heavy concrete)
60 million watts $2.4 \times 10^{15} \mathrm{n} / \mathrm{cm}^{2}-\mathrm{sec}$

$1.05 \times 10^{15} \mathrm{n} / \mathrm{cm}^{2} \cdot \mathrm{sec}$

97 liters

$52.7 \mathrm{~cm}$

$47.8 \mathrm{~cm}$

28

$8.113 \times 7.163 \mathrm{~cm}$

$58.4 \mathrm{~cm}$

$52.7 \mathrm{~cm}$

$154.4 \mathrm{~cm}$

$351 \mathrm{~g}$

$9.8 \mathrm{~kg}$

heavy water $\left(\mathrm{D}_{2} \mathrm{O}\right)$

1150 liters/sec

$1.72 \times 10^{6}$ pascals $65^{\circ} \mathrm{C}$

$\approx 175^{\circ} \mathrm{C}$

16

$7.6 \times 7.6 \times 1.78 \mathrm{~cm}$

$102.9 \mathrm{~cm}$

$31.8 \mathrm{~cm}$

$\mathrm{Dy}_{2} \mathrm{O}_{3}$ and $\mathrm{Eu}_{2} \mathrm{O}_{3}$

$208.3 \mathrm{~cm}$

$121.9 \mathrm{~cm}$

$22.9 \mathrm{~cm}$

$243.8 \mathrm{~cm}$ 
The HFBR is operated 24 hours per day for a period of either 14 or 24 days, depending on the number of fuel elements which are replaced with new fuel during the shutdown at the end of each operating cycle. If seven elements are replaced, the operating cycle will last 14 days, while replacement of 14 elements results in a 24 -day cycle. The refucling shutdown normally lasts for a period of 3 to 6 days, varying with the amount of maintenance and surveillance testing which must be done.

For safety reasons, all nuclear reactors are designed with a negative temperature coefficient of reactivity, so that any power surges which might occur will be self-limiting due to the automatic decrease in reactivity as the reactor heats up. This safety feature has an important effect on the maximum length of the operating cycle which can be obtained at the HFBR. During the summer months the efficiency of the cooling towers can vary over a wide range in a short time, depending on air temperature and humidity. The corresponding changes in reactor coolant temperature produce changes in the reactivity which become especially significant near the end of the fuel cycle, when there is little excess reactivity to spare. Negative reactivity effects under such conditions can sometimes result in insufficient reactivity being available to sustain the chain reaction and can cause a premature shutdown, shortening the operating cycle by as much as one day. Conversely, cold winter days coinciding wilh the end of the fuel cycle can proleng the cycle.

\section{THE CONFINEMENT BUILDING}

The reactor, its auxiliary equipment, and its experimental facilities are contained in a welded steel hemisphere 53.6 meters in diameter. While the reactor is in operation the air pressure inside the building is kept slightly lower than the atmospheric pressure outside to insure that any air leakage is inward rather than outward. Access to the building is provided by a system of air locks. This building provides 
the final confinement barrier against the escape of radioactive material into the environment. All ventilation air leaving the building is processed through high efficier.cy particulate filters and charcoal absorbers befrre being discharged from a 100 meter stack.

There are three basic floor levels in the building. The bottom floor is known as the Equipment Level. The main features of this level are a shielded cell in the center of the floor, containing the primary coolant system pumps and heat exchangers, and the fuel storage canal. The highly radioactive spent fuel elements are discharged into the canal through a chute passing down from the top of the reactor vessel through the concrete shielding. The canal presently has storage capacity for as many as 833 elements. The canal is 6 meters deep for most of its length, with a 9 -meter deep pit at the end of the fuel discharge chute. The spent fuel elements are stored under the shielding water of the canal until most of the radioactivity has died away and they can be shipped off site to : fuel reprocessing plant for recovery of the unused uranium-235.

Other auxiliary equipment located on this floor includes heat exchangers and pumps for the coolant for the thermal shield and the biological shield, purification systems for the $\mathrm{D}_{2} \mathrm{O}$ coolant and canal water, as well as the equipment supplying the building with electrical power, steam, hot water, and compressed air.

The Experimental Area occupies the middle flonr. The reactor is located in the center of the floor, with its nine horizontal beam ports surrounded by massive shielding and complex equipment for external beam experiments. Laboratories, computer equipment rooms, and a health physics office are also located on this floor level. A radial $18000 \mathrm{~kg}$ traveling beam crane serves this area. Truck and fork lift access is provided by two separate air locks. A balcony above the main floor is available for observation and accommodates washrooms, offices, and air conditioning equipment. A machine shop is located adjacent to this level outside the confinement building. 
The Operations Area is on the top floor of the building. The reactor shielding structure rises 2.3 meters above floor level in the center of the area. The reactor control room, the pumps and heat exchangers for the cooling system for the vertical irradiation tubes, the $\mathrm{D}_{2} \mathrm{O}$ storage tank for the primary coolant system, offices, work rooms, and the fuel storage vault are located on this floor. An $18000 \mathrm{~kg}$ overhead crane services the reactor top and the adjacent area in which replacement of spent fuel elements with new ones takes place.

\section{BEAM TUBE DESIGN}

The accompanying figures in this Section provide information which may be helpful to users in understanding the capabilities of the various instruments described in Section IV, or in planning their experiments if some new type of installation is contemplated. Several types of beam tubes were incorporated ir to the HFBR design. $\mathrm{H} 2$ is the only tube which "looks" directly at the core; it was designed specifically for nuclear studies employing fast neutrons. H3 is typical of the single thermal neutron tubes, used also at $\mathrm{H} 1, \mathrm{H} 5, \mathrm{H} 7$, and H8. Dual thermal tubes are used at $\mathrm{H} 4$ and $\mathrm{H} 6$, facilitating development of two beam lines at each of these ports. H9 is a special large diameter tube which was designed to accommodate a cold neutron moderator. The remaining figure shows a more-or-less typical section in elevation of a beam tube penetration through the biological shield into the reactor vessel, along with a typical double-axis spectrometer installation. 


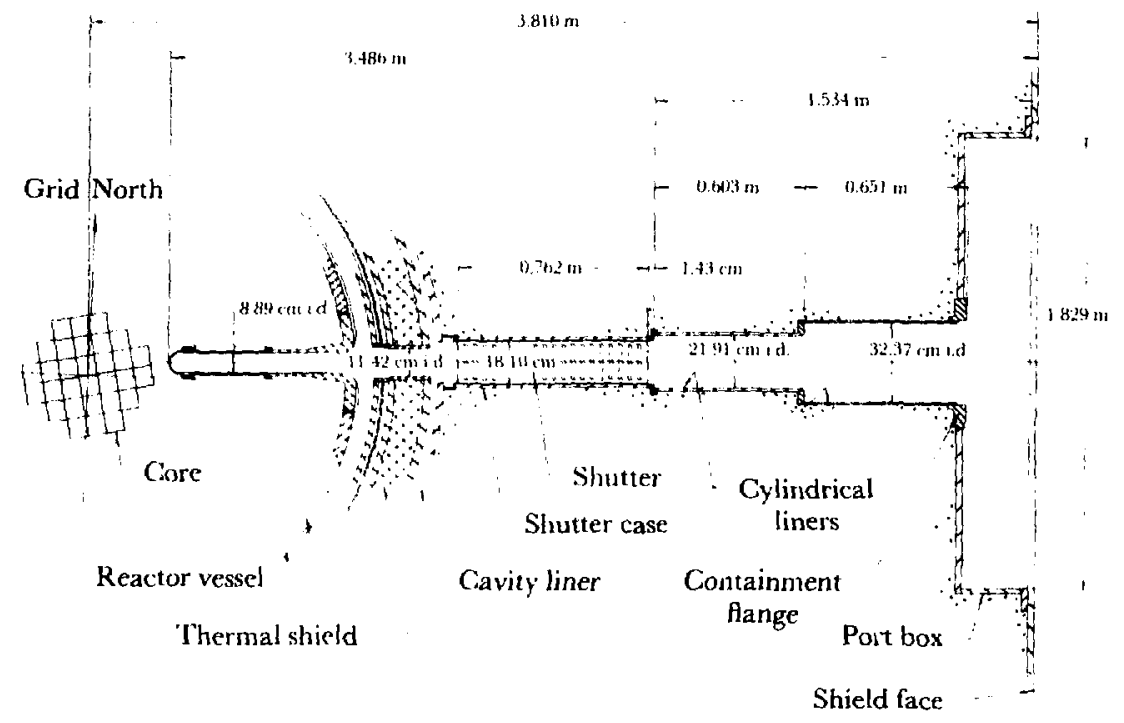

Plan of HFBR beam tube $\mathrm{H} 2$.

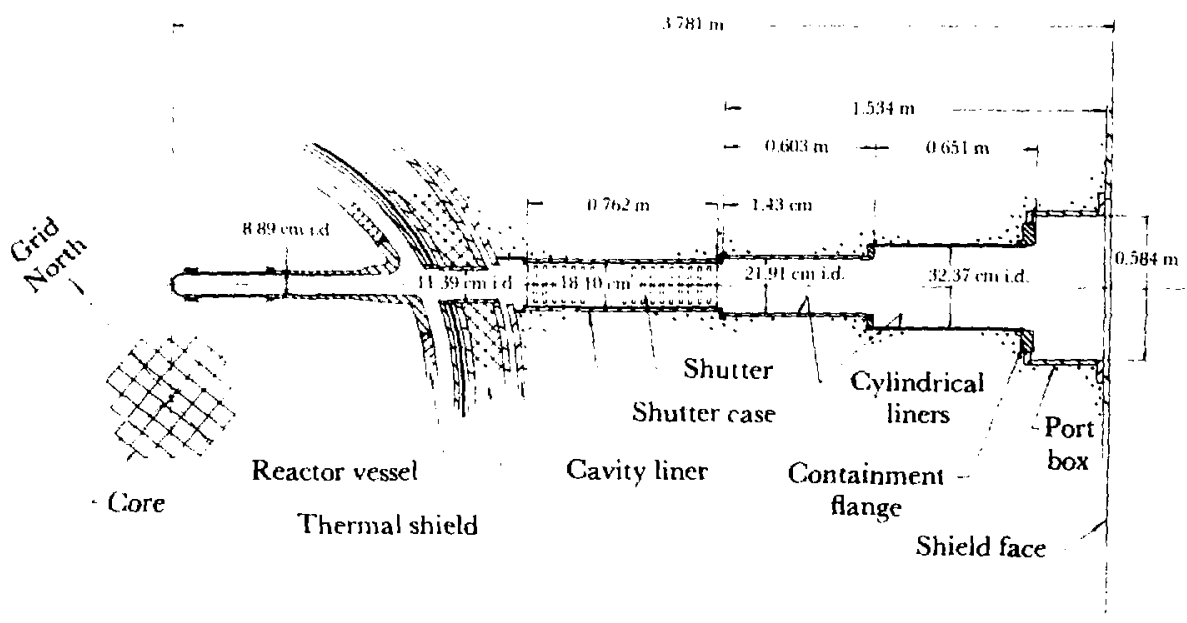

Plan of HFBR beam tube $\mathrm{H} 3$ typical of thermal tubes. 


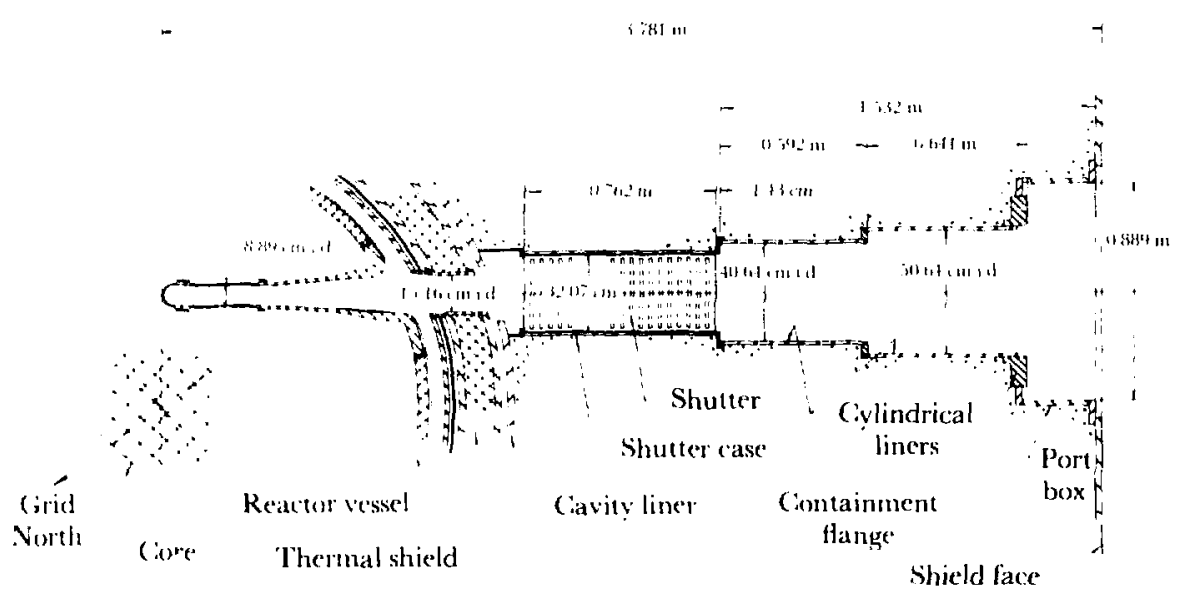

Plan of HFBR beam tube $\mathrm{H} 4$ typical of dual thermal tubes

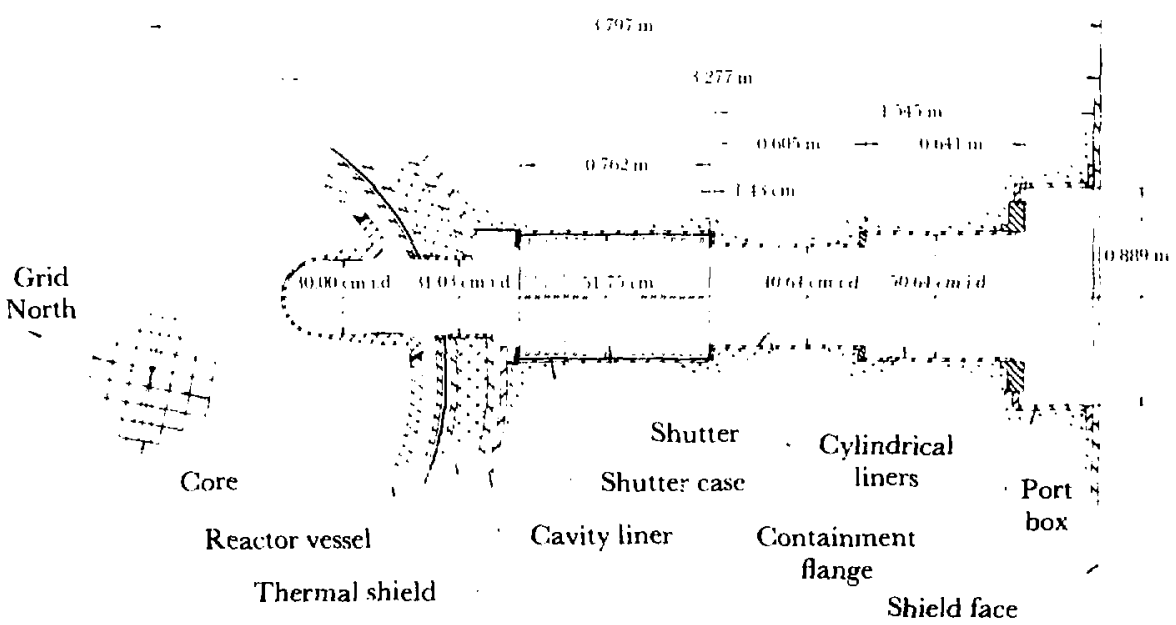

Plan of HFBR beam tube $\mathrm{H9}$. 


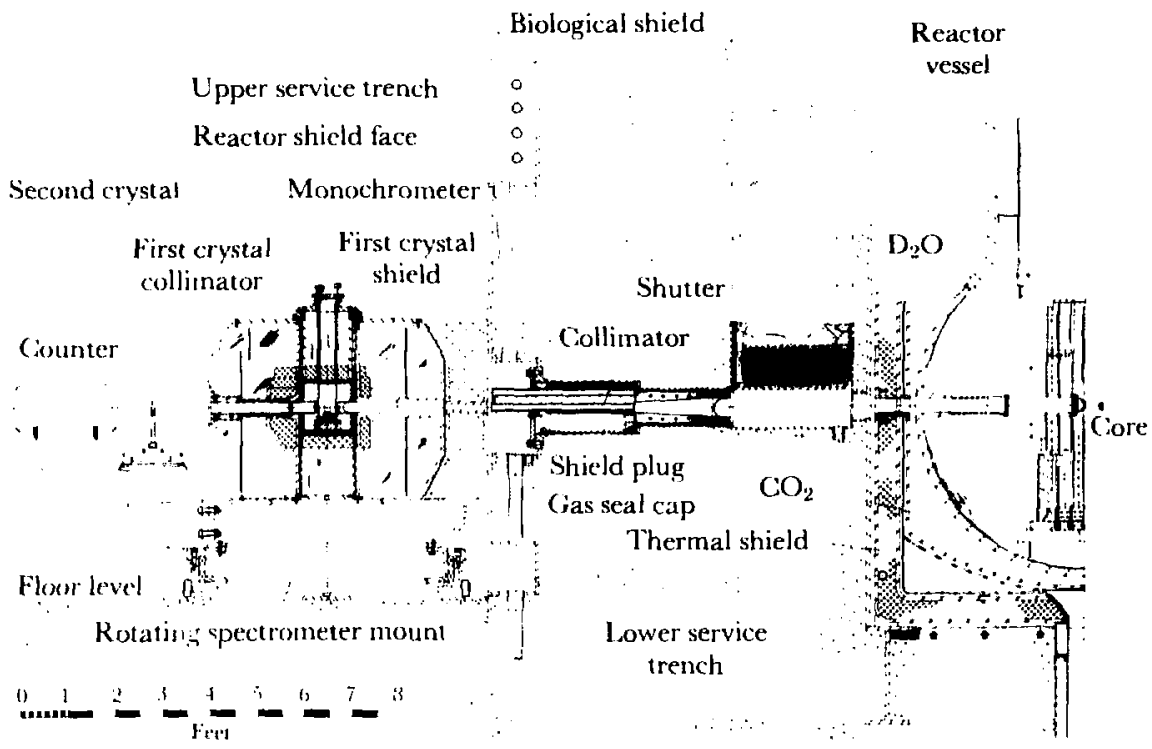

Elevation of double-axis spectrometer and beam tube (typical).

\section{COLD NEUTRON MODERATOR}

To provide intense beams of very low energy neutrons ( $\leq 5 \mathrm{meV})$, a liquid hydrogen moderator system has been installed in the H9 beam thimble. The moderator chamber contains 1.4 liters of liquid hydrogen and is located near the inner end of the thimble as shown in the accompanying figure. Circulating cold helium gas from an external refrigerator maintains the hydrogen at a temperature, of $19 \mathrm{~K}$. Neutrons from the surrounding heavy water blanket are moderated by scattering processes within the cold hydrogen, thus shifting the spectral distribution of the emerging beam towards lower energies. In operation the system serves as a cold neutron source for three separate beams, designated as $\mathrm{A}, \mathrm{B}$, and $\mathrm{C}$ on the accompanying figure. The experimental stations for these beams are described under Experimental Beam Facilities. 


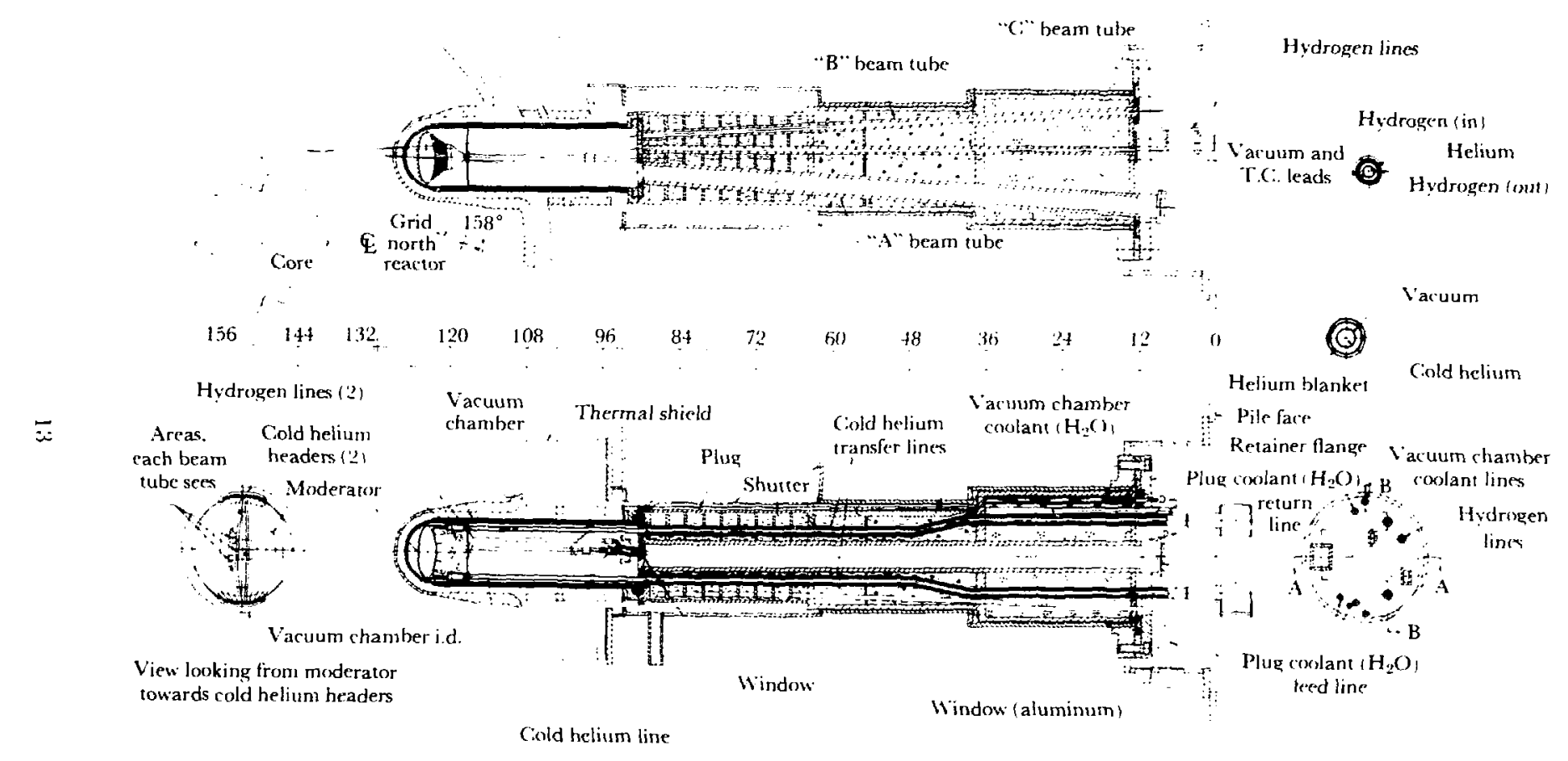

Cold neutron moderator and plug assembly installed in HG. 


\section{Safety at the HFBR}

The HFBR has achieved an outstanding safety record over more than 17 years of operation. This has been accomplished through careful design, planning, and review, combined with diligence in oluserving appropriate safety procedures. Such an achievement has been possible only through the continued cooperation of all HFBR users and operating personnel. For the sake of his or her own safety, as well as that of others, it is important for everyone working at this facility to respect and observe the safety guidelines presented in this section.

\section{USE OF THE CONFINEMENT BUILDING}

The HFBR confinement building is a restricted access area. All visitors during normal working hours must be accompanied by a person on the approved access list for the HFBR. Admission of visitors at times other than normal working hours may be arranged through the Reactor Division. A person may be placed on the access list with the recommendation of his Department Chairman and only after successful completion of a training and familiarization program given by the Heath Physics Group. Training and access information can be obtained by calling extension 4432 .

Because of the possibility of exposure to radiation and contamination with radioactive material, all persons entering the confinement building are required to wear film badges. All material and equipment to be removed from the building must first be checked by the Health Physics Group for possible radioactive contamination.

The closed atmosphere of the corfinement building dictates that strict precautions be observed with regard to hazardous materials in the building.

1. Toxic and flammable materials must be in safety cans which identify material stored within. 
2. Toxic and flammable macrials must be reported to Research Coordination (Ext. 4436), who will inquire as to the need, and obtain safety recommendations.

3. Other materials normally considered to be of minor toxicity or flammability must be examined closely if large quantities are required. Examples of such materials ar $\cdots$ oil, grease, paraffin, alkali metals, compressed gases, and cryogenic materials.

4. Any requirtement to bring explosive gases into the building must be cleared with Research Coordination fror appropriate safety recommendations. Examples of some explosive gases are: $\mathrm{H}_{2}, \mathrm{O}_{2}$, acetylene.

5. Flammable materials, such as paper cartons, excelsior, and computer printouts, must not be allowed to accumulate.

6. Please refer to the BNL Safety Manual or check with Research Coordination to determine the possible hazardous nature of unfamiliar materials.

7. Filemental mercury is strictly banned from the confinement building because of its possible interaction with aluminum reactor components. The use of mercury compounds should be reviewed by Research Coordination before such compounds are brought in to the corifinement buildingr.

\section{ACTIONS IN CASE OF HFBR EMERGENCIES}

Actions and responsibilities of an individual on becoming aware of an emergency in the HFPR are:

1. Sound the alarm, and summon assistance so that personal injuries and property losses may be held to a minimum.

2. Be familiar with the location and method of activation of manual alarms in his work vicinity.

3. Take emergency action within the scope of his training, to control or limit an emergency in his work vicinity, but avoid exposure to undue risks. 
4. On hearing an Emergency Signal do the following:

(a) On hearing a Warning Signal (continous ringing of HFBR fire bells), each person in HFBR, who is not a member of the HFBR Emergency Forces, shall leave HFBR by the nearest exit, and shali proceed directly to the HFBR Lobby. Each person shall be alert for further instructions given over the HFBR Public Address System, or by his Supervisor. Supplementary instruction will also normally be directed to the HFBR Emergency Forces over the HFBR Public Address System, or by other means.

(b) On hearing an Evacuation Signal (intermittent ringing of the HFBR fire bells), each person in the HFBR shall leave the building by the nearest exit, and shall proceed directly to the HFBR Lobby. The only exceptions are:

i. Persons who are in a position to save a life, or to take other vital emergency action enroute to the exit, without undue hazard to themselves;

ii. Persons receiving other specific instructions at the time from the Reactor Shift Supervisor or HFBR Local Emergency Coordinator.

\section{SAFETY REQUIREMEN'S FOR EXPERIMENTS}

Safety is a line responsibility from the Director of the Laboratory to Department Chairmen. Each experimenter at the HFBR is directly responsible to the Chairman of the Department with which he is associated to conduct his experiment in accordance with prevailing safety regulations. In general, the experimenter has the prime responsibility for planning, designing, fabrication, testing, operation, matitienance, and ultimate disposal of all equipment required exclusively for his experiment. The experimenter is responsibie for conforming to appropriate safety standards and for furnishing all information required for safety review by others. 
It is the responsibility of the Research Coordinator to work with the experimenters to assure that the HFBR facilities are used to the best advantage and in such a manner as to guarantee the safety of the reactor. The Coordinator will aid the experimenters in obtaining safety approval for their proposed experiments, seeking expert opinion where necessary to substantiate recommendations made to the RCES Committee. For this purpose the Coordinator will generally call upon an Experiments Review Team consisting of representatives from the Reactor Operations Group, Safety and Environmental Protection, and others from the Reactor Division who are familiar with experimental facilities and reactor characteristics.

In general, experiments to be conducted at the HFBR shall be designed and operated in such a manner that:

1. The safety of personnel working in the area is not compromised.

2. Reactor safety can be maintained under all credible conditions created by the experiment (whether normal or abnormal), such that the reactor is not damaged and radioactive releases to the environment are always kept below acceptable limits.

3. Each experiment does not interfere with the operation of any of the others.

4. A preplanned procedure exists for decommissioning each experiment and removing the equipment from the reactor building.

Experiments in beam tubes, irradiation thimbles or elsewhere around the reactor, which potentially could exceed the envelope of reviewed conditions discussed below, or which might present new and unique hazards, will be regarded as "unreviewed hazards." Under the general terms of the prime contract between Associated Universities, Inc. and DOE, and in accordance with pertinent sections of the DOE Manual, such "unreviewed hazards" must be referred to DOE for concurrence before they are permitted at the HFBR. All types of experiments that have been placed in and arouisd the reactor have been reviewed by the BNL Reactor and Critical 
Experiments Safety Committee (RCESC), and each new experiment proposed which falls outside the envelope of conditions previously approved wiil aiso be reviewed by the Safety Committee. The DOE Brookhaven Office is kept informed on a continuous basis of the experimental program and of the reviews and actions of RCESC.

\section{In-pile Experiments and Equipment}

The safety limits on experiments to be inserted into the reactor vessel experimental facilities (beam tubes and irradiation thimbles) are based upon two essential considerations. The first of these is that the maximum reactivity associated with any material to be inserted or removed from the reactor must not be so large that the instantaneous insertion or removal of the material could cause a nuclear transient which would damage the reactor. The second basic consideration is that all experiments to be inserted into the reactor vesse] experimental facilities must be of such a nature and constructed in such a way that in no circumstances will the containing beam tube or thimble in the vessel be damaged.

\section{Out-of-pile Experiments and Equipment}

With regard to reacter safety limitations on beam experiments, the placing of radiators (scattering blocks) or sample scatterers in the vessel heam tubes is subject to the limitations imposed above. The experimental apparatus placed at the beam ports is subject to the same process of review and testing as are experiments which are placed in the reactor. For example, experimental equipment containing cryogenic or high pressure components must be reviewed by the Safety and Environmental Protection Division. Equipment containing rotating machinery must be extensively tested at above maximum operating speeds for long periods of time to establish the safety

of the design. In all cases, the orientation of the rotating equipment to be used outside the shield must be such that failure of the rotor would not direct fragments into beam ports. 
Any experiments which cont emplate the use of potentially explesive materials, such as hydrogen, in or near the beam ports are subject to the same program of testing as for explosive materials in the vessel thimbles. That is, suitablecontainment for the explessive or reactive material shall be provided and must be proffected by actual experimonts in which the maximum possible enorgy release inside the containing vessel was acoomplished.

\section{HFBR User Policy}

The acilities described in this handbosk are open to the general scientific community. No charges will he imposed for their use unless the research is of a proprictary nature, in which case a full cost recovery fee will be charged for the amount of beam time used for the proprietary research. Beam time can be applied for by submitting a research proposal, which will be judged according to scientific merit by the Program Review Committee. For more det: ils contact I). Rorer or S.M. Shapiro. 


\section{Experimental Beam Facilities}

The instruments available at the HFBR have been developed to cover a wide range of scientific studies. Figure 1 shows a schematic floor layout of the various beam ports, $\mathrm{H} 1$ through $\mathrm{H} 9$, and the basic experimental installations at each port. The latter may beclassified according to their main use:

\begin{tabular}{cccccc} 
& Nuclear Physies & \multicolumn{3}{c}{ Inelastic Scattering } \\
H1-A & H1-B & H2 & H4-M & H7 & H9-A (cold neurrons) \\
& & & H5 & H8 &
\end{tabular}

\section{Neutron Diffraction}

H4-S (also small angle scattering) H6-M

$\mathrm{H} 6-\mathrm{S}$

\section{Biological Structure Studies}

H3-A

$\mathrm{H}$ i3-B

H9-B (cold neutrons)

Details on these experimental stations are given in the subsections which follow.

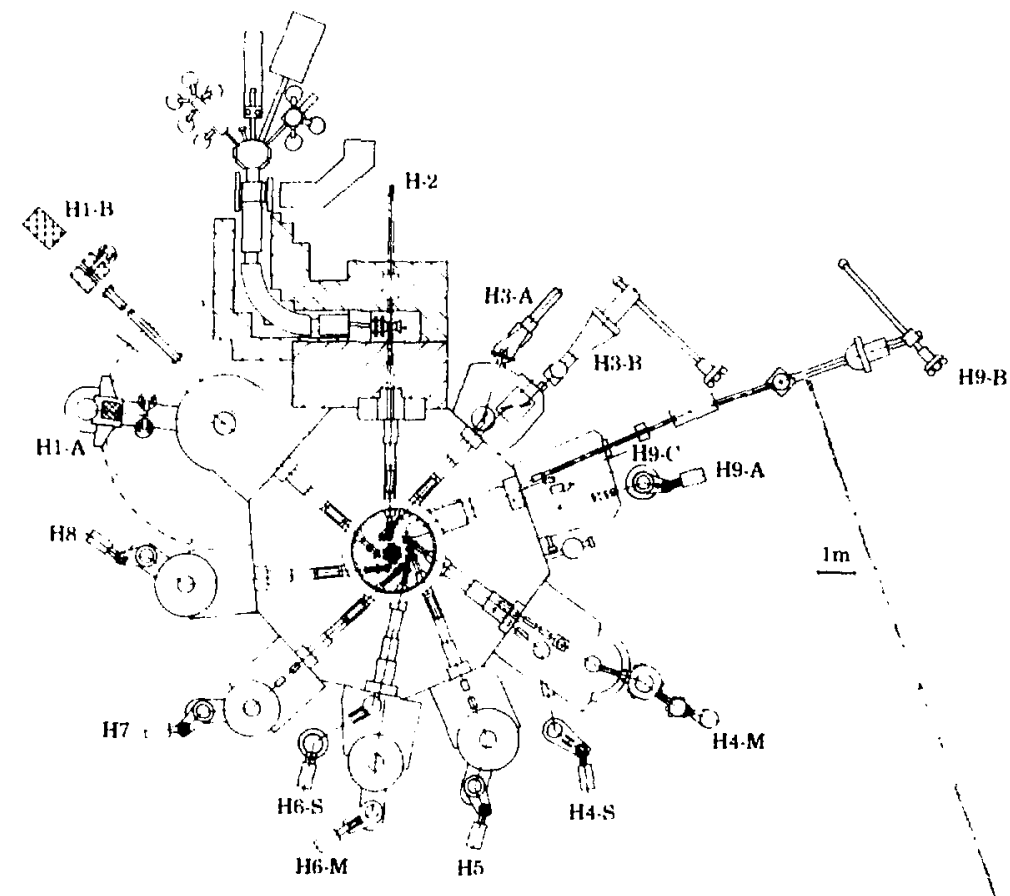

Schematic plan of spectrometers installed on the experimental level of the HFBR: 


\section{H1-A SPECTROMETER (NUCLEAR PHYSICS)}

$\mathrm{H} 1$ is a tangential beam of exceptional quality featuring high flux and low $\gamma$-ray backgrounds. The thimble terminates about $14 \mathrm{~cm}$ from the core center. Two beams are extracted from the $\mathrm{H} 1$ beam plug. HI-A provides a neutron beam whose properties can be varied to accommodate experim ^nts in several different areas of nuclear physics. Two types of beams are available:

1. A monochromatic beam obtained by Bragg diffraction from several crystals.

2. A high quality thermal beam obtained by filtering the reactor spectrum through crystalline quartz.

\begin{tabular}{|c|c|c|c|}
\hline \multicolumn{4}{|c|}{ H1-A Station Parameters } \\
\hline $\begin{array}{l}\text { Monochromators } \\
\text { Filters }\end{array}$ & $\begin{array}{l}\text { Energy } \\
\text { Range }\end{array}$ & Beam Size & $\begin{array}{l}\text { Intensity } \\
(\mathrm{E}=1.0 \mathrm{eV})\end{array}$ \\
\hline $\mathrm{Be}(1011)$ & $0.025-25 \mathrm{eV}$ & $2.5 \times 2.5 \mathrm{~cm}^{2}$ & $2.2 \times 10^{5} \mathrm{n} / \mathrm{cm}^{2}-\mathrm{sec}$ \\
\hline Quartz Filter $(58 \mathrm{~cm})$ & Thermal & $\therefore .27 \mathrm{~cm}$ diam & $1.5 \times 10^{\mathrm{H}} \mathrm{n} / \mathrm{sec}$ \\
\hline $\begin{array}{l}\text { Collimation: } 3.6 \mathrm{minu} \\
\text { Angular Range: } 0-90\end{array}$ & \multicolumn{3}{|c|}{$\begin{array}{l}\text { Detecturs: Neutron-BFis; } \gamma-\mathrm{ray}-\mathrm{Ge}(\mathrm{Li}) \\
\text { and m.ulti-Ge (angular correlation) }\end{array}$} \\
\hline
\end{tabular}




\section{H1-B SPECTROMETER (NUCLEAR PHYSICS)}

At H1-B, a flexible external sample facility offers sources for capture studies in the slow neutron, $\mathrm{eV}$, and $\mathrm{keV}$ range. Filters for tailoring the beam are contained in a 4-position rotary collimator external to the reactor shield. A set of easily modified filters can be rapidly interchanged so as to span a broad range of neutron energies in a study of a single nuclide. A 3-crystal pair spectrometer is used to detect primary $\gamma$-rays from $(n, \gamma)$ experiments using filtered beams at thermal, $2 \mathrm{keV}$, and $24 \mathrm{keV}$ with an efficiency of about $3 \%$ relative to a $7.6 \times 7.6 \mathrm{~cm}^{2} \mathrm{Nal}$ standard detector. Data are routed into a PDP $11 / 40$ computer and further analyzed using the computer facilities described under beam line $\mathrm{H} 2$.

\begin{tabular}{|c|c|c|c|c|c|}
\hline \multicolumn{6}{|c|}{ H1-B Station Parameters } \\
\hline Filter & $\begin{array}{l}\text { Beam } \\
\text { Energy }\end{array}$ & $\begin{array}{c}\text { Width } \\
\text { (FWHM) }\end{array}$ & $\begin{array}{l}\text { Size } \\
(\mathrm{cm})\end{array}$ & $\begin{array}{l}\text { Intensity } \\
\text { (n/sec) }\end{array}$ & $\begin{array}{c}\text { Purity } \\
\text { (䛦) }\end{array}$ \\
\hline $\begin{array}{c}22.86 \mathrm{~cm} \mathrm{Fe} \\
36.20 \mathrm{~cm} \mathrm{Al} \\
6.35 \mathrm{~cm} \mathrm{~S}\end{array}$ & $24.3 \mathrm{keV}$ & $2.0 \mathrm{keV}$ & $7.27 \times 2.8$ & $1.4 \times 10^{7}$ & 98 \\
\hline $\begin{array}{c}68.58 \mathrm{~cm}^{56} \mathrm{Fe} \\
(98.87 \%)\end{array}$ & $24.3 \mathrm{keV}$ & $1.0 \mathrm{keV}$ & $7.27 \times 2.8$ & $1.5 \times 10^{8}$ & 80 \\
\hline $\begin{array}{c}30.48 \mathrm{~cm}^{56} \mathrm{Fe} \\
17.78 \mathrm{~cm} \mathrm{Al}\end{array}$ & $24.3 \mathrm{keV}$ & $1.7 \mathrm{koV}$ & $7.27 \times 2.8$ & $4.20 \times 10^{\top}$ & 95 \\
\hline $71.1 \mathrm{~cm} \mathrm{Sc}$ & $2.0 \mathrm{keV}$ & $0.9 \mathrm{keV}$ & $7.27 \times 2.8$ & $7.1 \times 10^{7}$ & 70 \\
\hline Bi single crystal & thermal & Maxwellian & $\begin{array}{r}<7.27 \times 2.8 \\
\text { (variable) }\end{array}$ & $-10^{9}$ & \\
\hline
\end{tabular}

Detector: 3-crystal pair spectrometer 


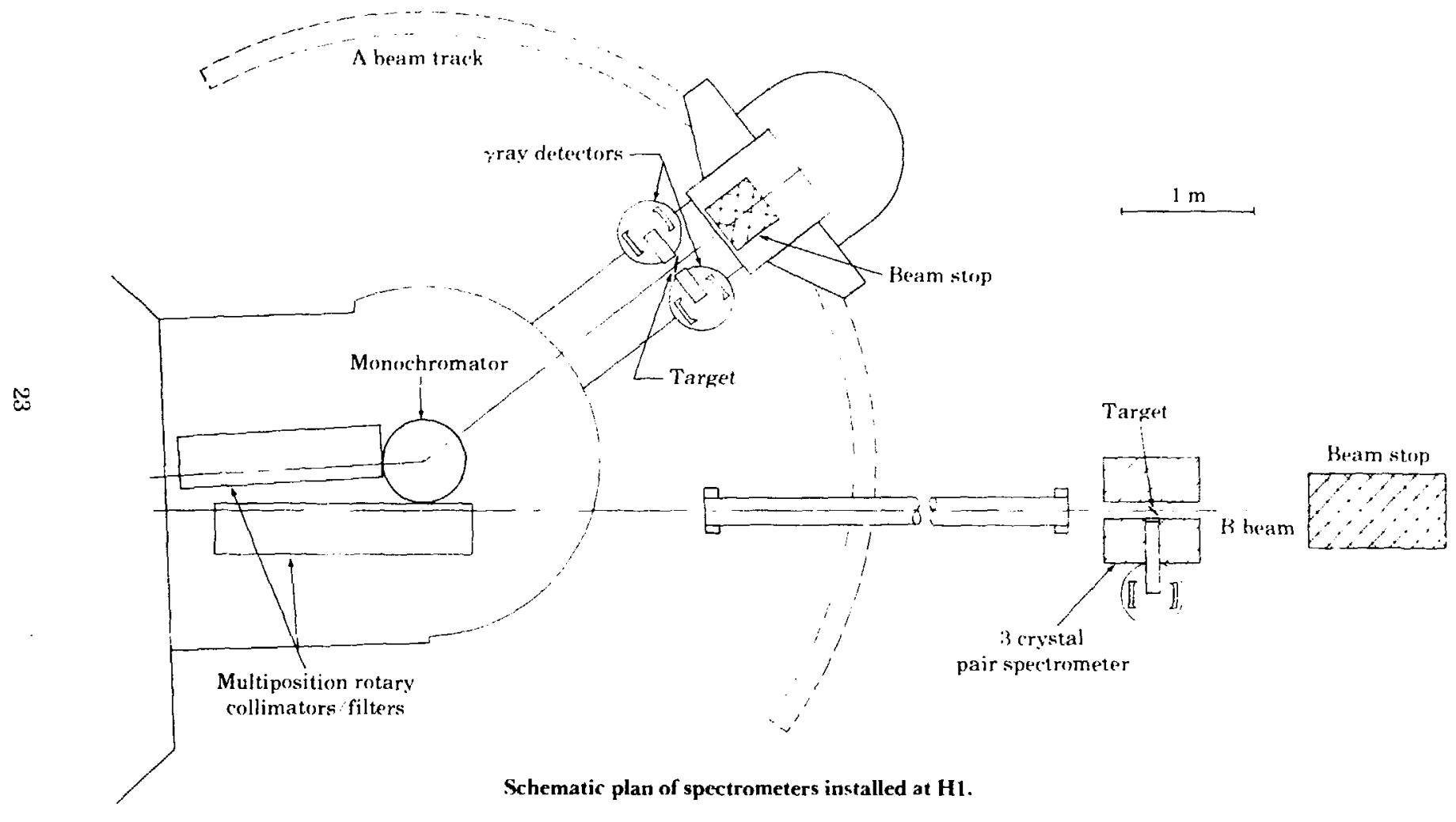




\section{H2 TRISTAN MASS SEPARATOR (NUCLEAR PHYSICS)}

An on-line isotope separator facility called TRISTAN is installed at the $\mathrm{H} 2$ beam line. An ion source containing $5 \mathrm{~g}$ of ${ }^{235} \mathrm{U}$ in a thermal flux of $2.5 \times 10^{10} \mathrm{n} / \mathrm{cm}^{2} / \mathrm{sec}$ produces ions of rare short-lived fission products. The ions are electrostatically extracted, accelerated to 50 $60 \mathrm{keV}$, and separated by a $90^{\circ}$ bending magnet. At the focal plane of the magnet the ions of the selected mass pass through a slit and are directed by a switching magnet to one of five detector stations. Data are recorded and preprocessed by a CAMAC-linked PDP-11/20 computer system. More detailed analysis is performed using a PDP. $11 / 34$ computer which may communicate with the $11 / 20$ via a 300 Mbyte dual purt disk. A PDP-11/45 computer is also available and is linked with the $11 / 34,11 / 20$, and the $\mathrm{H} 111 / 40$ via DMA transfers to a PDP-11/10 which controls a 60 Mbyte data storage disk.

\section{H2 Station Parameters - TRISTAN}

\begin{tabular}{|c|c|c|c|}
\hline Ion Source & & ments Produced & Yield Atoms/sec \\
\hline Surface Ionization & $\mathrm{Rb}, \mathrm{S}$ & s, Ba, Ce, Pr, Nd, Pm & $<10^{9}$ \\
\hline FEBIAI) & $\begin{array}{l}\mathrm{Zn}, \mathrm{G} \\
\mathrm{Ag}, \mathrm{C}\end{array}$ & $\begin{array}{l}\text { e, As, Se, Br, Kr, Rb, } \\
\text { n, Sn, Sb, Te, I, Xe, Cs }\end{array}$ & $<10^{7}$ \\
\hline \multicolumn{2}{|c|}{ Ge(Li), Hplie detectors } & \multicolumn{2}{|c|}{$\begin{array}{l}\gamma \cdot \text { ray spectroscopy, } \\
\gamma \cdot \gamma \text { angular correlations }\end{array}$} \\
\hline \multicolumn{2}{|c|}{ HpGe.Si(Li) detectors } & \multicolumn{2}{|c|}{$\begin{array}{l}\beta \text { spectroscopy, } Q_{\beta} \text { measurements, } \\
\text { conversion electron spectroscopy }\end{array}$} \\
\hline \multicolumn{2}{|l|}{$25 \mathrm{kG}$ magnet } & \multicolumn{2}{|c|}{ perturbed angular correlations } \\
\hline \multicolumn{2}{|l|}{${ }^{3}$ He detectors } & \multicolumn{2}{|c|}{$\begin{array}{l}\text { delayed neutron spectroscopy, } \\
\text { p-n measurements }\end{array}$} \\
\hline \multicolumn{2}{|c|}{ Time-of-flight spectrometer } & \multicolumn{2}{|c|}{ low-energy delayed neutron spectroscopy } \\
\hline \multicolumn{2}{|l|}{ Dye laser } & \multicolumn{2}{|c|}{ hyperfine interaction studies } \\
\hline
\end{tabular}




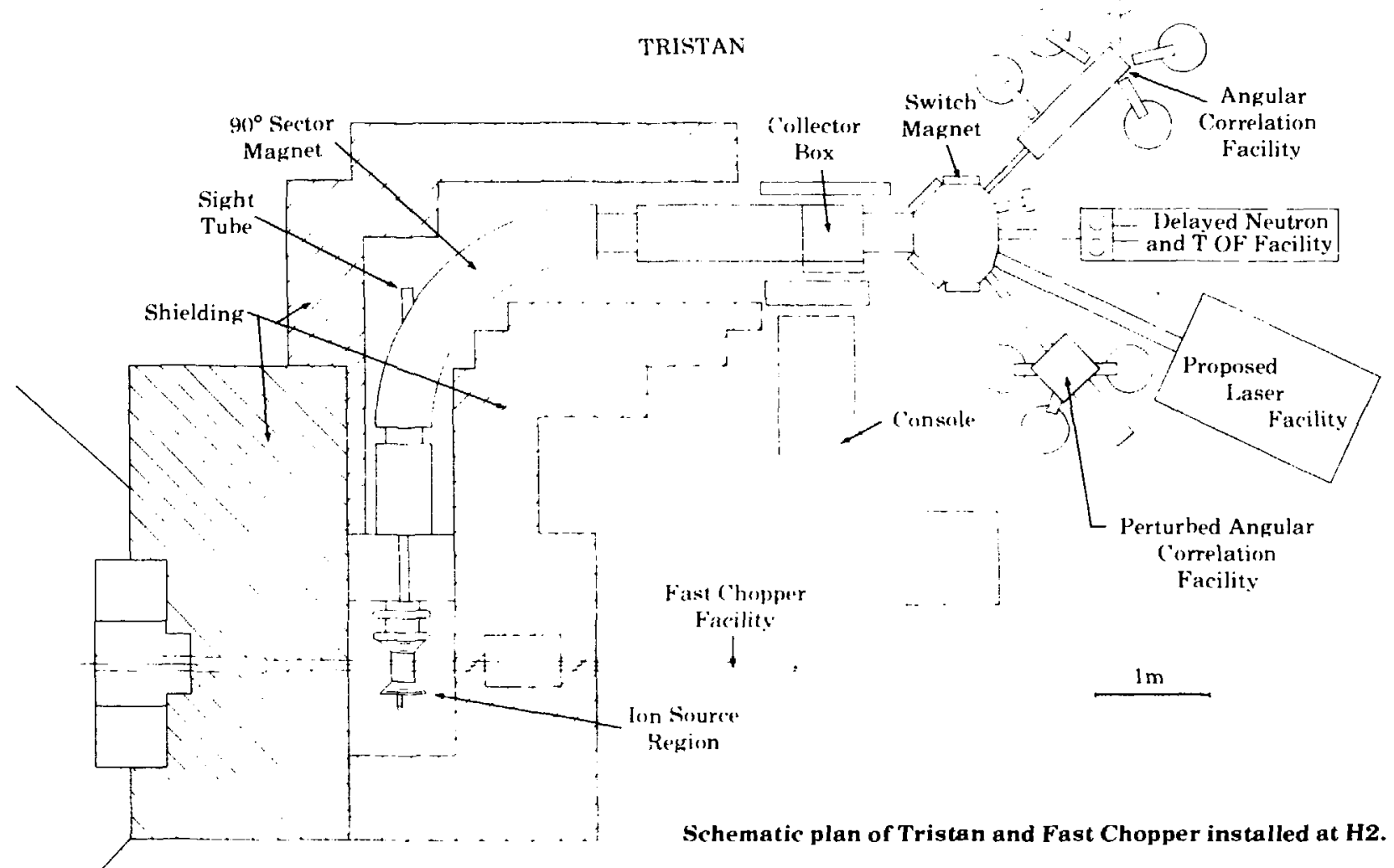




\section{H2 FAST CHOPPER (NUCLEAR PHYSICS)}

The $\mathrm{H} 2$ beam is also used by a fast chopper facility for time-of-flight analysis of resonance neutron capture $\gamma$ rays. The need fcr high intensities requires a high duty cycle and large beam aperture. The correspondingly low neutron resolution limits the device to the energy region below $10 \mathrm{keV}$ for most nuclei. Two rotors are available. Detector stations are placed at flight paths of 22 meters inside the reactor building and at 48 meters in a detector hut outside of the building. The PDP-11/20 based TRIS']AN data acquisition system is used to record the $\gamma$-ray events following neutron capture. 32 preselected timi-of-flinht gates sort the pulse-height spectra on-line, eliminating the need for off-line tape scanning.

\section{H2 Station Parameters - Fast Chopper}

\begin{tabular}{|c|c|c|}
\hline & Rotor: I & Rotor II \\
\hline Burst Width & $5 \mu \mathrm{sec}$ (minimum) & $1 \mu \mathrm{sec}(\operatorname{minimum})$ \\
\hline $\begin{array}{l}\text { Repetition } \\
\text { Rate }\end{array}$ & 1000 cycles $/ \mathrm{sec}$ & 1000 cycles'sec \\
\hline $\begin{array}{l}\text { Band Pass at } \\
\text { Full Speed }\end{array}$ & $2 \mathrm{eV}$ to $x$ & $2 \mathrm{eV}$ to $x$ \\
\hline $\begin{array}{l}\text { Flux at } 22 \\
\text { meters }\end{array}$ & $\frac{4.5 \times 10^{4}}{E} \mathrm{n} / \mathrm{cm}^{2} / \mathrm{sec} / \mathrm{eV}$ (av.) & $\frac{2.7 \times 10^{3}}{E} \mathrm{n} / \mathrm{cm}^{2} / \mathrm{sec} / \mathrm{eV}$ (av.) \\
\hline Speed Range & 1500 to $15000 \mathrm{rpm}$ & 1500 to $15000 \mathrm{rpm}$ \\
\hline $\begin{array}{l}\text { Neutron } \\
\text { Resolution } \\
\text { at } 22 \text { meters }\end{array}$ & $\frac{\partial E}{F}=0.0067 \mathrm{E}^{12}(\mathrm{E}$ in $\mathrm{eV})$ & $\frac{\Delta \mathrm{E}}{\mathrm{E}}=0.003 \mathrm{E}^{12}(\mathrm{E}$ in $\mathrm{eV})$ \\
\hline Beam Size & $10 \times 7.6 \mathrm{~cm}^{2}$ & $10 \times 7.6 \mathrm{~cm}^{2}$ \\
\hline $\begin{array}{l}\text { Neutron } \\
\text { Resolution } \\
\text { at } 48 \text { meters }\end{array}$ & $\frac{\Delta \mathrm{E}}{\mathrm{E}}=0.003 \mathrm{E}^{1.2}(\mathrm{E}$ in $\mathrm{eV})$ & $\frac{\Delta \mathrm{E}}{\mathrm{E}}=0.0006 \mathrm{~F}^{12}(\mathrm{E}$ in $\mathrm{eV})$ \\
\hline Beam Size & $20 \times 15 \mathrm{~cm}^{2}$ & $20 \times 15 \mathrm{~cm}^{2}$ \\
\hline Duty Cycle & $0.5 \%$ & $0.1 \%$ \\
\hline
\end{tabular}

Useful energy range: thermal to $10 \mathrm{keV}$. 


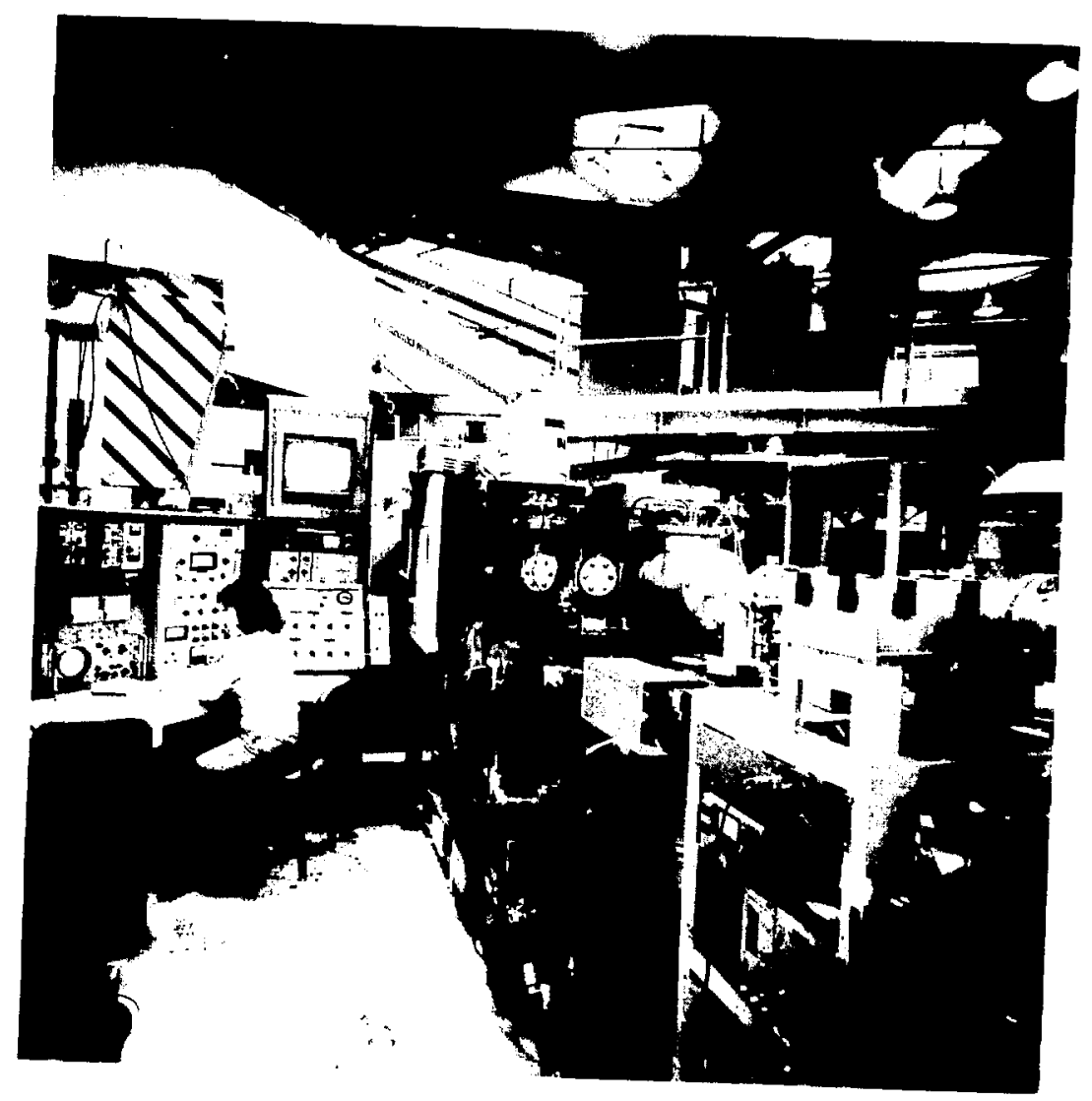

TRISTAN Mass Separator Facility located at $\mathrm{H} 2$. 


\section{H3-A SPECTROMETER FOR PROTEIN CRYSTALLOGRAPHY}

This protein crystallographic station features a two-dimensional position-sensitive counter with a four-circle diffractometer. The computer system controls the diffractometer, processes the counter data and permits on-line interactive display. The position-sensitive counter has an efficiency of $\sim 80 \%$ with a resolution of $1.5 \mathrm{~mm}$ and a counting rate of $\sim 10^{5} \mathrm{c} / \mathrm{sec}$; data are directly encoded into an extended memory. There is a remote controlled monochromator (pyrolytic graphite) with variable circular focusing collimation and provisions for filters.

\begin{tabular}{ll}
\hline & \multicolumn{1}{c}{ H3-A Station Parameters } \\
\hline Flux at sample & $-2.8 \times 10^{7} \mathrm{n} / \mathrm{cm}^{2} / \mathrm{sec}$ \\
Monochromator & $(002)$ pyrolytic graphite, \\
& $2 \theta=27.15^{\circ}$ (focusing) \\
Filter & Pyrolytic graphite \\
Wavelength $\lambda$ & $1.57 \AA(33 \mathrm{meV}$ (variable) \\
Beam size at sample (FWHM) & $6 \mathrm{~mm}$ diameter, $20^{\prime}$ divergence \\
& $($ variable) \\
Sample scattering angles & $-80^{\circ}<2 \theta<80^{\circ}$ \\
Detector & ${ }^{3} \mathrm{He}$ filled position-sensitive detector \\
& $20 \times 18 \mathrm{~cm}, 256 \times 128$ pixels. Detector to \\
& sample distance is $510-2000 \mathrm{~mm}$. \\
& Counter resolution $=1.5 \mathrm{~mm}$. \\
Efficiency & $\sim 80^{\circ} \%$ \\
\hline
\end{tabular}

\section{H3-B INTERMEDIATE RESOLUTION MEMBRANE STATION}

The membrane station will feature a two-dimensional positionsensitive detector with a sample changer or exterior cradle. The computer system controls the diffractometer, processes data and permits on-line interactive display. The position-sensitive detector will have an area of $\sim 30 \mathrm{~cm} \times 10 \mathrm{~cm}$ with a spatial resolution of $\sim 1.5$ $\mathrm{mm}$ and a maximum rate of $\sim 10^{5} \mathrm{c} / \mathrm{sec}$. Data are directly encoded into an external memory. The double monochromator will use multilayer devices with a wavelength from $\sim 2 \AA$ to $4 \AA$ with an adjustable $\Delta \lambda$.

Completion of the station is expected in the fall of 1984 . 


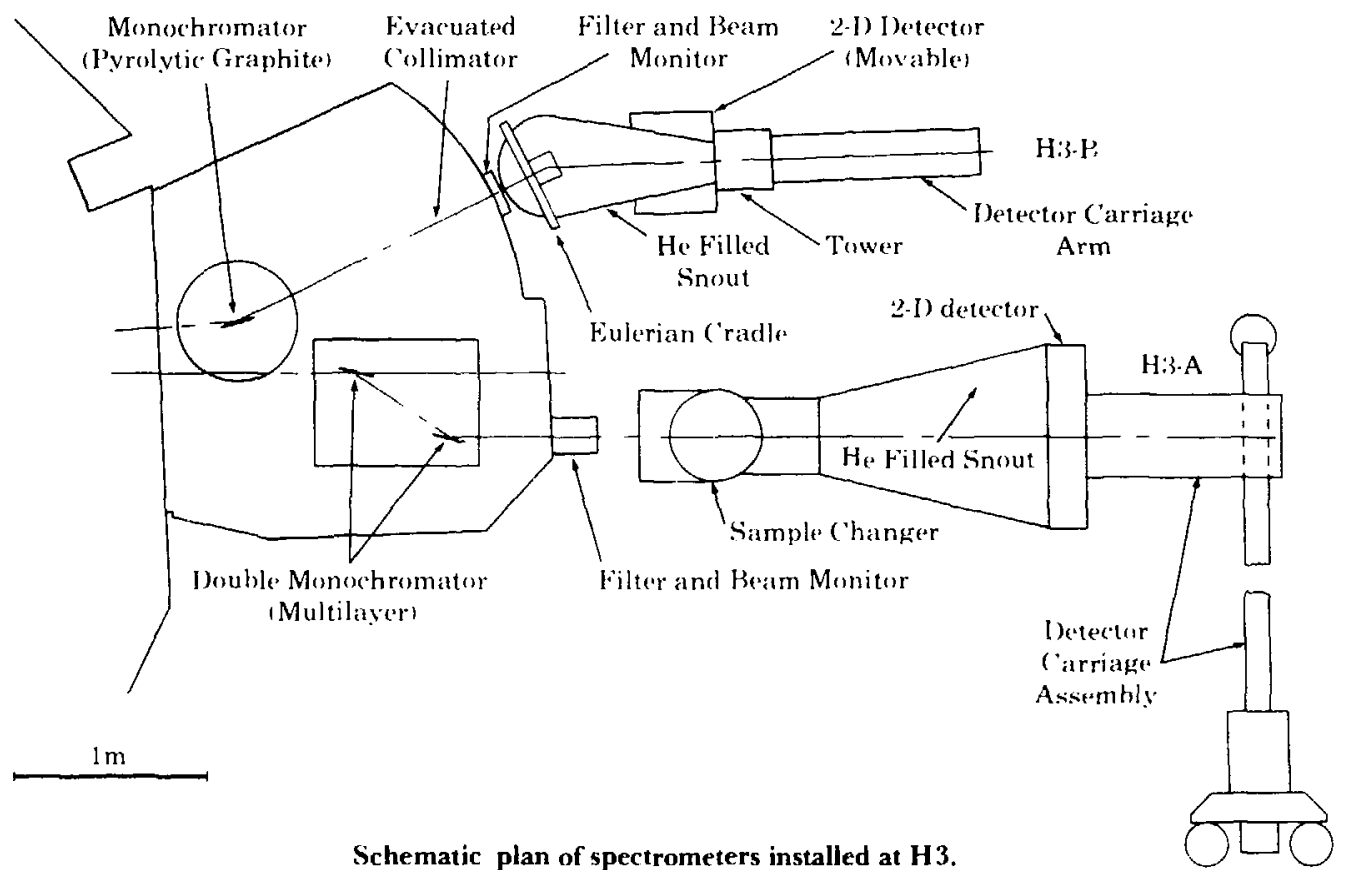




\section{H4-M SPECTROMETER (POLARIZED BEAM-INELASTIC)}

$\mathrm{H} 4-\mathrm{M}$ is currently being developed as a polarized beam spectrometer for elastic and inelastic scattering studies through the US-Japan Cooperative Research Program in Neutron Scattering. Both incident and final neutron energies can be scanned in a conventional triple-axis mode of operation by using either focusing pyrolytic graphite (002) or Heusler (111) polarizing monochromators or analyzers. The sample table is equipped with the standard two arm goniometer which is compatible with a variety of cryostats and furnaces. Sample and analyzer tables move on air pads, and the distances between monochromator, sample, and analyzer are adjustable. For polarized beam work, high efficiency flat coil $\pi$-flippers and guide fields are available. Time-of-flight capabilities with several detectors will also be implemented.

\section{H4-M Station Parameters}

Flux at monochromator position $3.5 \times 10^{9} \mathrm{n} / \mathrm{cm}^{2}-\mathrm{sec}$ Monochromator scattering angle $10^{\circ}<2 \theta_{\mathrm{M}}<108^{\circ}$

fit of $\lambda_{0}(\mathrm{PQ}()(1))$

$2.8<\mathrm{E}_{11}<240 \mathrm{mieV}^{2}$

$5.43>\lambda 0<0.58 \AA$

Beam siz*

$3.8 \times 7.6 \mathrm{~cm}^{2}$

Sample scattering angle

$-20^{\circ}<2 \theta \mathrm{s}<155^{\circ}$

I)rum to sample axis distance

$0.7<1<3 \mathrm{~m}$

betector

${ }^{3} \mathrm{He}$

In-pile collimation

$20^{\prime}, 40^{\prime}$

fxternal collimation

$10^{\prime}, 20^{\prime}$ or $40^{\prime}$ 


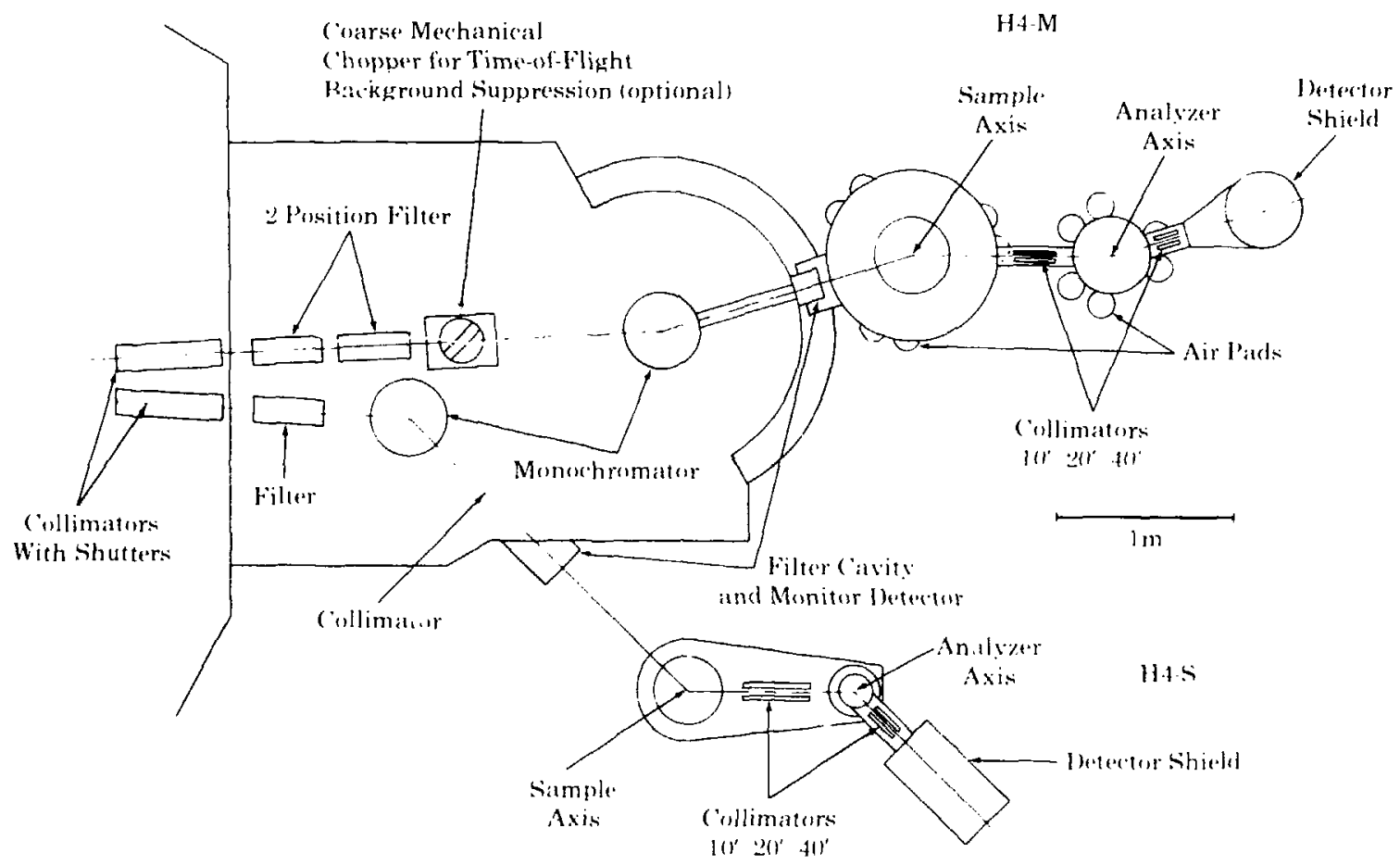

Schematic of neutron spectrometers installed at $\mathrm{H} 4$. 


\section{H4-S SPECTROMETER (DIFFRACTION AND SMALL ANGLE SCATTERING)}

H4-S provides a double-axis spectrometer for diffraction and also accommodates small angle scattering studies for molecular biology featuring a $2 \mathrm{D}$ position-sensitive detector. A fixed monochromator takeoff angle of $2 \theta_{\mathrm{M}}=41.1^{\circ}$ gives an incident energy of $\mathrm{F}_{0}=14.8 \mathrm{meV}$, from pyrolytic graphite; other energies are available by changing to different monoch romators. A standard goniometer accommodates a wide range of cryostats, furnaces, or magnets.

\section{H4-S Station Paraneters}

Flux at monochromator position $4.0 \times 10^{9} \mathrm{n} / \mathrm{cm}^{2} \cdot \mathrm{sec}$ Monochromator scattering angle $2 \theta_{M}=41.1^{\circ}$ $E_{0}$ or $\lambda_{0}(P G 002)$ $14.8 \mathrm{meV}(2.36 \AA$ )

Beam size at sample $5(\mathrm{~h}) \times 2.5(\mathrm{w}) \mathrm{cm}^{2}$ or $6 \mathrm{~mm}$ diam

Sample scattering angle $-30^{\circ}<20 \mathrm{~s}<125^{\circ}$

In-pile collimation $20^{\prime}, 40^{\prime}$

External collimation $10^{\prime}, 20^{\prime}, 40^{\prime}$

Betector $\mathrm{BF}_{3}$ and ${ }^{3} \mathrm{He}(2 \mathrm{D}), 17 \times 17 \mathrm{~cm}^{2}$ 


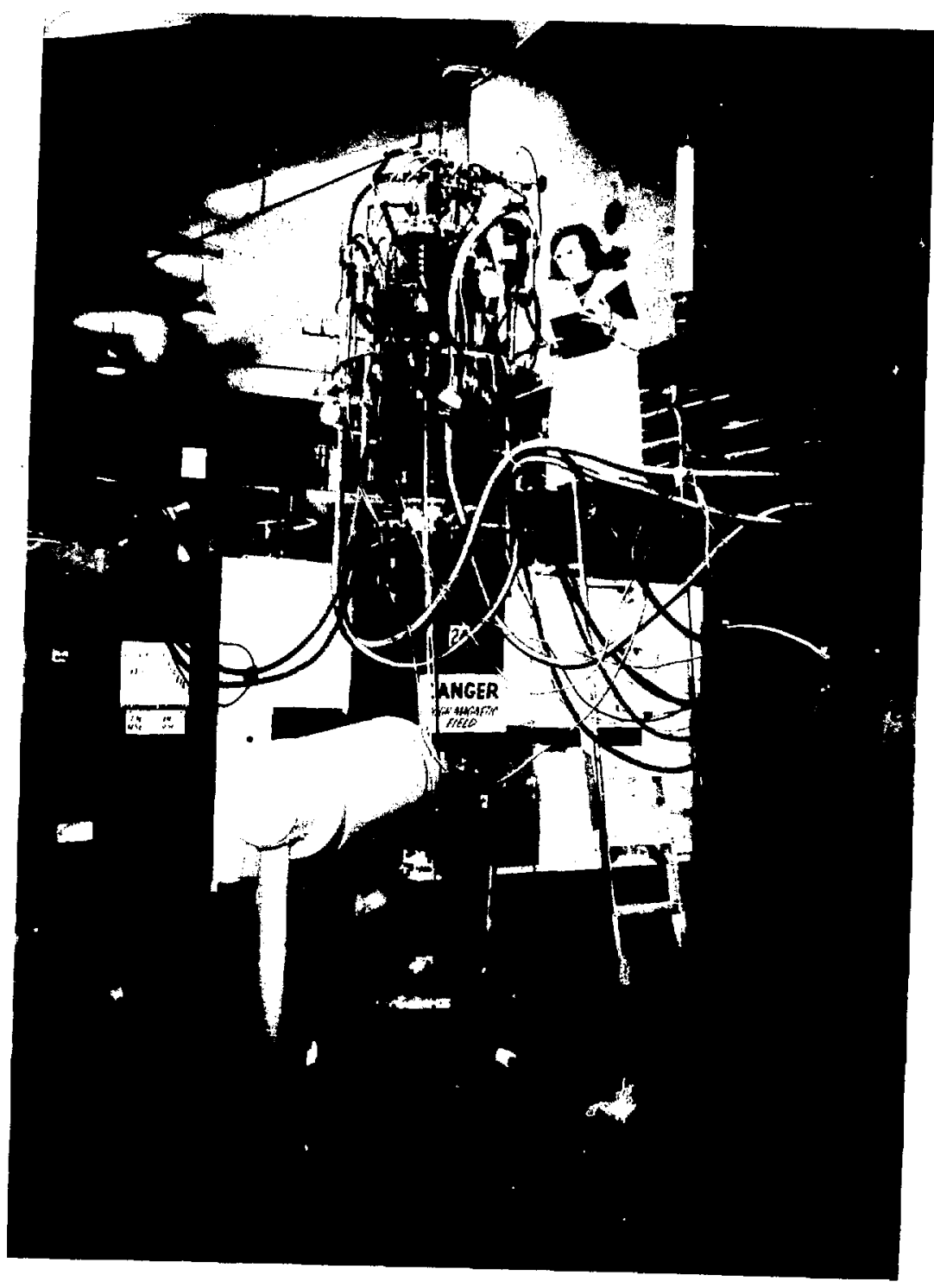

H4-S Spectrometer with a dilution refrigerator on sample axis. 


\section{H5 SPECTROMETER (INELASTIC SCATTERING)}

$\mathrm{H} 5$ is a triple-axis spectrometer used primarily for single crystal inelastic experiments, although it can often be used effectively for studying polycrystalline and amorphous samples. The instrument is fully automated for variable incident neutron energies. It is normally equipped with (002) pyrolytic graphite monochromator and analyzer crystals, but $\mathrm{Be}, \mathrm{Cu}, \mathrm{Zn}$, and $\mathrm{Ge}$ monochromators are also available. Optional in-pile Be and pyrolytic graphite filters are provided for removing higher order contamination. The sample table is equipped with manual two-axis goniometers with a $\pm 10^{\circ}$ range, and is compatible with a variety of available cryostats and furnaces. External collimation (other than in-pile) is provided by Soller slits with a $5.1 \times 5.1 \mathrm{~cm}^{2}$ cross section. The beam incident on the sample is monitored by a high transmission, low efficiency uranium foil detector.

\section{H5 Station Parameters}

Flux at monochromator position (20 ${ }^{\prime}$ in-pile collimation)

Monochromator scattering angle

E) or $\lambda_{0}(\mathrm{PG} 002)$

$$
4.2 \times 10^{9} \mathrm{n} / \mathrm{cm}^{2}-\mathrm{sec}
$$$$
10^{\prime \prime}<20_{\mathrm{M}}<55^{\prime \prime}
$$

Beam size

$8.5<\mathrm{E}_{13}<240 \mathrm{meV}$ $3.09>\lambda_{11}>0.58 \AA$

Sample scattering angle $5 \times 3.1 \mathrm{~cm}^{2}$

Analyzer scattering angle

$-45^{\circ}<2 \theta \mathrm{s}<125^{\circ}$

In-pile collimation

$-100^{\circ}<2 \theta_{A}<100^{\circ}$

External collimation

$10^{\prime}, 20^{\prime}$, or $40^{\prime}$

Detector

$10^{\prime}, 20^{\prime}$, or $40^{\prime}$

$\mathrm{BF}_{3}$ 


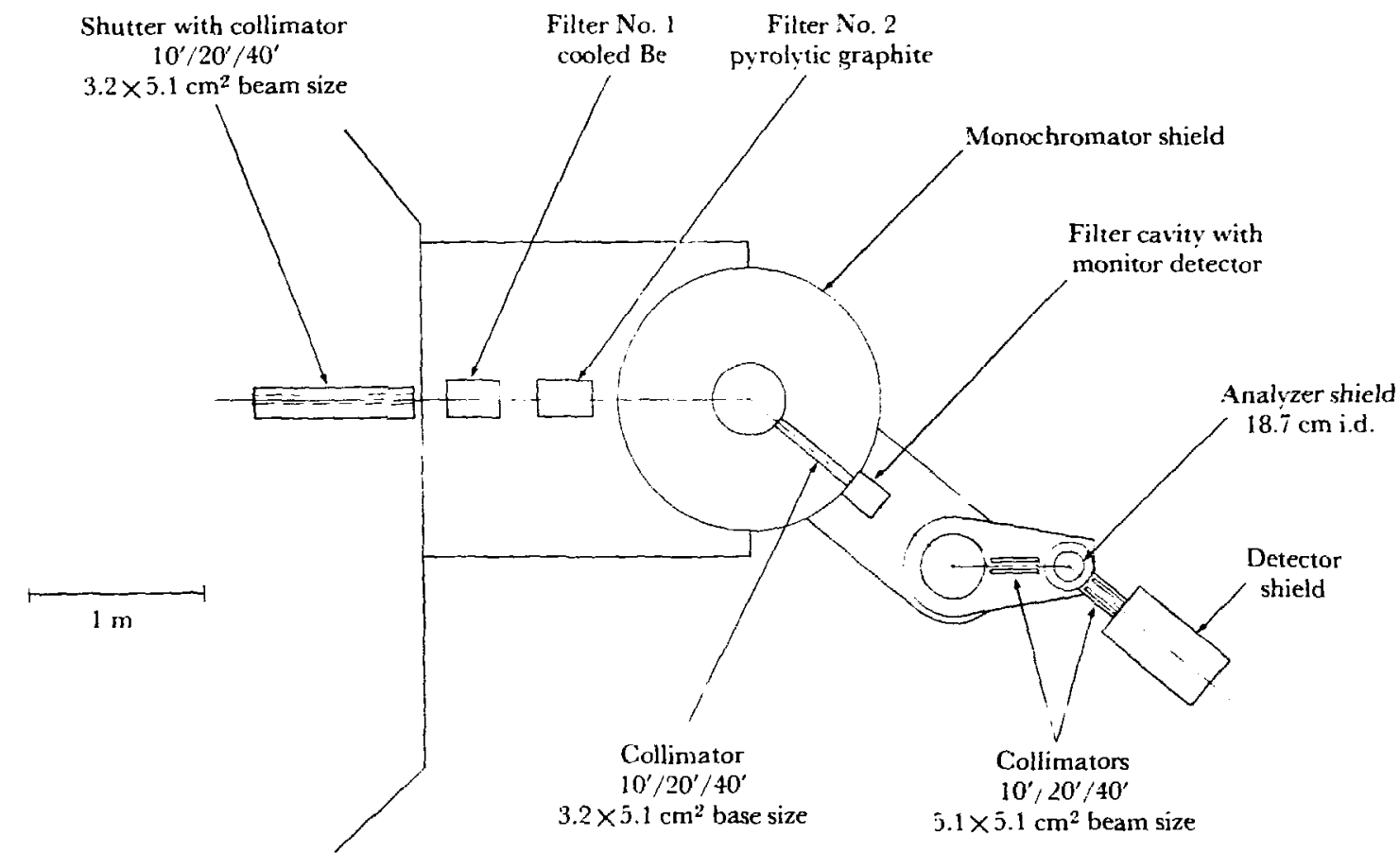

Schematic plan of triple-axis spectrometer installed at $\mathbf{H 5}$. 


\section{H6-M SPECTROMETER (DIFFRACTION)}

H6-M is a triple-axis spectrometer used primarily for single crystal elastic studies. A single crystal monorhromator is used with a variable scattering angle allowing for a choice of incident wavelengths. The spectrometer is equipped with a computer-controlled 4-circle goniometer which allows complete freedom in orienting single crystal samples. The instrument has an analyzer arm which will permit inelastic measurements, or permit diffraction measurements for zero energy transfer, thus reducing background. An extensive library of operating programs provides automatic crystal centering, unit-cell and orientation-matrix refinements, and collection of diffraction intensities by the step-scan method. Raw step-scan profiles are output on magnetic tape and processed off-line in the BNL CDCCYBER $70 / 76$ or VAX 11/780 computing system.

H6-M Station Parameters

\begin{tabular}{ll}
\hline $\begin{array}{l}\text { Flux at monochromator } \\
\text { (20' in-pile collimation) }\end{array}$ & $4.1 \times 10^{9} \mathrm{n} / \mathrm{cm}^{2}-\mathrm{sec}$ \\
Monochromator scattering angle & $21^{\circ}<2 \theta_{\mathrm{M}}<56^{\circ}$ \\
$\lambda_{0}$ or $\mathrm{E}_{0}$ (Be 002) & $1.69>\lambda_{0}>0.65 \AA$ \\
& $28.5<E_{0}<192 \mathrm{meV}$ \\
Beam size (maximum) & $3.2(\mathrm{~h}) \times 4.9(\mathrm{w}) \mathrm{cm}^{2}$ \\
Sample scattering angle & $-30^{\circ}<2 \theta_{\mathrm{S}}<113^{\circ}$ \\
Analyzer scattering angle & $-120^{\circ}<2 \theta_{\mathrm{A}}<120^{\circ}$ \\
In-pile collimation & $1.9 \mathrm{~cm}$ diam hole, or $20^{\prime}$ \\
External collimation & $10^{\prime}, 20^{\prime}$, or $40^{\prime}$ \\
Detector & $\mathrm{BF}$ \\
\hline
\end{tabular}




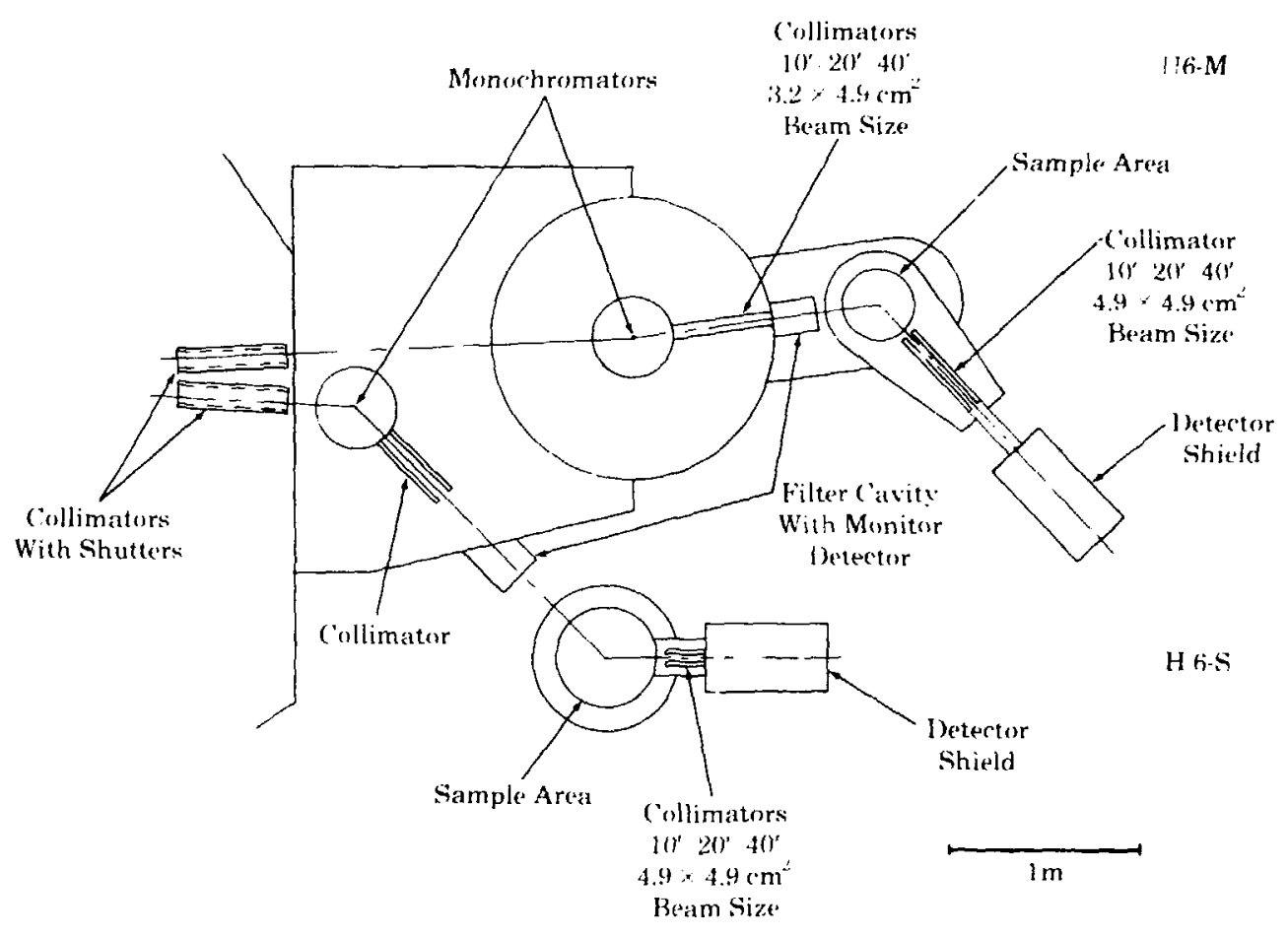

Schematic plan of spectrometers installed at $\mathrm{H6}$. 


\section{H6-S SPECTROMETER (DIFFRACTION)}

H6-S is a spectrometer used primarily for single crystal elastic scattering measurements. A single crystal monochromator is used with a fixed scattering angle $\left(2 \theta_{\mathrm{M}}=34^{\circ}\right)$ corresponding to $\lambda=1.16 \AA$ for the Ge (220) reflection or $\lambda=1.05 \AA$ for $B e$ (002). The spectrometer is equipped with a computer-controlled 4-circle goniometer which allows complete freedom in orienting single crystal samples. An extensive library of operating programs is available for automatic centering, unit cell and orientation matrix refinement, and collection of diffraction intensities by the step-scan method. Raw stepscan profiles are output on magnetic tape and processed off-line on the BNL CI)C-CYBER 70/76 or VAX $11 / 780$ computing system.

\section{H6-S Station Parameters}

Flux at monochromator $6.6 \times 10^{9} \mathrm{n} / \mathrm{cm}^{2}-\mathrm{sec}$

Monochromator scattering angle $2 \theta_{\mathrm{M}}=34^{\circ}$

$\lambda$, Ge $(220)$ or $B$ e $(002)$

$1.16 \AA$ or $1.05 \AA$

Beam size

$0.6 \mathrm{~cm}-2.5 \mathrm{~cm}$ (diam)

Sample scattering angle

$-21^{\circ}<2 \theta_{\mathrm{s}}<109^{\circ}$

In-pile collimation

$20^{\prime}, 40^{\prime}$

External collimation

$10^{\prime}, 20^{\prime}$, or $40^{\prime}$

I)tector

$\mathrm{BF}_{3}$ 


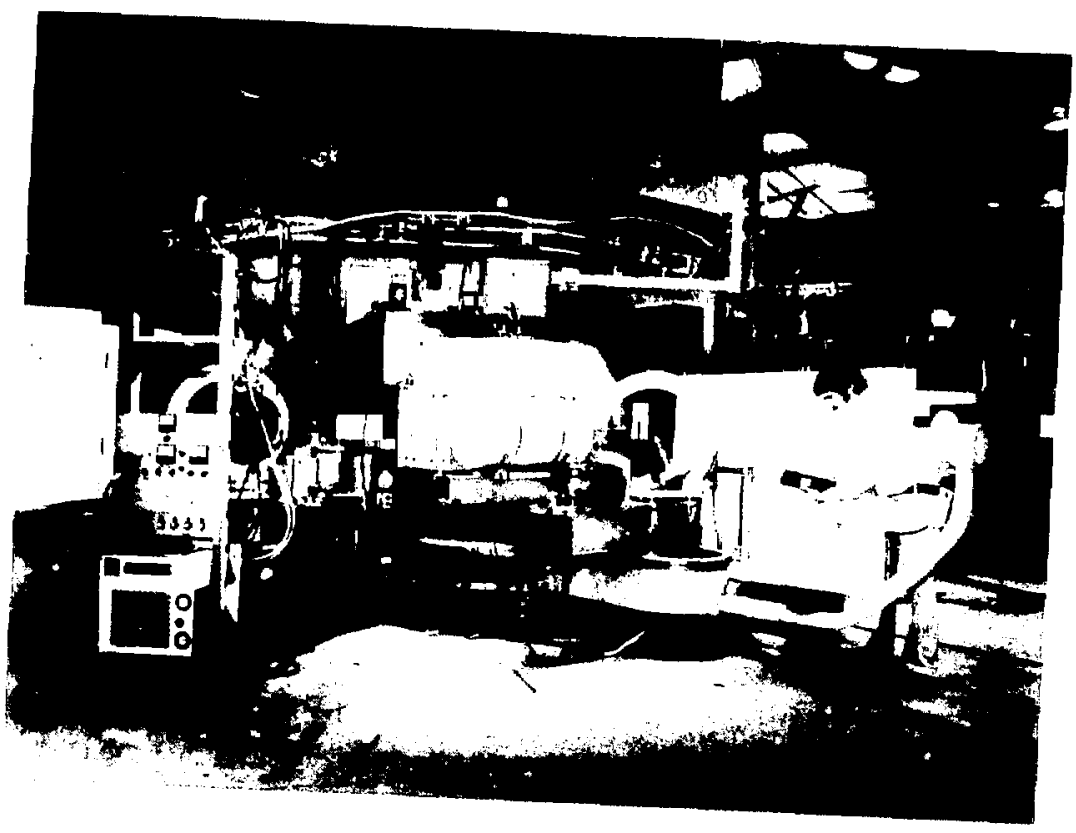

H6 Experimental Station. 


\section{H7 SPECTROMETER (INELASTIC SCATTERING)}

$\mathrm{H} 7$ is a triple-axis spectrometer used primarily for single crystal inelastic neutron scattering experiments, although it can also be used effectively for studying polycrystalline and amorphous samples. H7 is fully automated for variable incident neutron energies and scans with a fixed final energy can be performed. The spectrometer is normally equipped with pyrolytic graphite (002) monochromator and analyzer crystals, but $\mathrm{Be}, \mathrm{Cu}, \mathrm{Zn}$, and $\mathrm{Ge}$ monochromators are also available. Optional in-pile Be and pyrolytic graphite filters are provided for removing higher order beam contamination. Be and PG filters can also be placed after the sample for the fixed analyzer type of scan. The sample table is equipped with a manual two-axis goniometer with a $\pm 10^{\circ}$ range and is compatible with a variety of a vailable cryostats and furnaces. External collimation (other than in-pile) is provided by Soller slits with a $5 \times 5 \mathrm{~cm}^{2}$ cross section.

\section{H7 Station Parameters}

Flux at monochromator position

(20' collimation in-pile)

$4.1 \times 10^{9} \mathrm{n} / \mathrm{cm}^{2} \cdot \mathrm{sec}$

Monochromator scattering angle

$10^{\circ}<2 \theta_{M}<75^{\circ}$

E. i) ho (PG 002)

$4.9<\mathrm{E}_{0}<240 \mathrm{meV}$

$4.1>\lambda_{0}>0.58 \AA$

Beam size at sample

$5(\mathrm{~h}) \times 3.1(\mathrm{w}) \mathrm{cm}^{2}$

Sample scattering angle

$-45^{\circ}<2 \theta_{\mathrm{S}}<128^{\circ}$

Analyzer scattering angle

$-100^{\circ}<2 \theta_{\mathrm{A}}<100^{\circ}$

In-pile collimation

$10^{\prime}, 20^{\prime}, 40^{\prime}$

External collimation

$10^{\prime}, 20^{\prime}, 40^{\prime}$

Detector

$\mathrm{BF}_{3}$ 


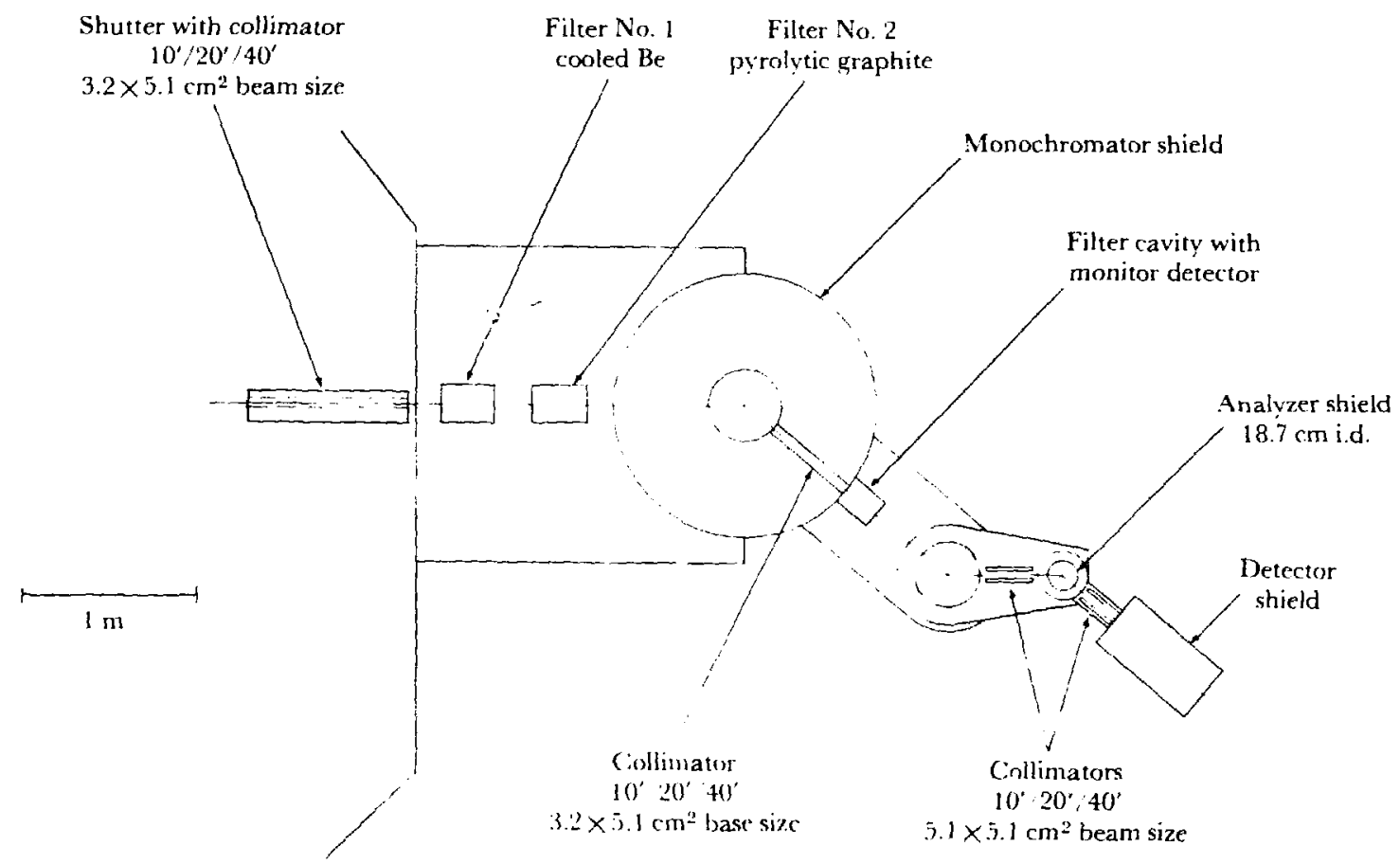

Schematic plan of triple-axis spectrometer installed at $\mathrm{H} 7$. 


\section{H8 SPECTROMETER \\ (POLARIZED BEAM, INELASTIC SCATTERING)}

$\mathrm{H} 8$ is a triple axis spectrometer used primarily for single crystal inelastic neutron scattering experiments. It is equipped with a monochromator housing that can accommodate either a PG (002) or a Heusler (111) crystal, for unpolarized and polarized neutron work, respectively. The incident energy can be varied remotely so scans with a fixed final energy can be performed. A Heusler (111) analyzing crystal, magnetic flippers, and guide fields can easily be positioned to allow for use as a fully polarized beam instrument. Cooled Be and pyrolytic graphite crystals are available for removing higher order beam contamination. The sample table is equipped with a manual two-axis goniometer with a $\pm 10^{\circ}$ range and is compatible with a variety of available cryostats and furnaces. External collimation is provided by Soller slits with a $5 \times 5 \mathrm{~cm}^{2}$ cross section.

\section{H8 Station Parameters}

Flux at monochromator position (20' in-pile collimation)

Monochromator scattering angle

Eo or $\lambda_{0}(P G 002)$

Beam size

Sample scattering angle

Analyzer scattering angle

$$
\begin{aligned}
& 4.2 \times 10^{9} \mathrm{n} / \mathrm{cm}^{2}-\mathrm{sec} \\
& 10^{\prime \prime}<2 \theta_{\mathrm{M}}<75^{\circ} \\
& 4.9<\mathrm{H}_{0}<240 \mathrm{meV} \\
& 4.1>\lambda_{0}>0.58 \AA \\
& 5(\mathrm{~h}) \times 3.1(\mathrm{w}) \mathrm{cm}^{2} \\
& -45^{\circ}<2 \theta_{\mathrm{S}}<140^{\circ} \\
& -1010^{\circ}<20_{\mathrm{A}}<100^{\prime \prime} \\
& 10^{\prime}, 20^{\prime}, 40^{\prime} \\
& 10^{\prime}, 20^{\prime}, 40^{\prime} \\
& \mathrm{BF}^{\circ}
\end{aligned}
$$$$
\text { External collimation }
$$ 
Shutter with collimator

$$
10^{\prime} / 20^{\prime} / 40^{\prime}
$$

Filter No. $1 \quad$ Filter No. 2

$3.2 \times 5.1 \mathrm{cn}^{2}$ bearn size

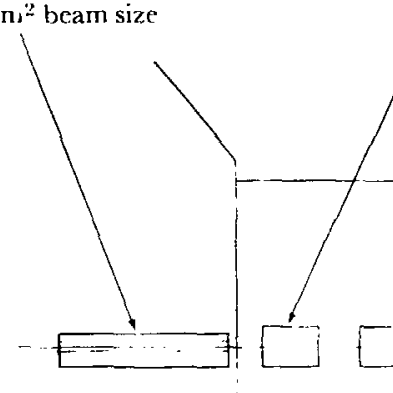

prrolvtic graphite

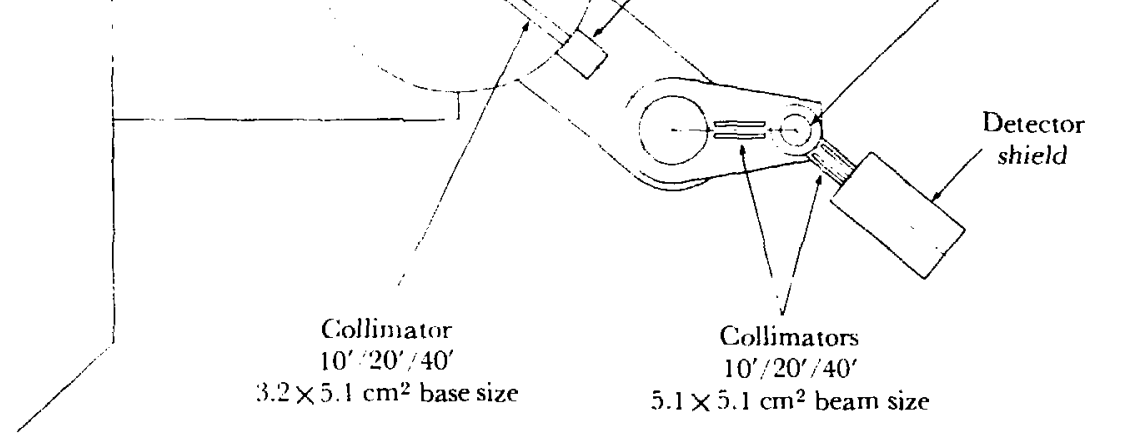

Schematic plan of triple-axis spectrometer installed at $\mathbf{H 8}$. 
H9-A SPECTROMETER

(INELASTIC SCATTERING - COLD NEUTRONS)

H9-A is a triple-axis type spectrometer situated on the cold neutron facility. It is used for high resolution inelastic neutron scattering studies of single crystal, polycrystalline, or amorphous samples. It is equipped with a double monochromator arrangement which allows for large monochromator scattering angles. A Be filter is placed before the monochromator for elimination of higher order beam contamination. The sample table is equipped with a manual twoaxis goniometer with a $\pm 10^{\circ}$ tilt range about two orthogonal horizontal axes, and is compatible with a range of available cryostats and furnaces.

\section{H9-A Station Parameters}

Monochromator scattering angle

$41^{\prime \prime}<2 \theta_{\mathrm{M}}<134^{\circ}$

Eif or $\lambda_{0}(\mathrm{PG}(00) 2)$

$2.15<\mathrm{E}_{11}<14.7 \mathrm{meV}$ 6.2 $>\lambda_{11}>2.35 \AA$

Beam size at sample

$7.5(\mathrm{~h}) \times 5(\mathrm{w}) \mathrm{cm}^{2}$

Sample scattering angle

$-50^{\circ}<2 \theta_{\mathrm{S}}<150^{\circ}$

Analvzer scattering angle

$-125^{\circ}<20_{\mathrm{A}}<125^{\circ}$

In-pile collimation

$15^{\prime}, 30^{\prime}$, or $60^{\prime}$

External collimation

$15^{\prime}, 30^{\prime}$, or $60^{\prime}$ before sample $10^{\prime}, 20^{\prime}$, or $40^{\prime}$ after sample

Detector $\mathrm{BF} ; 3$ 


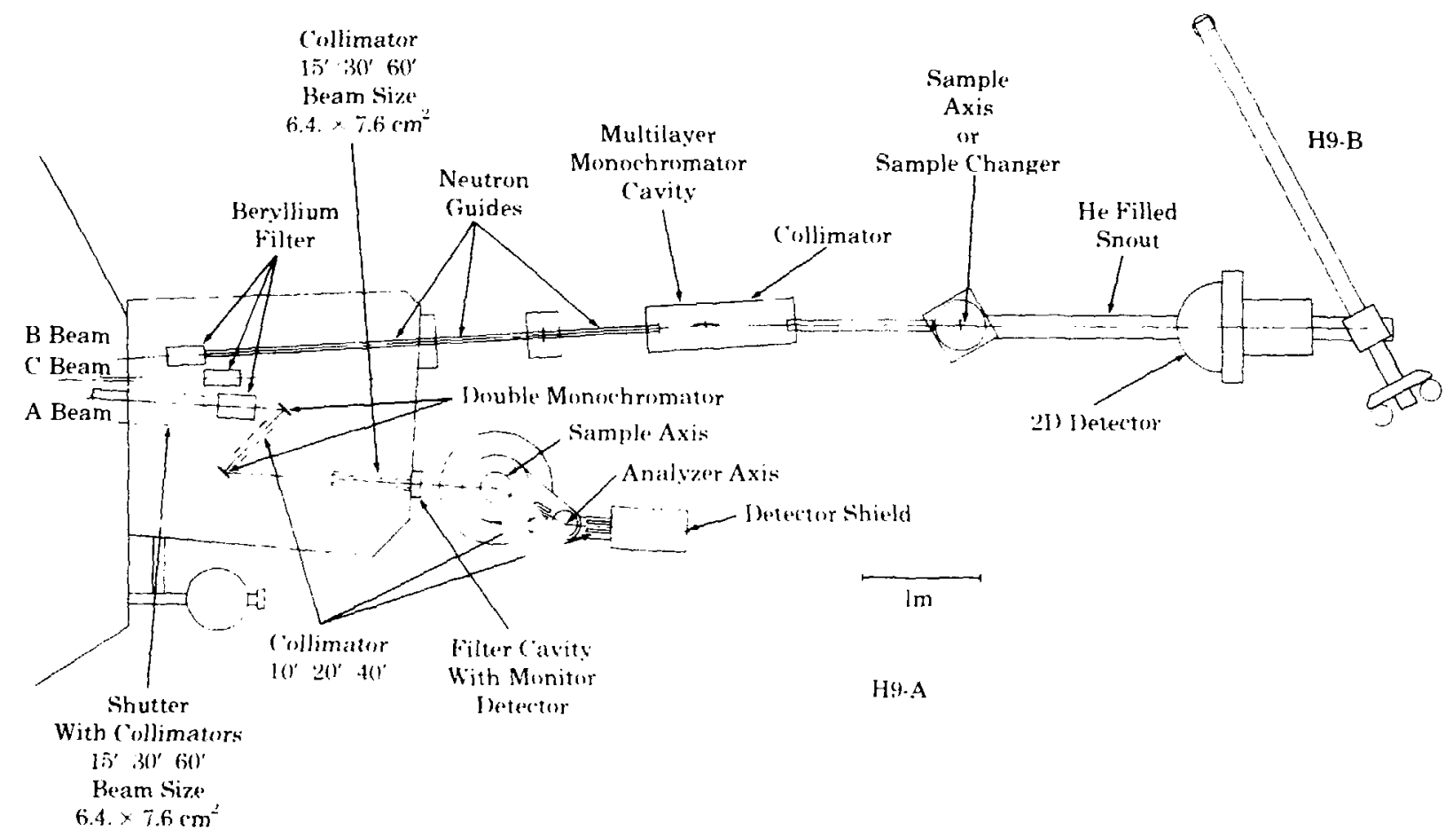

Schematic plan of spectrometers installed at $\mathbf{H 9}$. 


\section{H9-B SPECTROMETER \\ (SMALL ANGLE SCAT'TERING - BIOLOGICAL STRUC'TURE)}

The H9-B spectrometer is used for small angle diffraction studies on macromolecular biological structures. Samples can be oriented on a vertical axis or by an automated sample changer, and a twodimensional detector can be positioned automatically on an arc of variable radius. 'This allows for the required flexibility to investigate both solution samples and oriented preparations.

The spectrometer utilizes a Be-filtered cold moderator beam emerging from Ni-coated neutron guides ( $25.4 \times 50.8 \mathrm{~mm}$ ). Monochromatization is achieved with exchangeable Fe-Mn or Ge-Mn multilayers with bilayos spacings between 50 and $150 \AA$. The monochromatic beam is collimated over a length of $2 \mathrm{~m}$ by a series of apertures of decreasing diameter. Typically, the primary beam has a diameter of fi mm at the sample. A PI)P $11-34$ computer with a large external memory is used for experimental control and preliminary data analysis.

H9-B Spectrometer Parameters

\begin{tabular}{|c|c|}
\hline Wavelength range & $4-10 \AA$ \\
\hline Wavelength spread (FWHM) & $6-15 \%$ \\
\hline Beram divergence (FWHM, horizontal) & $14^{\prime}$ \\
\hline Flux at sample (5 $\Lambda .6 \mathrm{~mm}$ boam) & $1-2 \times 10^{16} \mathrm{n}\left(\mathrm{cm}^{2}-\mathrm{sec}\right.$ \\
\hline Jetectorareal & $50 \times 50 \mathrm{~cm}^{2}$ \\
\hline Detector resolution & $3 \mathrm{~mm}$ \\
\hline Sample-detector distaner & $5(1-20) \mathrm{cm}$ \\
\hline Range of scattering angles & $0-4 i^{\prime \prime}$ \\
\hline Rest spectrometer resolution & $1000 \AA$ \\
\hline Minimum $Q(\lambda=\bar{\lambda} \AA .2 \mathrm{~m}$ detector distance $)$ & $0.000 .2 \AA^{1}$ \\
\hline
\end{tabular}




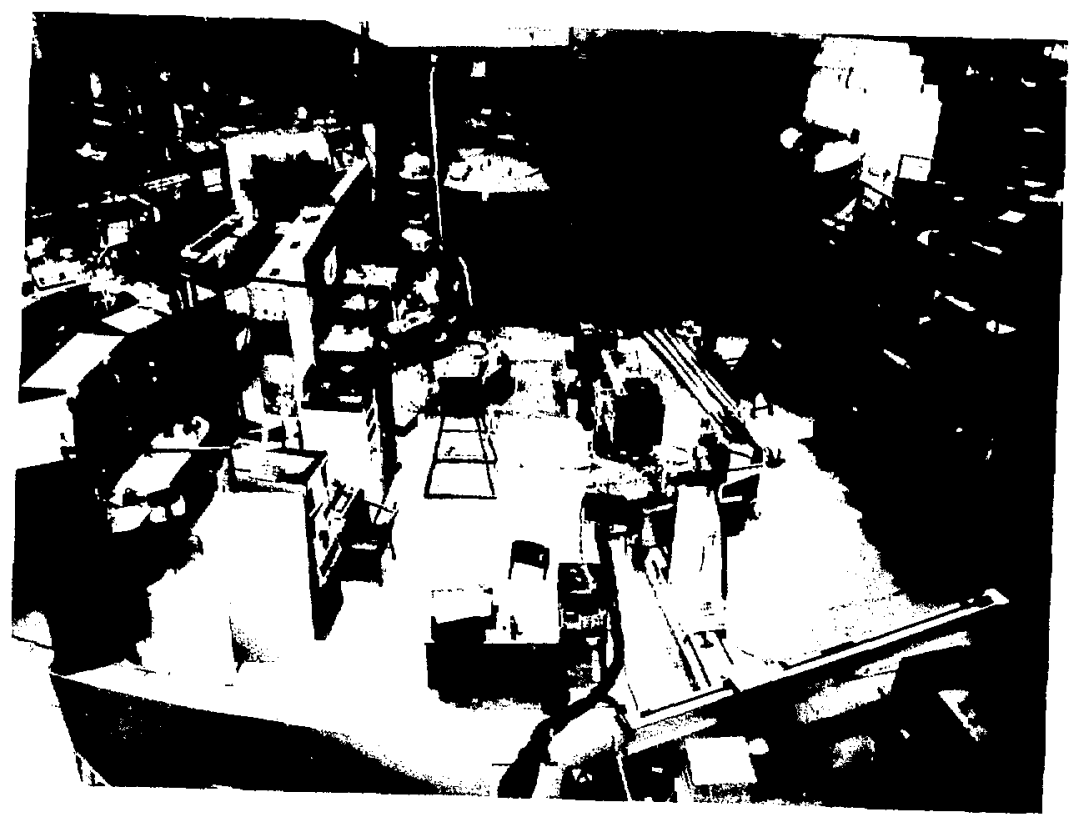

H9 Experimental station. 


\section{ANCILLARY EQUIPMENT}

A variety of cryostats, furnaces, and magnets is available to control the sample environment. Most of the instruments have standardized mounts or adaptors so as to permit ready interchangeability at various experimental stations. The ranges covered are given below.

Cryostats and refrigerators

Furnaces and ovens

Magnets

Pressure
$0.03 \mathrm{~K}<\mathrm{T}<325 \mathrm{~K}$

$300 \mathrm{~K}<\mathrm{T}<1700 \mathrm{~K}$

$0-90 \mathrm{kG}$ vertical

$0-24 \mathrm{kG}$ hurizontal

0 to $30 \mathrm{k}$ bar

\section{COMPUTER CONTROL SYSTEM}

The various scientific disciplines utilizing the reactor have different needs for control and data acquisition. Each instrument is computer controlled and data are collected and stored either on magnetic tape or on disc. Some preliminary on-line data analysis is performed at the HFBR but many of the data are transferred to a larger computer at the user's laboratory where the final data analyses are performed. 


\section{Irradiation of Samples at the HFBR}

Irradiation experiments at the HFBR play an important role in the overall research program. Seven vertical thimbles provide a variety of neutron energy spectra for sample irradiations. Thermal or slow neutrons are used primarily for neutron activation analysis ("fingerprinting" unknown substances by artificially induced radioactivity) and for the production of special purpose radioisotopes. Due to the high neutron flux available, it is possible to produce highly radioactive samples from small quantities of material (high specific activity), and to produce certain isotopes in quantities unattainable by any other practical means. Fast neutron irradiations are vital to the study of radiation damage in materials and are playing an important role in the program to develop a fusion rea:tor.

Three of tlse irradiation thimbles (V10, V11, and V12) are located in the reflector portion of the reactor, while the others are positioned at the core edge (V13 and V14) and at the core center (V15 and V16). The thimbles are fitted with a set of reentrant tubes connected to a separate $\mathrm{D}_{2} \mathrm{O}$ cooling system which circulates a flow of 45 liters $/ \mathrm{min}$ downward through the center and upward through the outer annular region of each tube. Samples are placed in aluminum capsules which are immersed in the $\mathrm{D}_{2} \mathrm{O}$ for cooling. Each capsule is attached to the end of a 10 meter length of $6 \mathrm{~mm}$ diameter aluminum tubing which is used to lower the sample capsule into the reactor and to withdraw it after the irrradiation. In addition, this tubing can be used to vent the capsule, to fill it with gas for heat transfer, and to bring out a pair of thermocouple leads, if desired. A hydraulic "rabbit" is also available at Facility V11 which permits rapid insertion and retrieval of samples for precisely-timed irradiations of short duration.

Irradiations can be scheduled by contacting Reactor Research Coordination at extension 4056 or 4436 . All proposed irradiations 

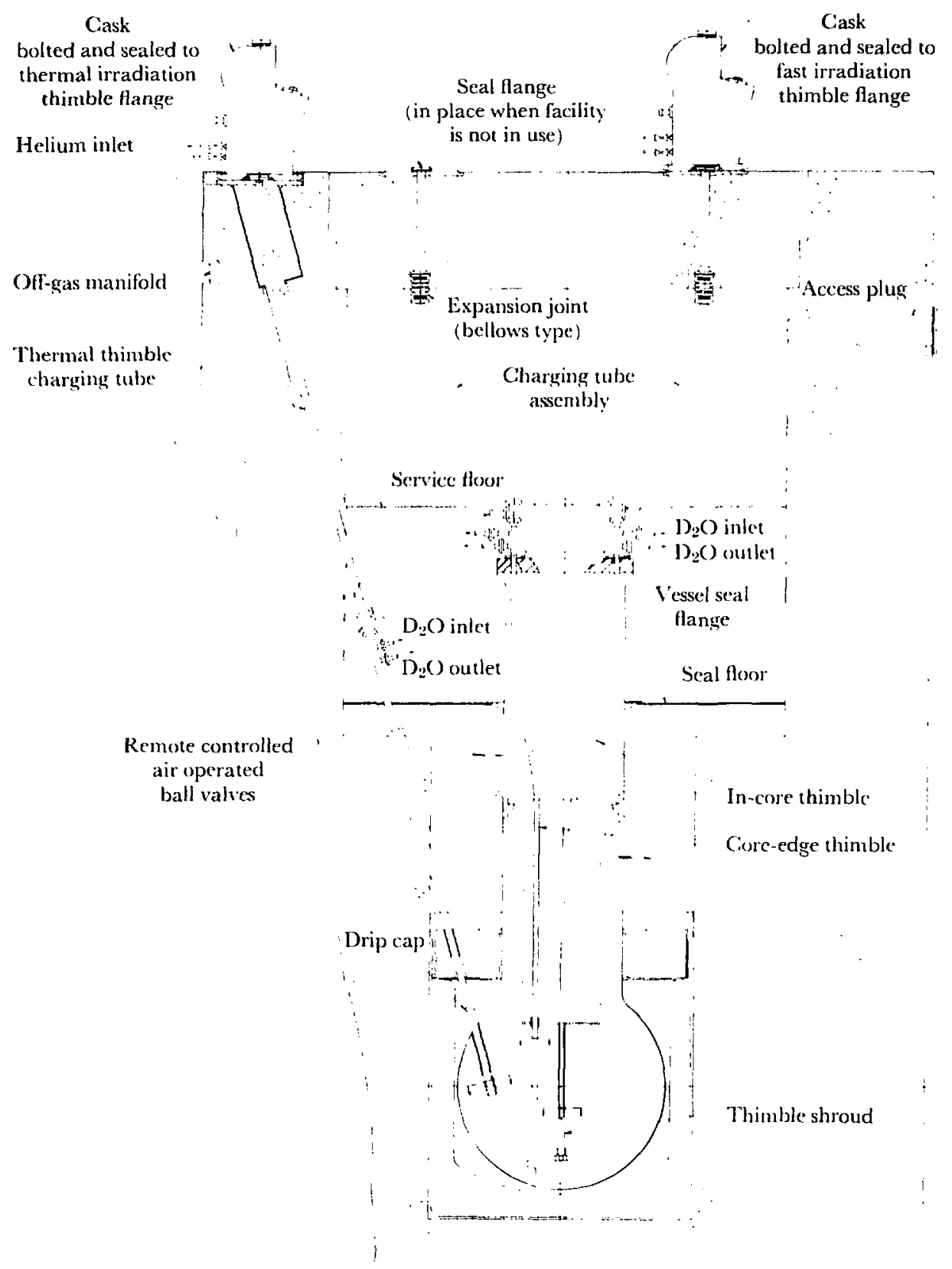

Elevation showing location of several irradiation thimbles within the reactor. 
are reviewed by the Research Coordinator for their potential impact on reactor safety. Proposed irradiations of samples which might cause large reactivity changes or present unusual hazards, such as those involving fissionable materials, or materials which can decompose and react with vessel components or reactor coolant, must be reviewed and approved by the Reactor and Critical Experiments Safety Committee before they can be placed in the reactor.

\section{HFBR Irradiation Facilities}

\begin{tabular}{|c|c|c|c|c|c|}
\hline \multirow[b]{2}{*}{ Facility } & \multicolumn{2}{|c|}{ Flux, neutrons ent'sec } & \multirow{2}{*}{$\begin{array}{c}\text { Heating Rate. } \\
W \mathrm{~g} \\
\text { (in aluminum) }\end{array}$} & \multicolumn{2}{|c|}{$\begin{array}{l}\text { Useable } \\
\text { Dimensions }\end{array}$} \\
\hline & Thermal & $\begin{array}{c}\text { Fust } \\
(>1 \mathrm{MeV})\end{array}$ & & $\begin{array}{c}\text { l)iam } \\
(\mathrm{cm})\end{array}$ & $\begin{array}{l}\text { longth } \\
\text { (cm) }\end{array}$ \\
\hline V10 & $2.7 \times 10^{1.1}$ & $7.5 \times 10^{11}$ & 0.38 & 2.4 & 7.6 \\
\hline V11 & $1.5 \times 10^{1.4}$ & $9.0 \times 10^{101}$ & $0.2: 3$ & 2.0 & 7.6 \\
\hline V12 & $3.8 \times 10^{1.4}$ & $8.3 \times 10^{11}$ & 1.20 & 2.4 & 7.6 \\
\hline $\mathrm{V} 13^{*}$ & $8.3 \times 10^{1.4}$ & $9.0 \times 10^{13}$ & 6.0 & 1.5 & 7.6 \\
\hline V14 & $8.3 \times 10^{1.4}$ & $9.0 \times 10^{13}$ & 6.0 & 1.9 & 7.6 \\
\hline V15 & $2.0 \times 10^{3.4}$ & $3.0 \times 10^{1.4}$ & 12.0 & 1.9 & 7.6 \\
\hline V $16^{*}$ & $2.0 \times 10^{1.4}$ & $3.0 \times 10^{14}$ & 12.1 & 1.5 & 7.6 \\
\hline
\end{tabular}

* Accessible for placrment and removal of samples only during reactor shutalown. V li3 and V!G can accommodate two samples each of the size given. 


\title{
VI. General Information for Visitors
}

\author{
THE IAABORATORY AND ITS ORGANIZATION
}

The Brookhaven National Laboratory is operated by Associated Universities, Inc. (AUI) under a prime contract with the Department of Energy (DOE). Nine northeastern universities sponsor AUI. The Board of Trustees consists of two representatives from each university (one a principal administrative or corporate officer, and the other a scientist) and not more than six Trustees-at-Large. Visiting Committees, appointed by AUI, provide a continuing independent evaluation of the research programs carried out by the various Scientific Departments. The internal organizational structure of the laboratory and a site map are shown in the accompanying figures.

The formation of AUI in 1946 and the subsequent establishment of Brookhaven provided a new approach to the support of research by the Federal government, especially with regard to the development and use of large scale research tools and other specialized equipment inappropriate for construction and operation by an individual university. These facilities are used by Brookhaven staff members in research and development work in national programs under DOE direction. From its inception as a National Laboratory, however, Brookhaven has promoted the use of its special facilities by qualified visiting scientists without regard to their institutional affiliations.

\section{APPOINTMENTS}

Everyone working at Brookhaven must have a valid appointment and 1.I). card. Guest appointments are arranged through the Scientific Department identified with the visitor's research area. I.D. cards are issued for one year, at the end of which they must be renewed. Temporary I.D. cards for guest's family members can be obtained at Personnel. Under the AUI contract with DOE, a Guest 


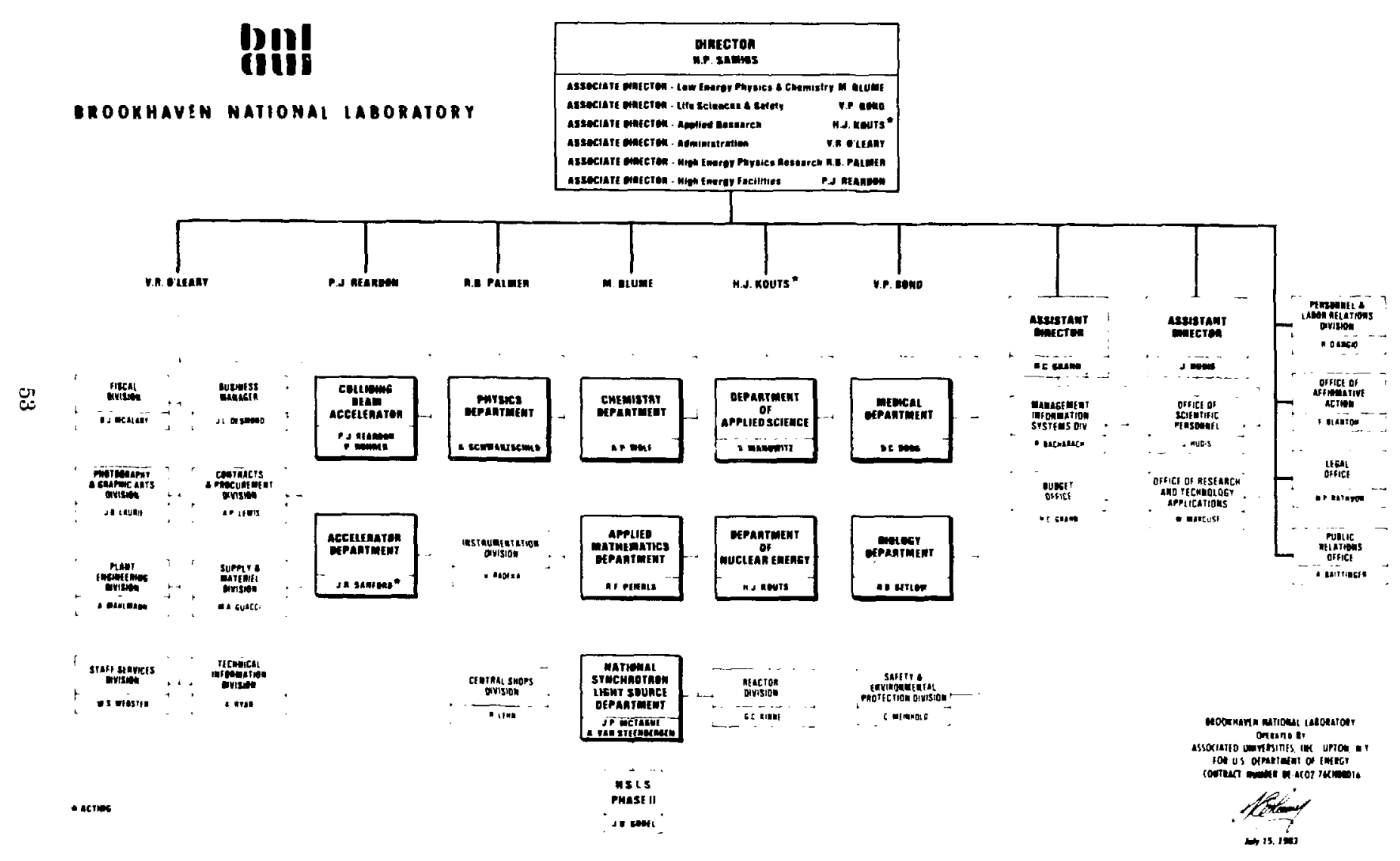




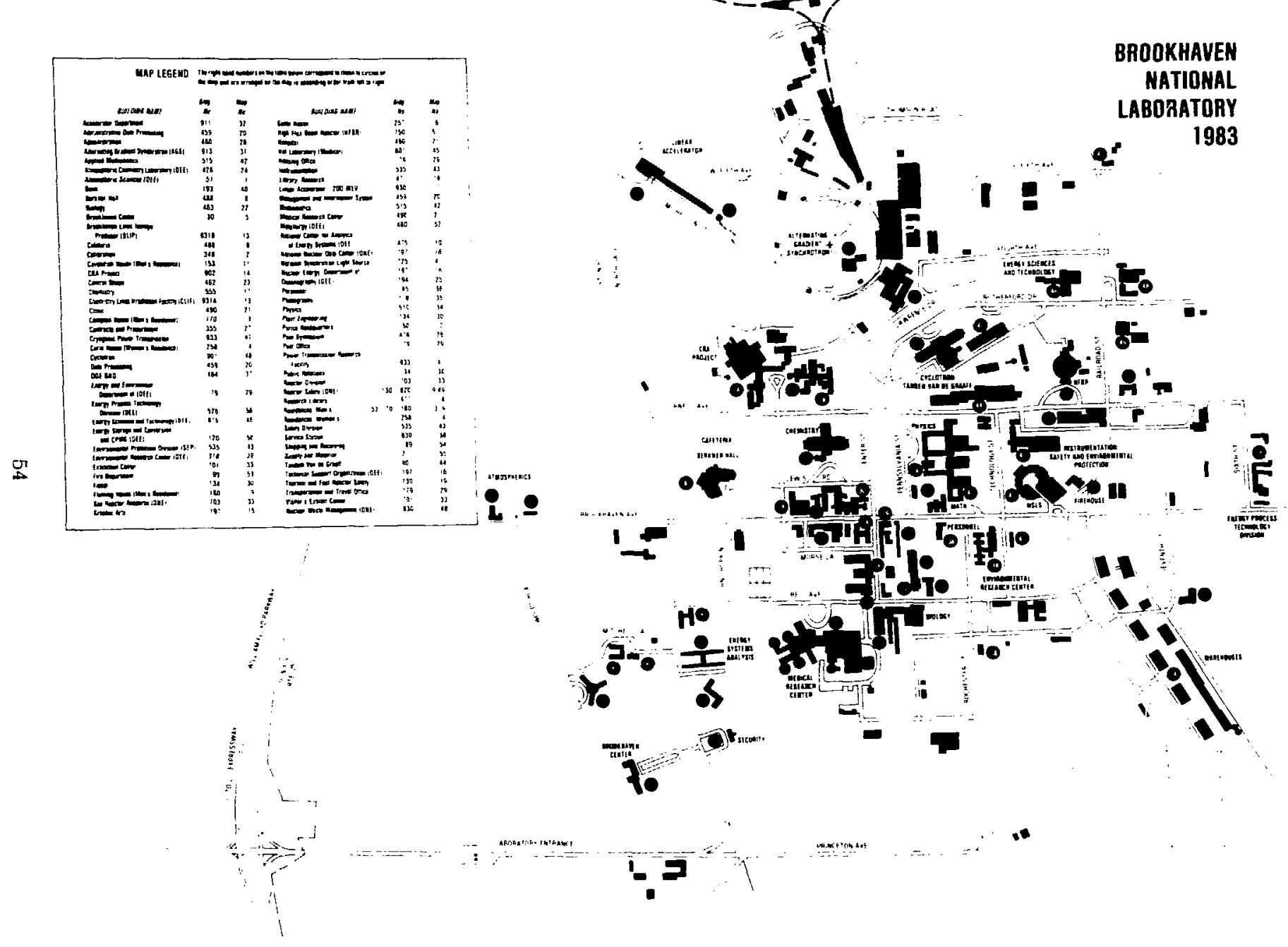


Patent Agreement is required. The latter may be signed at the time the guest appointment is made. Guests must make their own provisions for medical insurance since no coverage is provided under a guest appointment. An exception is made for foreign visitors, who may participate in the Brookhaven insurance plan at their own expensce.

\section{TRANSPOR'TATION}

MacArthur Airport, located in nearby Islip, provides direct flights to and from several kast Coast eities and Chicago. Long Island limousine and Winston I.imousine provide service between the I a aboratory and the New York (ity airports. A I cong Island Railroad train leaves New York (Penn Station) Monday through Friday at about 8:40 a.m. and arrives in Patchogue at about 10:16 a.m. where visitors are met by a Laboratory bus. The train also stops at Jamaica (the station closest to John F. Kennedy and LaGuardia Airports) at about 8:57 a.m. Since the I song lsland Railroad schedule changes seasonally, the exact departure time should be checked.

A Laboratory vehicle leaves the Public Relations Office (Bldg. 134) at 4:20 p.m. on working days to transport travelers to the MasticShirley railroad station. The train to New York City arrives at Penn Station about 6:30 p.m. Please make advance reservations by calling Ext. 2345 .

Transportation between the Laboratory and the Patchogue railroad station, or MacArthur (Islip) Airport may be provided if no overtime is involved and requests (which must have the approval of the Department Chairman) have been made in advance by calling the Transportation Office (Ext. 2535). Transportation is not provided to Kennedy or LaGuardia airports.

There is limited bus service to certain local areas from the BNL main gate. Bus schedules may be obtained at the Travel Office. A number 


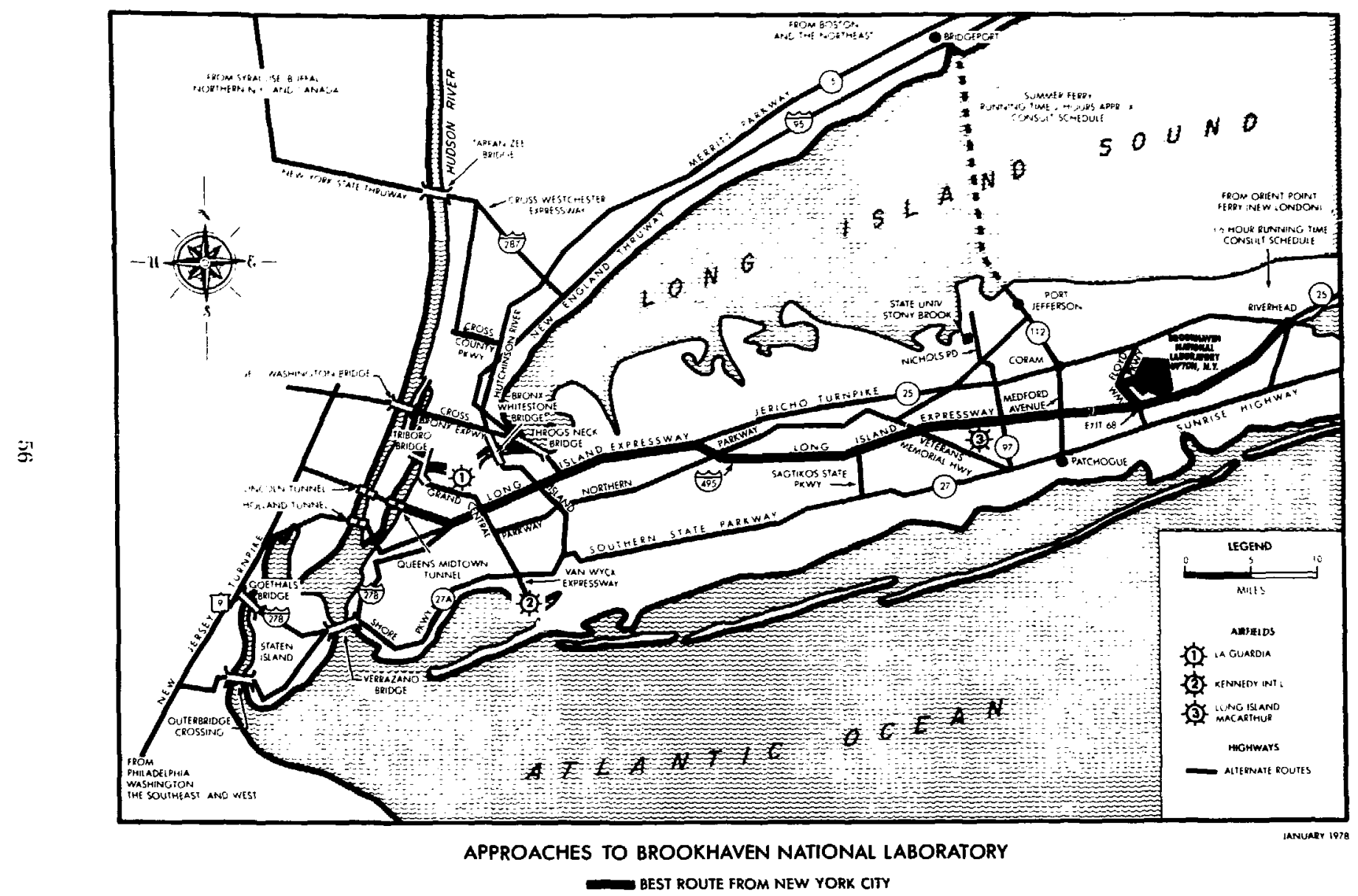


of taxicab companies are listed in the yellow pages of the Suffolk telephone book.

For those driving their own or rental automobiles, the aceompanying map indicates the best route to the laboratory. The main gate of the laboratory, at the west end of Princeton Avenue, is open for use at all times. Two other gates, at the north and south ends of Upton Road, are open at peak traffic periods only' Monday through Friday rexcluding holidays). Rental (ars are available at MacArthur and the New York airports.

\section{HOLISING}

Brookhaven maintains on site a Guest House, dormitories, and a limited number of furnished apartments. Formal housing agreements are required prior to occupancy of all accommodations except for less than 30 day occupancy of the Guest House and dormitory space.

Apartments are assigned, when available, only on request from the Department with which a guest appointment is held. The apartments are supplied with furniture, towels, bed linen, kitchen facilites and utensils. Irons, toasters, and other appliances are not supplied; however, coin-operated washers and dryers are located in the A partment Area. The regular apartments have TV antenna connections, but the detached units do not.

Rents for housing units at Brookhaven National Laboratory are established by a survey of prevailing rates for comparable housing in the communities surrounding the Laboratory. This procedure is prescribed by the Office of Management and Budget pursuant to Public Law 88-459.

The BNL Housing Office (Ext. 2541) is open Monday through Friday from 8:30 a.m. to 5:00 p.m. Those arriving after working hours, during weekends, or on holidays may obtain their keys from the 
Laboratory Police. Checkout time is 3:00 p.m. Problems relating to accommodations should be reported to the Housing Office during normal working hours or to the Laboratory Police (Ext. 2238) outside of normal working hours.

\section{FOOD SERVICE}

For t service is available on site as outline below:

$\begin{array}{ll} & \text { Cafeteria } \\ \text { Breakfast } & 7: 30 \text { a.m. }-10:(00 \text { a.m. } \\ \text { Lunch } & 11: 15 \text { a.m. }-1: 30 \text { p.m. } \\ \text { Supper } & 5: 00 \text { p.m. }-6: 30 \text { p.m. }\end{array}$

The Cafeteria is open from $7: 30 \mathrm{a}$.m. unti] 6:30 p.m. Monday through Friday. Only the Snack Bar is open from 10:00 a.m. until 1 $1: 15$ a.m. and $1: 30$ p.m. until 5:00 p.m.

On weekends and holidays service is limited to the Grill Station, which is open from 9:(1) a.m. to 2:00 p.m.
'Tap Room, Brookhaven Center

None

None

(i:()) p.m. $-9: 00$ p.m.

Sandwiches only after 9:00 p.m. until 11:(1) p.m.

The Tap Room is open from 5:00 p.m. 10 11:15 p.m. daily except Saturday.

Building closed at $11: 30$ p.m.

Information on off-site re staurants may be obtained from the Public Relations Office (Ext. 2:34:).

\section{O'THER SERVICES AND AMENITIES}

Medical Care. The Industrial Medicine Clinic of the Medical Department is available for emergencies (Ext. 2222) and first aid. For first aid or medical information call Ext. 3670 weekdays and Ext. 3676 nights and weekends.

For nonemergency personal and family medical problems, users are expected to avail themselves of private physicians and facilities. Physicians at the clinic may be consulted for information on physicians practicing nearby. 
Cashier. Personal checks for up to $\$ 100$ may be cashed at the Cashier's Office in BIdg. 1:34 8:30 a.m. to 4:45 p.m. Monday through Thursday, 7:30 a.m. to 4:45 p.m. Friday. Second-party institutional checks may also be cashed, but not second-party personal checks. Certain personal bills such as those for on-site housing and telephone service are paid here.

Banking Service. The Barclays Bank of N.Y. has a branch office on site that provides all regular banking services. Hours are from 9:00 a.m. to 3:00 p.m. on Monday thorugh Friday. Personal checks may be cashed only if the user has an account there.

Automobile Service Station. An on-site service station is open from 8:00 a.m. to 6:00 p.m. on weekdays.

Post Office. BNL is fortunate in having a first-class U.S. Postal Service Office on site (Bldg. 179). Window service is available Monday through Friday, 8:00 a.m. to 5:00 p.m. U.S. mail is delivered to and picked up from BNL twice a day by truck, leaving the site 11:30 a.m. and 4:45 p.m. Boxes can be rented by those who do not wish to have personal mail delivered to an office address at $B N L$. There is no mail delivery to residences.

Hospitality. A Hospitality Committee, composed of the wives of staff members, offers help in the orientation of the wives of guest appointees. Dorothy Marelli, Ext. 4262 in the Personnel Office, acts as liaison agent. A folder, distributed to all the apartments, contains a brochure of the activities of the Brookhaven Employee's Recreation Association (BERA), which are open to anyone with a guest appointment. It also contains sketch maps showing local shopping facilities, ferry schedules, a LIRR timetable, and other useful material.

Film Service. BERA's film service for film processing, film, and other photographic equipment is located in Berkner Hall. 
Newspaper. The New York Times, the Wall Street Journal, and some local papers are on sale in the Cafeteria in Berkner Hall.

Brookhaven Center. The Center is open from 5:00 p.m. to 11:30 p.m. every evening except Saturday. Light dinners, bar service, a lounge area, and TV are available.

Recreation - On Site. The recreation facilities at the Laboratory include the swimming pool and gymnasium, tennis courts and softhall fields, picnic area, and the Recreation Building. Announcements of activities and events are carried weekly in the Brookhaven Bulletin and posted on various office bulletin boards. These include an annual concert series, lectures, films, and special events. The BERA activities pamphlet has details on all on-site recreational activities.

Recreation - Off Site. Good swimming, boating, and fishing are within 16 kilometers $(10$ miles) of the Laboratory.

You are invited to use Brookhaven Town recreation facilities as a tenant at Brookhaven National Iahoratory. A bumper sticker issued by the Town Recreation I Department is required for access to these facilities. It may be obtained at the Town Recreation Office, Old Town Road, in Coram (north and west of the intersection of Routes 25 and 112). Bring with you a copy of your BNL Housing Agreement or a copy of your housing bill and your automobile registration. Hours are from 8:00 a.m. to 4:00 p.m. Monday through Friday.

BERA periodically offers tickets to the Metropolitan Opera and some sports events. Call Ext. 2873 for information.

Weather Forecast. (all Meteorology, Ext. 2263.

Pets. Prior approval to harbor pets in apartments must be obtained from the Housing Office. Pets are prohibited in dormitories. 
Schools. Children age 5 and over living on the Laboratory site may attend a public elementary school (Grades Kindergarten through 6), or a Juniur-Senior High School (Grades 7 through 12) at no cost. Students at both schools are transported to and from the Laboratory by school bus. Generally, the school term begins a day or two after Labor Day (first Monday in September) and ends late in June. Registration takes place at the Middle Island School I District. Central Administration Offices, Yaphank Road, Middle Island, NY 119533. Tel. No. (516)345-2162. The sehool district requires proof of residency (lease is good) plus one other proof (light bill, phone bill, etc.). They will wait a few weeks for the second proof as most new arrivals wouldn't have such a document available immediately.

Immunizations. The school district and the New York State Public Health law require proof of the following imınunizations: :3 I)PT (diphtheria, whooping cough, and tetanus) shots (but 4 are preferred); 3 to 4 doses of oral trivalent polio vaccine; plus 1 single dose each of measles, mumps, and rubella - live - given after 12 months of agre.

Nursery School. For pre-schoolers, a cooperative school (with parent participation), known as the Upton Nursery School, has been organized on the Laboratory site for children ages 3 and 4 . School begins about the second week in September and ends the second week in June. Classes are small and children attend one-half day for usually 2 or 3 days per week. At present, the fee is $\$ 46.00$ per month for 3 days, $\$ 33.00$ for 2 days. Enrollment is limited and it is advisable to pre-register well hefore arrival. Write Upton Nursery School, P.O. Box 324. Upton, N.Y. 11973.

Day Care Center. Kids $R$ Us is a pre-school learning center located on the grounds of the Middle Island Presbyterian Church, $1 / 4$ mile from the Laboratory. It is open to children 18 mos. - 5 years of age, and operates from 7:45 a.m. to 5:30 p.m. Monday through Friday. Interested parents are invited to visit any time, or call (516)924-802' on week days. 
Stores. There are no stores or shops on site. The nearest off-site stores are shown on a map available at the Housing Office (Ext. 2541 ).

Shopping Trips. For those needing transportation, a car leaves the children's shelter in the Apartment Area every Tuesday and Friday at 9:00 a.m. It arrives at Pathmark in Shirley at 9:15 a.m. or the village of Patchogue at 9:30 a.m. It leaves at 12:00 p.m. (in the back of Richard York, Patchogue), and returns to the Apartment Area by 12:30 p.m. 'Ihis service operates on request only. Please call Ext. 25:35 the day hefore you wish to use this service. 


\section{Directory}

BNL Telephone No.

Area Code 516, 282-2 123

For Information On

Who

Where

Tel.

Automobiles: government vehicles

S. Saccardi

2 Center

Ext.

Brookhaven Bulletin

B. Petersen

37 Brookhaven

2535

Hospitality Commitee

D. Marelli

Housing Office

D. Met:

Personne!

dentification cards

Insurance - medical

Personnel

Mail

Medical check-up

Medical emergencies

Notary Public

Mail Room

Ind. Med. Clinic

Ind. Med. Clinic

58 Brookhaven

2345

2 Center

4262

285:

58 Brookhaven $\quad 2877$

2 Center 2534

30 Bell 3670

30 Bell 2222

M. Goldman 40 Brookhaven 3324

R. Flack 40 Brookhaven 3316

G. Callister 30 Bell 3694

Nursery School

Personnel Records

Plant Safety

Recreation Office

Salary Checks

Sailing Permits

Shopping Trips

Taxes

Transportatiol _arrival

Transportation departure

B. Laskee

58 Brookhaven 2873

M. Austin

R.W. Young

B. Laskee

58 Brookhaven

2875

$20 \mathrm{~N}$. Technology 4271

M. DuBois

58 Brookhaven

2873

F. Federmann

37 Brookhaven

2487

S. Saccardi

37 Brookhaven

2482

F. Federmann

2 Center

2535

Office of Scientific

Personnel

Transportation

Office

37 Brookhaven

2482

Office of Scientific

Personnel

Travel Office

40 Brookhaven

3336

2 Center

2535

Travel Reservations

Visas

G.A. Price

40 Brookhaven

3336

2 Center 2531

40 Brookhaven $\quad 3336$ 


\section{Appendices}

\section{A. PHYSICAL CONSTANTS AND CONVERSION FACTORS}

Avogadro's number

Bolizmann's constant

Planck's constant

Bohr magneton

Nuclear magneton

Noutron magnetic moment

Neutron rest mass

Proton rest mass

Electron rest mass

Speed of light (vac)
$\mathrm{N}_{\mathrm{A}}=6.02204 \times 10^{23}$ molecules $/ \mathrm{mol}$

$\mathrm{k}_{\mathrm{R}}=1.38066 \times 10^{-16} \mathrm{erg} / \mathrm{K}$

$\mathrm{h}=6.6262 \times 10^{27} \mathrm{erg} \mathrm{sec}$ h $=1.0546 \times 10^{27} \mathrm{erg} \mathrm{sec}$

$\mu 13=9.2741 \times 10^{21} \mathrm{erg} / \mathrm{gauss}$

$\mu N=5.0508 \times 10^{2-1}$ erg gauss

$\mu_{n}=1.913$ nuclear magnetons

$\mathrm{m}_{11}=1.00866650$ (atomic mass units)

$$
m_{\mathrm{n}}=1.674995 \times 10^{2.4} \mathrm{~g}
$$

$\mathrm{m}_{p}=1.00172765$ (atomic mass units)

$$
\mathrm{m}_{\mathrm{p}}=1.67265 \times 10^{2-1} \mathrm{~g}
$$

$\mathrm{m}_{*}=5.4858() \times 10^{-1}$ (atomic mass units) $\left.\mathrm{m}_{\mathrm{e}}=0.5\right] 100 \mathrm{MeV}$ $c=2.997925 \times 10^{10} \mathrm{~cm} / \mathrm{sec}$

\section{Multiply}

by

$1.6606 \times 10^{3.1}$

$9.3150 \times 10^{\text {8 }}$

Barns

$1 \times 10^{2-4}$

Electron volts

$1.60219 \times 10^{12}$

Curies

$3.70 \times 10^{111}$

Half-life

1.443

Roentgens to get

grams

electron volts square $\mathrm{cm}$

ergs

disintegrations/sec

meanlife $=(\text { decay constant })^{-1}$ esu of ions $/ \mathrm{cm}^{3}$, standard air

$\mathrm{MeV}$ absorbed/g air

\section{1}

$5.24 \times 10^{7}$ 


\section{B. WAVELENGTH, FREQUENCY, ENERGY RELATIONSHIPS}

\section{Vulue at $1 \mathrm{eV}$}

Neutron wavelength: $\lambda(\AA)=\frac{0.286}{\sqrt{\mathrm{E}(\mathrm{eV})}}$

$0.286 \AA$

Time-of-flight: $\quad t(\mu \mathrm{sec}, \mathrm{m})=25,3 \lambda(\AA)=72.4 \mathrm{~K}(\mathrm{e} \cdot \mathrm{V})$

$72.4 \mu \mathrm{sec}, \mathrm{m}$

Frequency: $"(\mathrm{~Hz})=\frac{\mathrm{E}(\mathrm{e} \mathrm{V})}{\mathrm{h}}$

$2.418\left(1 \times 10^{14} \mathrm{~Hz}=241.80 \mathrm{THz}\right.$

$$
\text { wisec }{ }^{1} 1=2 \pi \text {. }
$$

$151.95 \times 10^{1.3} \mathrm{sec}^{1}$

Neutron wave number: $n\left(A^{2}\right)=\frac{2 \pi}{\lambda(\AA)}$

$21.45 \AA^{\prime}$

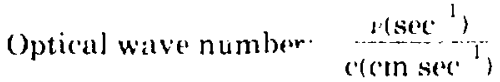

$8.01655 \times 10^{3} \mathrm{~cm}^{1}$

Temperature: W - $\frac{\text { huleV }}{\mathrm{k}_{\mathrm{k}}\left(\mathrm{erg} \mathrm{K}^{\mathrm{T}}\right)}$

1. $16\left(1015 \times 10^{4} \mathrm{~K}\right.$

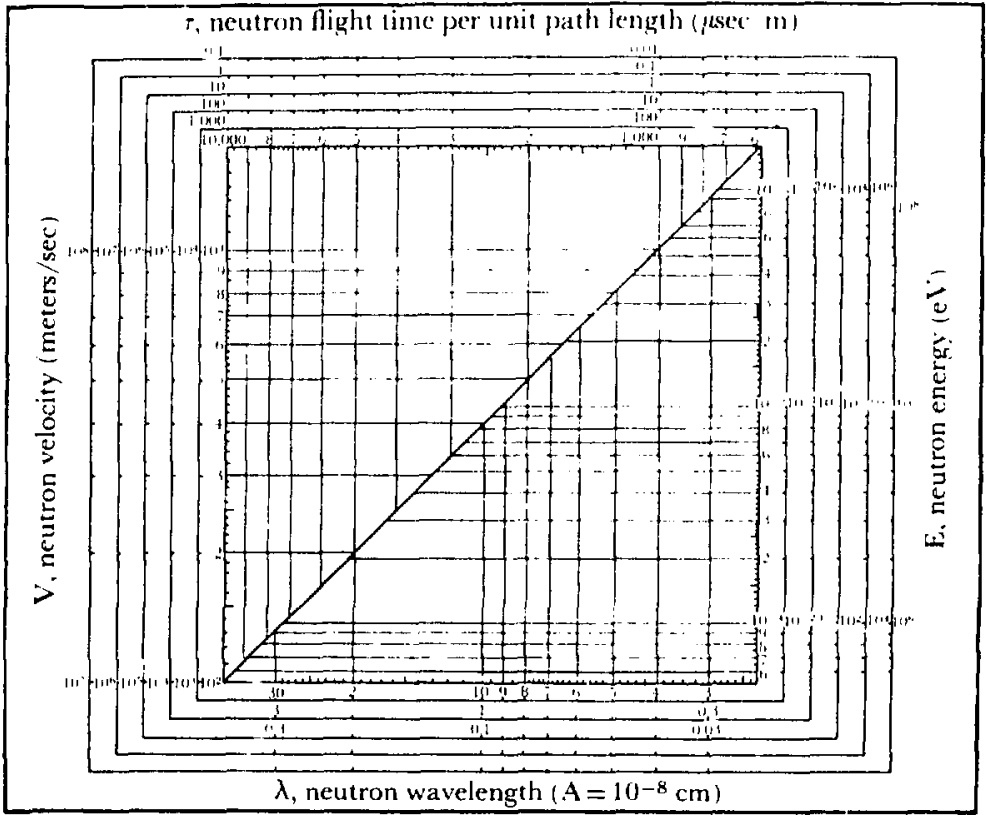

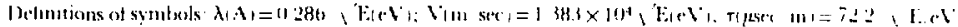

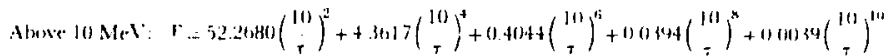

Graph relating neutron energy, wavelength, velocity, and time-of-flight. Courtesy McGraw-Hill. 


\section{RADIATION UNITS}

Unit of absorbed dose $=$ rad $-i(10$ ergs absorbed energy per gram of material.

Unit of dose equivalent $=$ rem $=($ ahsorbed dose $) \times($ quality factor $)$

\section{Type of Radiation}

Beta and Gamma Rays

Neutrons (0)-1 keV)

Neutrons (1 MeV)

\section{Quality Factor}

]

2

Exposure to a thermal neutron flux of 68() neutrons $/ \mathrm{cm}^{2}$-sec will result in a dose equivalent rate of 2.5 mrem hour, or 100 mrem per 40-hour week.

Sec the RNI. Safety Manual for further intormation and for radiation exposure guidelines. 


\begin{tabular}{|c|c|c|c|c|c|c|c|c|c|c|c|c|c|c|}
\hline & & & & & $\begin{array}{r}\text { Coherer } \\
\text { p }\end{array}$ & $\begin{array}{l}\text { tron Sicalte } \\
\text { pd by l.. Ko }\end{array}$ & $\begin{array}{l}\text { ring Amp } \\
\text { resiter and }\end{array}$ & $\begin{array}{l}\text { litudes in l' } \\
\text { W.B.Yelon }\end{array}$ & $\begin{array}{l}\text { in of } 10^{-12} \\
x=11\end{array}$ & & & & & \\
\hline Element & Isotope & b & Filement & Isstope" & " & filement & Isotope & b & Ellement & Isetope & b & Fiement & Isotope & b) \\
\hline $\mathrm{H}$ & 辛 & $\begin{array}{r}-0.374 .1 \\
0.667 .4\end{array}$ & K & ${ }_{3 i}^{\prime \prime \prime} K$ & $\begin{array}{l}41367 \\
1135 i 4\end{array}$ & $\therefore$ & sit & $\begin{array}{l}1799 \\
132\end{array}$ & $\therefore$ & & 1142 & $w$ & $n=w$ & 1) 47 \\
\hline $\mathrm{He} \cdot$ & $\mathrm{H}$ & & $c_{3}$ & & 1125 & & $\begin{array}{l}\text { sit } \\
\cdots+1\end{array}$ & $\begin{array}{l}1192.4 \\
119\end{array}$ & B:i & & 11.20 & & 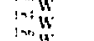 & 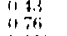 \\
\hline $\mathrm{Ne}^{\circ}$ & the & $\begin{array}{l}0.32 h \\
1104\end{array}$ & . & $\therefore 4$ & 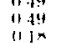 & $\mathrm{kit}$ & & 11534 & l.: & & $17 m=$ & & I & $1+119$ \\
\hline $\mathrm{L}_{1 .}$ & ${ }^{n} \mathrm{~A}$ & 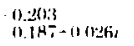 & $\Delta x$ & & $12:$ & kir & & aini & $\because$ & $\therefore$ & 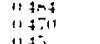 & $k_{*}$ & & $1+9.2$ \\
\hline & $i n$ & $42 \geq 21$ & $\mathrm{Ti}$ & & (1):3titin & $\mathrm{kt}$ & & $110 \mathrm{sin}$ & {$\left[x_{x}\right.$} & & $11+.$. & 1) & $i_{n \rightarrow n} n$ & 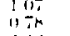 \\
\hline Bere & ${ }^{4} \mathrm{Br}$, & (1) $7-74$ & & $T_{1}$ & $\begin{array}{l}11.473 \\
\text { 11: } 34.45\end{array}$ & sir & 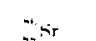 & 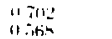 & $\therefore$ & & 1114 & & $\cdots\left(\begin{array}{c}1 \\
x_{1}\end{array}\right.$ & $\left.\right|_{1.4} ^{1.4}$ \\
\hline H & & 05.55 & & $\because{ }^{4} \mathrm{~T}$ & 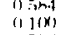 & & in & $11: 16 i$ & & $\therefore \mathrm{Nd}$ & 4 & $1 r$ & & 1 / Fi \\
\hline & $1: \mathrm{H}_{\mathrm{B}}$ & ${ }^{861-161}$ & & $\mathrm{~T}$ & 13.9 .93 & r & & 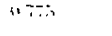 & & "Sd & $5 \div$ & Mn & & "4s) \\
\hline (" & & 06644 & $r$ & & $(0,0.3428$ & $\% r$ & & "iln & $\mathrm{Pm}$ & $I^{\prime} \mathrm{m}$ & $i 2 k$ & Au & & $" 76.5$ \\
\hline & $\because c$ & $\begin{array}{l}0,6: 3 \\
062\end{array}$ & ( $r$ & 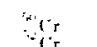 & 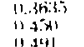 & Sh & & 1170.4 & $\dot{v i n}_{\mathrm{i}}$ & 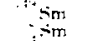 & $\left(\begin{array}{ll}0-15 \\
(16)\end{array}\right.$ & $\mathrm{H}_{k}$ & & 1 zhit. \\
\hline$n$ & ix & 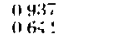 & Min & & 11.53 .3 & Ml. & & (1) & Fiu & $=\pi$ & " & $\mathrm{Ti}$ & & $11,-4$ \\
\hline 0 & sto & 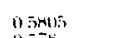 & $\mathrm{Fe}$ & & & ku & & 11721 & F.1. & $" \mathrm{Fu}$ & 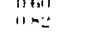 & $\mathrm{PH}$ & & $49,4+11$ \\
\hline & 140 & 40 & & $F$ & 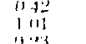 & $k h$ & & $\because \because$ & tirt & $\because \mathrm{lid}$ & 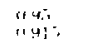 & $\therefore$ & & ne \\
\hline $\mathrm{F}$ & ${ }^{19} \mathrm{p}$ & 6565 & $\therefore$ & & 4 & Fid & & 1"in1 & $T$ & & 112 & $\mathrm{kn}$ & & \\
\hline $\mathrm{Ne}$ & "Ni & $11+5$ & $x_{1}$ & & (1) & Ak & $\therefore-$ & 11.347 & $1 n$ & mis & $l_{116} 6$ & $K: 1$ & & $1: 1$ \\
\hline $\mathrm{Na}$ & ${ }^{4} \mathrm{~N}$ & $0: 36: 3$ & & $N_{1}$ & 11.9 & & $A K^{\prime}$ & $n+1: 1$ & & $\because 11$ & 11,4 & A & & \\
\hline Mig & ${ }^{4} \mathrm{Mg}$ & $\begin{array}{l}\ln 5.3575 \\
0.5494\end{array}$ & & 等 & $11 \%$ & ed & $\therefore C_{d}$ & $\begin{array}{ll}113 \\
11\end{array}$ & & $=i \frac{1}{1}$ & 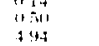 & Th & & $1):+1$ \\
\hline & 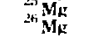 & $\begin{array}{l}0.362 \\
0.192 .2\end{array}$ & & (3) & 1...m & & 18 & 11 tiri & in: & & basto & $\mathrm{m}: \mathrm{a}$ & & $18: 91$ \\
\hline $\mathrm{Al}$ & & (1.:3449 & cu & 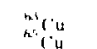 & 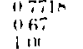 & In & 'In & 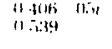 & $\mathrm{F}, \mathrm{r}$ & $\therefore F_{T}$ & nan: & r & $\because !$ & 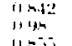 \\
\hline $\mathrm{si}$ & & 10.4449 & $\%$ & & (t) 5 titu & $\therefore n$ & & 116229 & & $r . r$ & & & & \\
\hline $\mathrm{P}$ & & 0.513 & $7 . \mathrm{n}$ & "ingn & $4: 2$ & & $\because-9 n$ & $11, \ldots$ & Trm & & "athe & $N_{i}$ & & ? 111 \\
\hline$s$ & & $0.2 k_{4}$ & & $\cdots 7 n$ & $\begin{array}{l}\text { inf fit } \\
\text { "ntill }\end{array}$ & & & & in & & $: 12$ & $l^{\prime \prime u ~}$ & $\therefore p^{10}$ & $11 \div$ \\
\hline $\mathrm{Cl}$ & 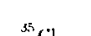 & 0.9579 & (ia & & 11724 & Sh & & 11 inthit & I.u & & $11^{-i}$ & & $\therefore \cdot p_{18}^{3}$ & 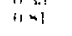 \\
\hline & 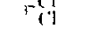 & 0.3010 & (ii. & & $(1 \times 19: 3$ & T. & & 11. in & $\mathrm{Ht}$ & & $11 \div$ & Ani & & 110.3 \\
\hline Ar & & $010 \times 4$ & As & & 11 hism & 1 & & 1.i.ion & $\mathrm{T}: \mathrm{i}$ & & it fitt: & $1 \mathrm{~m}$ & & 114.1 \\
\hline & *Ar $\mathrm{Ar}$ & $(1+2)$ & & & & $x_{i}$ & & 11 twa & & & & & & \\
\hline
\end{tabular}


E. Bragg Angles (20 $\left.\theta_{M}\right)$ for Commonly-l sed Monochromators

\begin{tabular}{|c|c|c|c|c|c|c|c|c|c|c|c|c|}
\hline & & & & & & & & & & & Zins & 'iagnetite \\
\hline & & despacing $(A)$ & $\begin{array}{l}3.26622 \\
1.92366 \%\end{array}$ & $\begin{array}{l}2.0(00018 \\
3.14131\end{array}$ & $\begin{array}{l}1.71576 \\
3.48351\end{array}$ & 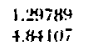 & $\begin{array}{l}3.35411, \\
B .87325\end{array}$ & $\begin{array}{l}1.677188 \\
37+6.11\end{array}$ & $\begin{array}{l}1.791601 \\
3.56702\end{array}$ & 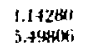 & 2.4675 & 4.8470 \\
\hline$E(m+1)$ & $k(A)$ & $\lambda / 1$ & $(i 11)$ & (220) & (311) & $(331)$ & (a) $(2)$ & $(0)(4)$ & (10):21 & 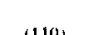 & (mons & 1.4 .609 \\
\hline $11 ;$ & (1) $\begin{array}{l}-- \\
4 !:\end{array}$ & $\ldots$ & & & & & (1) A & $(1+n+1)$ & $(1010=1$ & (1101 & $(1012)$ & (11i) \\
\hline 10 & Witi & 年 & 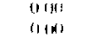 & $\begin{array}{l}y(x) \\
10(x)\end{array}$ & 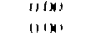 & 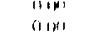 & 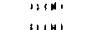 & 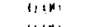 & nks: & 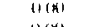 & (1) & $O(H)$ \\
\hline 13 & $\because 6518$ & $=38+4$ & $1,1 \times 1$ & 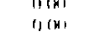 & 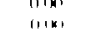 & (1) & 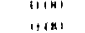 & 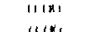 & $3(x)$ & $\theta(0)$ & $(0, k)$ & $1.1 \div .81$ \\
\hline 20 & 119825 & i, 3454 & $1 \%, 4:$ & was & irk. & (m) & it: & $n(x)$ & $\begin{array}{l}n \\
(1)+x) \\
(1)(x)\end{array}$ & 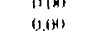 & (1) & 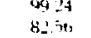 \\
\hline $2 i$ & 1 (N,184 & $532(1)$ & $12=24$ & bisk1 & $11 \times x$ & 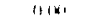 & $1 i=11 i$ & 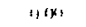 & пик & $(H(N)$ & $(100)$ & 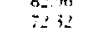 \\
\hline 311 & 1.2033 & 3214 & $10,1: 4$ & $0(0)$ & $\because 1 k$, & $611 \times 1$ & We: : & $n(n$, & 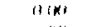 & (not) & 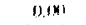 & 6519 \\
\hline $3 \%$ & $1.244 \pi$ & +844 & 15 & "16" & tik: & m*t & $\because 2$ & $\|\left(1+w_{i}\right.$ & 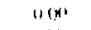 & $0(n)$ & $1964: 2$ & 54.83 \\
\hline 711 & 1.3844 & $4 \div 2$ & $H=0.2$ & $(1+n)$ & $0101 k^{\prime}$ & 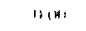 & $84--$ & $\because(n)$ & $u(x)$ & 00 & 1627 & $55 \mathrm{til}$ \\
\hline 43 & itis & $+2+s+3$ & $814^{4 \prime}$ & $11 \% \mathrm{k}$ & $11+n 1$ & "11m, & 304 & "1\%" & $018 \times 2$ & $a(x)$ & $711+i_{5}$ & 5218 \\
\hline$\because 0$ & $\operatorname{lin} 14$ & $40.4 \pi$ & $\ldots$ & ") & $n 1 x=$ & "11н1 & $-4:$ & 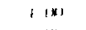 & 0101 & $11(k)$ & $1110\left(x^{n+1}\right.$ & 4012 \\
\hline$\because i$ & $16 \%+2$ & $\{9, \ldots\rangle$, & $\because \because$ & $1+\cdots$ & wex) & $11 ; x+$ & th is & $16 x$ & $(\| \mathrm{k})$ & $0(x)$ & $19 ! 274$ & 40,89 \\
\hline $61 !$ & $1 \times 13:$ & ib4:29 & of $\mathrm{kg}$ & 119 & $11+x+$ & $110 \times w_{1}$ & $m x^{-1}$ & $14 w$ & $010 \times 1$ & $n(k)$ & W & +78 \\
\hline 1,5 & 15.11 & sit: & $\therefore i$ & 1244 & 111K. & $13(1,4)$ & ה: & fokt & 16.3ㄴ.' & $11 \times 1$ & 4) $4 ?$ & 4:43 \\
\hline in & 83811 & $4+1 \%$ & $\therefore 11$ & $11^{-}+:$ & $(3 ;(n)$ & rirkt & $n=$ & $n(w)$ & it: & $(1, k)$ & $x=6$ & 11 सा \\
\hline$\therefore$ & 19025 & $\because " w_{t} n$ & 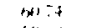 & $111=$ & sin. & $11 \%+1$ & $3 x^{4}$ th & 164 & it 3 i & (1) (rit) & $\mathrm{H} 4 \mathrm{OH}$ & $34 \mathrm{sH}$ \\
\hline 8.11 & $1.96+14$ & 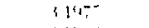 & $18 \ldots$ & $1+\cdots, 17$ & $1+1$ & 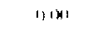 & wit & 1448 & $\therefore 20 \%$ & $(r(m)$ & (2) $\div$ & $30: 2$ \\
\hline s: & 20234 & \&10:2: & in, & 11117 & $1+184$ & inen & $\therefore(p)$ & 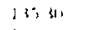 & 11044 & (r) (K) & $\therefore$ & 8.33 \\
\hline 90 & $088+1$ & S4II 48 & ;4 & $1,-4+1$ & 22414 & iH & $i i t i$ & $3-38+1$ & $114:$ & (1) (મ) & $\because$ is & it 24 \\
\hline $9 ;$ & $21+1=$ & $2+34+4$ & $\therefore$ it & 1,14 & $11 \mathrm{ket}$ & $w \omega$ & 78 & $1 \geq 2\left(x_{1}\right)$ & 11994, & $(1)(k)$ & 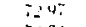 & 35.7 \\
\hline 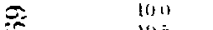 & $219 \%$ & $\therefore 8+x+11$ & $\therefore 104$ & : & ii 114 & $118 x+$ & int $4^{-}$ & $\cdots n$ & \$15 4? & " (n) & io 84 & $4 \div$ \\
\hline 105 & 2.511 & 27012 & iil $\cdots$ & $46 t^{\prime \prime \prime}$ & $i^{1} \mid x+3$; & 10x' & $+4 \mathrm{i}^{-}$ & 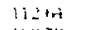 & $\because 234$ & $\theta(w)$ & 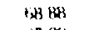 & 334 \\
\hline 110 & $23(4)\}$ & 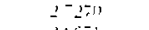 & 545 & 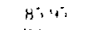 & 11.14 & mox & $4 \div$ & $1116-4$ & 1:41: & $n(x)$ & $\sin \left(k_{1}\right)$ & $32 .+k^{3}$ \\
\hline $11 ;$ & 23538 & $\therefore, 6=1$ & स1" & sin & $11 . \ldots$ & inixi & fin & firi: if & $(4+6,3)$ & $u(x)$ & tist? & 314 \\
\hline 12.0 & $24 t ;$ & 20160 & $4 \div 1:$ & $81:$ & $m 8$ & "nw & $\therefore$. & :11:4 & $4 i \because$ & $\theta(x)$ & bitisy & 3127 \\
\hline 123 & $2,4.561$ & 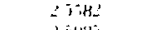 & $\sin : 1$ & $-\because i i$ & $\because-1+$ & $i n+i^{-}$ & 44 & $\cdots+$ & 4511 & (in) & bi: $2+4$ & 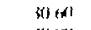 \\
\hline 130 & $2.50+8$ & $\therefore 3180^{\circ}$ & file. & $\because \cdots$ & 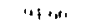 & 1 int & $\because 4$ & 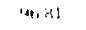 & $\mathrm{HS} \mathrm{KA}$ & $\cdots+x_{1}$ & 61111 & $24(\mathrm{~m})$ \\
\hline 131 & 2.532 & 2 thin & $7+=$ & $\because 14$ & $\because$ & $1+\ldots$ & f... & $1+413$ & $B t,>H$ & $n(1)$ & 39.84 & $\underline{x}+2$ \\
\hline $1+0)$ & 234943 & $2+1: 2$ & $4+4$ & $-z_{1}$ & 'n! & $13:$ & 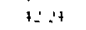 & “世 & 8481 & $b(x)$ & $5 H_{6,11}$ & 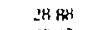 \\
\hline $1+j$ & $2+4 ; 3$ & $1 \%$ & $4 \div 2 \times 4$ & $\because \therefore s$. & 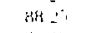 & $\because 21:$ & $41:$ & mi & Bins & $b(x)$ & 35 & 285 \\
\hline 150 & $25^{4} \alpha+4$ & 2156 & it 314 & $1+4$ & siti & 1.8 & $+11+4$ & Ho $2=7$ & 41 is & wix) & $i n+k$ & $27 \mathrm{kH}$ \\
\hline 15.3 & 2730 & $\therefore 973$ & fl it: & - & 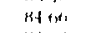 & int il & Hait & Bit. H. & $\because 7$ & Inor & $5+4$ & $\therefore+2$ \\
\hline It 0 & 27888 & $\therefore+n !$ & H1 301 & , w s K.: & Btins & $1211^{\circ}$ & $\therefore \mu$ & $6.4:^{-}$ & 782 & $m=1$ & 35.4 & $-26,48$ \\
\hline 16.5 & $28: 14$ & 221606 & $348 t$ & 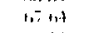 & 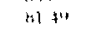 & $1 i n i$ & $\mathrm{in}^{\mathrm{2}-}$ & मi:" & 7684 & 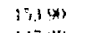 & 336 & 36.5 \\
\hline 170 & $2.86+3$ & 21436 & $39=1$ & tot il & bi, is: & $11 \ldots$ & is: :- & $m, n$ & $\because 5.11$ & 14: 34 & 1278 & 2016 \\
\hline 17.3 & $2(\sin 6) 1$ & $\therefore(1, g)$ & $48 n:$ & $\ldots$ & 促, & 11286 & $\therefore$ & Bit :- & $-4: 2$ & $1+218$ & $31 \%$ & 257 \\
\hline 180 & 29474 & 21118 & in $(n)$ & $0,4+11$ & $\cdots 6$ & $11114:$ & 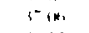 & - sin: & 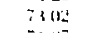 & 1182 & i1 18 & $25+1$ \\
\hline 18.5 & 298401 & 2008 & 绎 & $0,34:$ & $-t, 117$ & $1.4-1$ & in if & $\therefore i$ & $\because k$ & $1.3 \mathrm{Bt}$ & $50+4$ & 500 \\
\hline 19.0 & 30281 & 21774 & 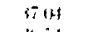 & bist" & $\therefore 1 \%$ & lim, it & $t i t_{2}+\mathrm{H}$ & $-n+1$ & $\therefore 7$ & $1+11+1$ & $19 \div 3$ & $2+72$ \\
\hline 19.5 & $36 k i 7$ & 2.6482 & 36,5 & (b) $\div$ & $-3-4$ & $19+4.4$ & $\therefore \therefore$ & $\because \because$ & nis $: 2$ & 1273 & $190 \mathrm{OH}$ & 24.34 \\
\hline 20.0 & 3.1068 & $202 \%$ & 36,15 & (1) 74 & $\because-1$ & ing: $\mathrm{kn}$ & Sin & $\because i$ & $\cos 2$ & $2: 471$ & 48.38 & $2+C B$ \\
\hline 20.5 & 3.1454 & $1(x)=$ & 561 & .1301 & $71+28$ & lowions & $4 \cdots$ & -116 & $6=$ & 12185 & 475 & 2378 \\
\hline 210 & 383.35 & 21,73 & 515 & $34: 2$ & $70+n^{4}$ & 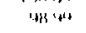 & $3+\therefore$ & - I (w) & tot.8? & 1113 & $471 \%$ & $234^{2}$ \\
\hline 21.5 & 3.2212 & $1450 \%$ & 47 & 88.57 & $108 \div 5$ & $4+1 !$ & $\therefore \mathrm{HI}$ & $\because 12$ & 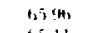 & 11717 & Hit its & 2322 \\
\hline 22.0 & 3.2884 & 19283 & 44 & 3int & $\cos 8 \cdot 4$ & wisi & in+i & $-61 H$ & bis1! & $115,4=$ & $40(8)$ & 229 \\
\hline 225 & 3.2953 & 190017 & 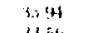 & 391 & with & 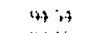 & 111 & $n+4$ & $(n+3)$ & lukn: & $4 \therefore$ & 2364 \\
\hline 230 & 33317 & 18459 & 3150 & $x^{\prime}$. & Bit2 & 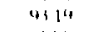 & 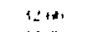 & OHA & bis & 111 n) & +443 & $23+4$ \\
\hline 31.5 & 3.3677 & 1867 & 3210 & $\therefore 64$ & (the, 31 & पा & $z$ & $n=$ & 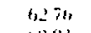 & $\lim 43$ & 44.43 & 22.19 \\
\hline 240 & .1 .4133 & 1840,2 & 3285 & 5467 & 6i;is & $m_{B_{1}}$ & 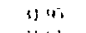 & thit it & 6203 & 107 i5 & 93.4 & $21 x_{3}$ \\
\hline 249 & $3+386$ & 18273 & $324^{* 4}$ & $3+46$ & is & $84+4$ & 3161 & $(x), 1 \geq=$ & 61.32 & $1\left(H, 1^{t h}\right.$ & 4.1.4 & 211 \\
\hline
\end{tabular}


E. Bragg Angles (20, for (ommonly-l sed Mo.achromators (continued)

\begin{tabular}{|c|c|c|c|c|c|c|c|c|c|c|c|c|}
\hline \multirow[b]{3}{*}{ E. (mol) } & & \multirow[b]{2}{*}{ 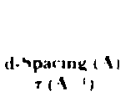 } & \multicolumn{4}{|c|}{ (rermantum } & \multicolumn{2}{|c|}{ C,raphure } & \multicolumn{2}{|c|}{ Herilluum } & \multirow{2}{*}{$\begin{array}{c}\cdots i \\
2,4675 \\
2,5+4 ; 32\end{array}$} & \multirow{2}{*}{$\begin{array}{c}\text { Sagnntile } \\
+.4470 \\
1.29633\end{array}$} \\
\hline & & & $\begin{array}{l}3.212,27 \\
1.423 t w 1\end{array}$ & $\begin{array}{l}2 .(K E) 13 \\
31+1\} 1)\end{array}$ & 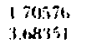 & $\begin{array}{l}\text { 1.24784 } \\
+.4310 \%\end{array}$ & $\begin{array}{l}3.3741, \\
1.6722\end{array}$ & 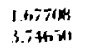 & $\begin{array}{l}1.741001 \\
3.217012\end{array}$ & 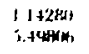 & & \\
\hline & hes') & $\lambda(1)$ & आ111! & $2220\}$ & $(311)$ & $(3 n)$ & $\left(k K_{2}\right)$, & $(x \times+1)$ & $(m) 2)$ & $(1110)$ & $\left(\mathrm{H} r_{2}\right)$ & (111) \\
\hline$\therefore 1$ & s:si, & $1 \mathrm{kes} \mathrm{ss}_{\mathrm{S}}$ & $\leq 17$ & i: & $1,+4.14$ & H & $3 i=$ & $\therefore i=$ & . 110.4 & $1.4,14$ & $+11 \times 1$ & 2111 \\
\hline $\begin{array}{l}\therefore ; \\
\therefore 11\end{array}$ & 1 itsk! & $1^{-6}+211$ & :18: & $\because \because 1$ & 14 & $x_{1}=3.1$ & $11+\cdots$ & $1, \therefore$ & 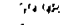 & W1 & tL is & 21 \\
\hline $\begin{array}{l}-40,0 \\
4: 5\end{array}$ & $\therefore$ & $1:-m$ & $\| 1$ & $\therefore \cdots$ & 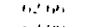 & 81. 21 & $31 \times x_{1}$ & 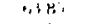 & 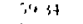 & $117 \times$ & t211 & 21 is \\
\hline $\begin{array}{l}\because 45 \\
\therefore \because 1\end{array}$ & irat:- & $1-m^{2}$ & is & $\therefore 11$ & 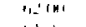 & $4=2+1$ & "1 & 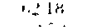 & nis $\div 2$ & 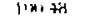 & $+1-1$ & $20 \mathrm{~kg}$ \\
\hline 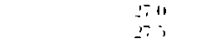 & $i(x)+4$ & 1. 14. & $\left\{1+\omega_{i}\right.$ & $\therefore$ is & ..1 & 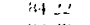 & $41+4$ & $\therefore$ & it 1 & $12 x+2 y 1$ & S1 भi & 2606 \\
\hline $\begin{array}{l}2 \because 3 \\
3 x+11\end{array}$ & $3 e+411$ & $1 \because 4$ & $(n+1):$ & $\because 118$ & 政 & $k: 2 k$ & $\because$ 蜲 & 1,184 & $\therefore 4$ & 4 & 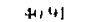 & 位 \\
\hline $\begin{array}{l}3401 \\
311\end{array}$ & $(1+\cdots, x)$ & $1-m_{i}:$ & 414 & $\therefore$ & , & $16:-9$ & 43 & $, 1,5^{-}$ & in, in & an, & 111 ; & (1) 31 \\
\hline $\begin{array}{ll}31 ; \\
\because 411\end{array}$ & i:n8" & $16+4:$ & $411 \%$ & 1831 & 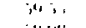 & $61 \%$ & $=4$ & $f(x) d x^{4}$ & $\cdots$ & 4itis: & $H+16$ & (2) 13 \\
\hline 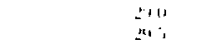 & $i \neq 11$ & lan: & $-2+581$ & Inti: & in $4 k$ & Bsis?: & 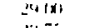 & "w" & $\therefore * 1$ & it is & 1474 & 1443 \\
\hline 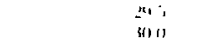 & $3 \div 3:$ & $1+1+1=$ & $\because ;$ & $\cdots=$ & 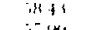 & 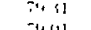 & $2 \pi$ & is is & $\because \cdots$ & "wi & $14 H$ & $1+76$ \\
\hline $\begin{array}{l}31101 \\
\text { tor: }\end{array}$ & ( & $1+316$ & $\because n$ & thin & $i(n)$ & ?11011 & 年 & 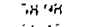 & $\because 4 \mathrm{HH}$ & $\because \because \div$ & 31,111 & 1462 \\
\hline wi i & $B H A+x_{1}$ & $161=$ & $E+1+1$ & tis $1:$ & $\therefore$ 淀 & 满: & $\therefore x$ & int: & if 34 & 4 & 14 in & $j^{n+5}$ \\
\hline "1" & 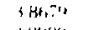 & 10,244 & 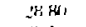 & $4 \cdots$ & is $8:$ & $\therefore+4$ & $\therefore 13$ & $\because 4$ & 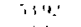 & 160,14 & 的H & $1+\frac{k 4}{4}$ \\
\hline si i & $\{k+*+1$ & 10114 & $24 \mathrm{in}_{1}$ & 101 & 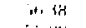 & $\because 2$ & $\therefore \ldots$ & $\because i$ & $\therefore 4$ & $8+\ldots$ & 312 & 1411 \\
\hline$\because 11$ & $\{9248$ & 1 ) पमसल & य & 1 & $\because n$ & $\because n$ & $\therefore$ & if 14 & $\therefore 1 \times 1$ & 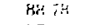 & 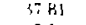 & $19 \%$ \\
\hline$\because \because$ & $\sin (x) 4$ & $1 \mathrm{izsti}$ & 细11 & $11,-4$ & $\therefore t s$ & 48 & $\therefore 3 t_{t}$ & $\because+\cdots$ & $\because 2$ in. & $n=$ & $\therefore 31$ & 1884 \\
\hline «14 & $\{\{n \mid n\}$ & $1: 74$ & $\therefore 84$ & trs is & $i 1^{-}$ & $-1+43$ & $\therefore-1$ & $\therefore k$ & $\therefore 1$ & s. 124 & 521 & 146,14 \\
\hline $16 \vdots$ & $4012 \ln x$ & $1,5,24$ & $\therefore \sin$ & in. & it is & 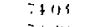 & $\therefore 44$ & $\therefore:$ & 111 & $B *, 2=$ & tris: & $14:$ \\
\hline $\begin{array}{l}411 \\
45=\end{array}$ & $4051 \mathrm{MM}$ & 1 & $\therefore 1$ & tal & 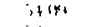 & $\because 3$ & $\therefore \div$ & $\because n$ & $\therefore \|$ & sit; & $i t, i t$ & $18+1$ \\
\hline $\begin{array}{l}345 \\
370\end{array}$ & 4 I BKIH & $1 ; i+4+1$ & $\therefore \square$ & fis & $i s, n$, & $\because \because$ & $\therefore$ if & $i t \mathrm{es}$ & 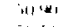 & $x-1$ & in ith & 1488 \\
\hline $\begin{array}{l}501 \\
35 \div\end{array}$ & $+1(x+x)$ & 1 1 2488 & $\therefore 11$ & $+4,4^{2.4}$ & $\therefore \therefore$ & $\because 21 ;$ & $\because n$ & 42 & $\because 1 \% ;$ & Ms: & $\{t, i r$ & $18: 1$ \\
\hline $35 \%$ & +1.3642 & 1ंगम & 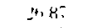 & $f(x)$ & 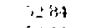 & I & $\therefore 31$ & $\because \mathrm{H}$ & 'A1!? & $H_{2}=1$ & $\{i k\}$ & 1H: 132 \\
\hline $3+0$ & + lixk: & 1 intat & $s_{1}+w_{3}$ & $+4: 2$ & $\because \because+4$ & $-\mid(x)$ & $\therefore$ & $\therefore 4 !$ & 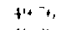 & $8=.1$ & $\therefore \because$ & 1784 \\
\hline $3 k \div$ & +1473 & $14 \%$ & $2+5$ in & $41 \%$ & $\therefore=1 \%$ & $211+4$ & $\therefore \cdots$ & :"1"!' & 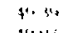 & $n s t$ & $\therefore 3$ & $1 \%$ \\
\hline 30 & 4251 & $14 \pi t^{4}$ & It is & thent & 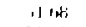 & $1,1+84$ & $\therefore(b)$ & $\therefore \cdots$ & $f+11 ;$ & $d+1 i$ & $\sin$ & $1: n i$ \\
\hline 37 & $45+2$ & 14 iin & $I, 1 i$ & +14 & is $\$ 1$ & int it & $\therefore+4$ & $\therefore$ & i...t. & $801 \div 1$ & $4 x$. & $1: i 3$ \\
\hline 180 & 4. 284 & $1+1+2$ & $\therefore(4$, & +30 & $m c_{2}$ & 1.15 84.4 & $\therefore \therefore$ & is $\mathrm{H}_{\mathrm{H}}$ & $16: 4$ & -1.45 & $4+i 6$ & $i ;+1$ \\
\hline 395 & 4.31115 & $116 \mathrm{x}$ & -1.67 & $4 \leq 74$ & mins & $+x: 4$ & $\therefore 16$ & $\therefore \%$ & $4 x+1$ & $\because \therefore$ & 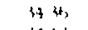 & $1 ; \psi_{1}$ \\
\hline 190 & $+6: 384$ & $1+48.3$ & $27 t, 2$ & $1 \leq 1$ & $n \leq 4$ & $\therefore 81$ & $-7+4$ & 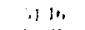 & F十"W & $-x+1$ & 413 & $\therefore H$ \\
\hline $34:$ & +3661 & $1+341$ & $\therefore$ ti & 4,17 & $H+(x)$ & $\therefore 14$ & $\therefore \%$ & 2181 & 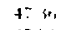 & $28 f^{\circ}$ & $31 \% 1$ & 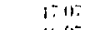 \\
\hline+160 & $+i^{1} 137$ & $1+4 ! n$ & $\therefore \alpha_{1}$ & $41 \mathrm{s"}$ & $1 \cdots$ & ox, in. & 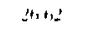 & $314^{-}$ & $4 \div 4$ & $\because+6$ & $33 \%$ & $1+4+4$ \\
\hline$\$ 05$ & $1+21$ & 14t: & 21 & $+1+2$ & $3+4$ & 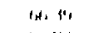 & $24 H_{1}$ & \#ił & th -4 & 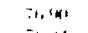 & $44+7$ & $\ln (4)$ \\
\hline+111 & $+4+8: 3$ & $1+1 \ldots$ & -14 & $\$ 18$ & 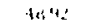 & $1, \ldots+14$ & $24: 1$ & +481 & $4+4$ & $\therefore 4$ & is $p$ & $1+n$ in \\
\hline$+1 i$ & $: 47=$ & 1 fIATi & $2+832$ & fl & $48+(d)$ & $\therefore 4$ & $\therefore 16$ & $4^{2}+7^{4}$ & $4 k_{1}: i$ & $\because \because 4 s$ & $13(\mathbf{k})$ & $\ln 66^{2}$ \\
\hline+20 & $+502=2$ & if $140 \mathrm{ins}$ & $24=$ & *11 $k+4$ & $4 H=M$ & linth. & 4011 & $+4:=$ & tikt & $\therefore 2-$ & 128 & in is \\
\hline+23 & $4.5288^{4}$ & 1,3874 & $34 \div 2$ & $41 ; ; 8$ & isint & $1,4 t+2$ & $\therefore 35$ & $48 \mathrm{H}$ & 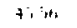 & $-4 \therefore$ & $E=(\dot{s})$ & $b_{1}+$. \\
\hline+30 & 45515 & 1354 & 43 & I11 44 & 1714 & $\tan \mathrm{in}^{2}$ & $\therefore 3$ & $3 H$ ' $x$ & $A L H$ & -424 & $1:+6$ & $15, \mathrm{H}_{\mathrm{H}}$ \\
\hline $4.3 \div$ & 45,814 & $15: 11$ & 2421 & $f(1, \mathrm{ks}$ & 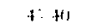 & $1,4 \%$ & 2134 & 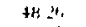 & $f i(x)$ & $-1 i t$ & 45 & in 2 \\
\hline+10 & $4+x) 81$ & 1 itsi & 24111 & 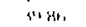 & $i=i$ & 1,18 & $\therefore 4$ & 8. & $44:$ & 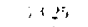 & 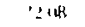 & 10,17 \\
\hline+45 & $+6,4+2$ & $13,5,4$ & $\therefore 4$ & {$[+1+1$,} & H, & 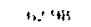 & $\therefore 1$. & 千 & $+14:$ & $\because \therefore$ & is 84 & $1 \cdot(x)$ \\
\hline $4+6$ & $f \operatorname{ten}(x):$ & $164:$ & $\therefore \%$ & 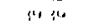 & th it & fi.' in & 2114 & 3it & $74: 1$ & $\therefore 4$ & 11 & $1 ; \omega_{t}$ \\
\hline $4 i$ & toweteri & 1 it & $\left\{x+n^{\prime}\right.$ & wis & It, $z^{\prime \prime}$ & $\therefore 2$ & $\therefore 3 H_{1}$ & +11 & $4+4$ & $\therefore \mathrm{HH}$ & 434 & $1 ;(x)$ \\
\hline$\#, 11$ & +1117 & 1 \& & $\therefore$ it. & 34 & $4,4:$ & (1.) $4:$ & $\therefore 4$ & sh 13 & 41\% & $\because 14$ & it 35 & $1 ; 81$ \\
\hline 40 & 4752 & $18 \vdots n$ & $23+1$ & 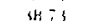 & $\therefore i t$ & , 1 t & $\therefore \mathrm{ki}$ & 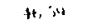 & 714 & $\therefore 1147$ & 1118 & $19 \div 8$ \\
\hline+71 & $+7+26$ & istos & $\therefore 4$ & 14. & if & 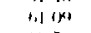 & $\therefore+4$ & $H+1:$ & +126 & 213 & 11011 & 1 tit of \\
\hline $4 ;$ & $+K^{2}$ & 1112 & $\because 1 \%$ & (4) सा & $4 \because$ & (2) it & $\because z_{i t}$ & to & $\begin{array}{l}+24 \\
\end{array}$ & Fot & $4+\mathrm{HA}$ & $19 \mathrm{n}$ \\
\hline+60 & +813 & $1 \mathrm{~min}$ & 2irk, & in & $45(x)$ & $(x) 14$ & $\therefore+4$ & Iम & $4: 3$ & $n+4+4$. & $\left\{11+x^{4}\right.$ & 1ith \\
\hline$+8 i$ & $+83(4)$ & $1=443^{\circ}$ & $\because \cdots$ & 抎州, & $4+17$ & 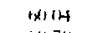 & $\because 214$ & $1 . \cdots$ & $\because \therefore$ & $\therefore \therefore$ & 31,1 & $\therefore+1$ \\
\hline+4.01 & 4 then:24, & (11!'! & $\because \mu_{i}$ & $\therefore n$ & thit & 政 & 2211 & $4 i s i$ & $422^{-}$ & indi & (11) $\alpha_{4}$ & $\therefore:$ \\
\hline
\end{tabular}




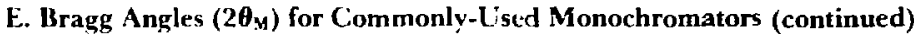

\begin{tabular}{|c|c|c|c|c|c|c|c|c|c|c|c|c|}
\hline & & \multirow[b]{2}{*}{$\begin{array}{c}\text { d. }>\text { paring }(A) \\
\text { T(A })\end{array}$} & \multicolumn{4}{|c|}{ Germanium } & \multicolumn{2}{|c|}{ Graphite } & \multicolumn{2}{|c|}{ thervillium } & \multirow{2}{*}{ 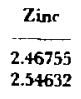 } & \multirow{2}{*}{$\begin{array}{c}\text { Magnerite } \\
4.8470 \\
1.2963\end{array}$} \\
\hline & & & $\begin{array}{l}3.266127 \\
1.92366\end{array}$ & $\begin{array}{l}2.0(10) 14 \\
3.1+131\end{array}$ & $\begin{array}{l}1.70576 \\
3.683 .51\end{array}$ & $\begin{array}{l}1.29789 \\
+.8+167\end{array}$ & $\begin{array}{l}3.354 i \mathrm{i} \\
1.8 \overline{3} 325\end{array}$ & $\begin{array}{l}1.67706 \\
3.74650\end{array}$ & $\begin{array}{l}1.79160 \\
3.50702\end{array}$ & $\begin{array}{l}1.14280 \\
\mathbf{5 . 4 9 6 0 6}\end{array}$ & & \\
\hline$E(m e V)$ & $\mathbf{k}(\mathbf{A})$ & $\lambda(A)$ & (111) & (220) & (311) & (336) & (002) & $(\mathbf{0 n + 4 )}$ & (002) & (110) & (002) & (111) \\
\hline 5010 & +9124 & $2 z^{2}+1$ & $2 z$; & 1724 & +414 & 5914 & 2198 & 4983 & 41.83 & 68.06 & 30.04 & 15.16 \\
\hline$\therefore, 1$ & $+(m, 1:$ & $1264 i$ & $\therefore 46$ & 3041 & 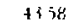 & 站 4 & 2170 & +437 & 4140 & 6730 & 27.4 & 15.01 \\
\hline 321 & 30000, & $1 \geq 2,2 \div$ & $\geq 214$ & in it & +334 & $37 \div 9$ & 215 & 4392 & 4098 & 66.56 & 29.45 & 14.87 \\
\hline 30 & $305: 7$ & $124 \geq 1$ & 2143 & $3 t: " \omega$ & 4271 & 5719 & 2135 & $7+18$ & 40.57 & 65.85 & 29.16 & 14.73 \\
\hline $3+4)$ & $? 1050$ & $12: 3103$ & 212 & 3584 & $4 \geq 30$ & 5.61 & 2114 & +305 & +018 & 65.16 & 28.88 & 14.59 \\
\hline 550 & 315213 & $1219 \mathrm{~h}$ & $215 !$ & 35.50 & 4189 & 5 ta.1) & 2045 & $+26 \mathrm{tH}$ & 39.80 & 64.50 & 28.61 & 14.45 \\
\hline 3601 & 3987 & $1208 t$ & $\therefore 11$ & 1517 & $41 \div 0$ & 55 so & 2076 & 1224 & 39.42 & 63.85 & 28.35 & $1+.32$ \\
\hline 370 & $2+44$ & 119811 & 2113 & $3+87$ & $\$ 112$ & 2,478 & 2057 & +185 & 3906 & 63.22 & 28.10 & 14.20 \\
\hline 580 & $\therefore 2967$ & 1 18it, & 20) 45 & 34 it & 40 is & $i+45$ & 2030 & +147 & 38.7 & 62.61 & 27.85 & 14.07 \\
\hline $3 * 0$ & 23361 & 11723 & 207 & 1424 & (i) 38 & 5145 & 20.22 & $\$ 110$ & 3837 & 62.02 & 27.61 & 13.95 \\
\hline 600 & ; 3811 & $1+67 \hbar$ & $20 \div 9$ & $133^{24.4}$ & +003 & 3.140 & 20.05 & 4077 & 38.04 & 61.44 & 27.37 & 13.84 \\
\hline 61.0 & $i+258$ & 115841 & 2014: & $34 \mathrm{ni}^{3}$ & 396,9 & $=2(x)$ & 1988 & 40.39 & 3771 & 60.88 & 27.14 & 13.72 \\
\hline 020 & 34701 & $11+89 r$ & $20 ? ! 3$ & 333 & 893 & 3253 & $19: 2$ & 40.05 & 3739 & 60.34 & 20.92 & $13.6 !$ \\
\hline 630 & $531+0$ & 11345 & 21104 & 1310 & 3901 & 5208 & $14 \%$ & $84 \div 2$ & 3: 09 & 39 I & 26.70 & 13.50 \\
\hline 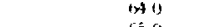 & $i 57 \mathrm{~h}$ & $1130 \mathrm{~h}$ & 1443 & 3283 & 8871 & 3164 & $14+1$ & 1040 & 36.78 & 39.29 & 26.40 & 13.39 \\
\hline 650 & ; 6009 & 11218 & 1478 & 3253 & 3840 & 31.21 & 14.5 & 89.08 & 3649 & 38.79 & 26.28 & 13.29 \\
\hline tho 0 & ; f $6+38$ & 15131 & 1462 & 1232 & 3804 & 51) 79 & 1411 & 3873 & 36.20 & 58.3 & 26.07 & $\begin{array}{r}13.19 \\
\end{array}$ \\
\hline 670 & i GAffrit & 11050 & $19+8$ & 3219 & 5780 & 3019 & $18 \%$ & 38.47 & 3592 & 57.82 & 25.88 & $\begin{array}{r}13.09 \\
\end{array}$ \\
\hline 680 & $i 728 \bar{\imath}$ & $10968 B$ & 1433 & $118: 3$ & $37 i$ & 1909 & 18.82 & 3817 & 3565 & 57.35 & 25.68 & $\begin{array}{l}12.99 \\
\end{array}$ \\
\hline 691 & 57706 & 10898 & $191 \%$ & 3154 & 3722 & $+9,(6)$ & 18.68 & 5788 & 35.38 & 56.90 & 25.49 & 12.90 \\
\hline 700 & 381.3 & $10811)$ & 1905 & 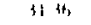 & 3645 & 4922 & 1855 & 360 & 3512 & $56.4 j$ & 25.31 & 12.81 \\
\hline 713 & $5,353 ?$ & 10734 & 1841 & $\because 11$ & $36,6+3$ & +8.85 & $18+1$ & $3: 33$ & 3486 & 56.02 & 25.12 & 1271 \\
\hline 720 & $5.84+7$ & 10654 & 1878 & 3091 & $36+1$ & $+8+9$ & $18 \times 9$ & 3700 & 34.61 & 55.60 & 24.95 & 12.63 \\
\hline 731 & 5.9553 & 10586 & $186 i$ & 31154 & 3615 & 1811 & 18.16 & 3679 & 3437 & 55.18 & 24.77 & 12.54 \\
\hline 740 & 39760 & 10514 & 1852 & 31) 48 & $35 \%)$ & +779 & 18.03 & 36.54 & $3+13$ & 34.78 & 24.60 & 12.45 \\
\hline 750 & 60163 & $10+4+4$ & $18+1$ & $\| 2 i$ & \{în & 474 & 1791 & $36.2 \mathrm{~d}$ & 3389 & 5438 & 2443 & 12.37 \\
\hline 750 & 80563 & 10375 & 18.28 & $300+4$ & $5 ; 1$ & 4712 & 1779 & 36.04 & 33.66 & 53.99 & 24.27 & 12.29 \\
\hline 770 & 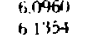 & $\begin{array}{l}10307 \\
103041\end{array}$ & 1816 & $298 b_{2}$ & 317 & t674 & 1768 & $\begin{array}{l}35.79 \\
35.75\end{array}$ & 3343 & 5.361 & 24.11 & 12.21 \\
\hline $\begin{array}{l}780 \\
790\end{array}$ & $\begin{array}{l}135+4 \\
617+6\end{array}$ & $\begin{array}{l}10211 \\
10176\end{array}$ & 1804 & $29+37$ & 4494 & to 4 - & $13 \mathrm{~h}$ & 3555 & 3321 & 53.24 & 23.95 & 12.13 \\
\hline $\begin{array}{l}79.0 \\
800\end{array}$ & 62136 & $\begin{array}{l}1017 \mathrm{~b} \\
10112\end{array}$ & $1 \div 92$ & $24+7$ & 347 & to $1 \mathrm{th}$ & 1745 & 35.32 & 3.300 & 52.67 & 23.80 & 1205 \\
\hline & i. 2523 & $\begin{array}{l}1012 \\
1019\end{array}$ & 1781 & -428 & $34+8$ & 4585 & 174 & 35.09 & 32.78 & 52.52 & 23.65 & 11.98 \\
\hline $\begin{array}{l}810 \\
82.0\end{array}$ & $6 \times 0 \times 8$ & $\begin{array}{r}10049 \\
\text { 'q4BB }\end{array}$ & 1770 & 2910 & $3+26$ & 4555 & 1723 & 34.87 & 32.58 & 52.17 & 23.50 & 11.90 \\
\hline $\begin{array}{l}8.0 \\
83.0\end{array}$ & $\begin{array}{l}0.3299 \\
6\end{array}$ & 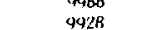 & 1759 & 2842 & 3405 & $5 \leqslant 0$ & 1713 & $\begin{array}{r}34.65 \\
33.13\end{array}$ & 32.37 & 31.82 & 23.35 & 11.83 \\
\hline $\begin{array}{l}83.0 \\
84.0\end{array}$ & 63670 & 9863 & 18 & $2 \mathrm{H}^{-14}$ & $13 \mathrm{BH}$ & 4497 & 1702 & 34.43 & 3217 & 5149 & 2321 & 11.76 \\
\hline $\begin{array}{l}84.0 \\
850\end{array}$ & 5.,4048 & $\begin{array}{l}98103 \\
4810\end{array}$ & 1738 & $28 \mathrm{st}$ & 3166 & 469 & 1692 & 34.22 & 31.97 & 51.16 & 23.07 & 11.69 \\
\hline $\begin{array}{l}850 \\
86.0\end{array}$ & $\begin{array}{l}\text {. } \\
6.44272\end{array}$ & $\begin{array}{l}4810 \\
475.1\end{array}$ & $1: 27$ & 2839 & $13+2$ & $44+1$ & 16.82 & $\begin{array}{r}34.01 \\
33.81\end{array}$ & 3178 & 30.84 & 22.93 & 11.62 \\
\hline $\begin{array}{l}88.0 \\
87.0\end{array}$ & $\begin{array}{l}0.4777 \\
6.4797\end{array}$ & 36937 & $\begin{array}{l}1717 \\
1707\end{array}$ & 2822 & 3122 & 5414 & 1672 & 3781 & 31.59 & 50.52 & 22.80 & 11.55 \\
\hline $\begin{array}{l}87.0 \\
88.0\end{array}$ & 6.5169 & $96+1$ & $\begin{array}{l}17(1) 7 \\
1097\end{array}$ & $28 / 1+1$ & 3103 & 4187 & 1662 & 33.04 & 3140 & 50.21 & 2266 & 11.48 \\
\hline $\begin{array}{l}88.0 \\
89.0\end{array}$ & 6.5538 & $\begin{array}{l}7 x+1 \\
4587\end{array}$ & 1697 & 2784 & 1283 & 4161 & 1633 & 33.41 & 31.22 & 49.90 & 22.53 & 11.42 \\
\hline $\begin{array}{l}89.0 \\
900\end{array}$ & 6.59 & 4534 & 1688 & 2731 & $32 \mathrm{bt}$ & 4353 & $16+3$ & $\begin{array}{r}33.22 \\
33.03\end{array}$ & 3104 & 49.60 & 2240 & 11.35 \\
\hline $\begin{array}{l}900 \\
91.0\end{array}$ & $\therefore$ u & 4481 & 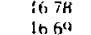 & 2737 & 3246 & 4310 & 164 & 3303 & 30.86 & 49.31 & 22.28 & 11.29 \\
\hline $\begin{array}{l}11.0 \\
92.0\end{array}$ & 0.6633 & 9429 & 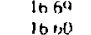 & $17+2$ & $122 i$ & 4285 & 1635 & $32 \mathrm{HA}$ & 30.69 & 49.02 & 22.15 & 11.23 \\
\hline $\begin{array}{l}92.0 \\
93.0\end{array}$ & 6.6995 & 9374 & $\begin{array}{l}\begin{array}{l}6,10,0 \\
16,51\end{array} \\
\end{array}$ & 2727 & $32(x)$ & 1260 & 1010 & $32 \mathrm{fth}$ & 30.52 & 48.73 & 22.03 & 11.16 \\
\hline $\begin{array}{l}93.0 \\
94.0\end{array}$ & $\begin{array}{l}6.7354 \\
6.7354\end{array}$ & 9329 & $\begin{array}{l}16.51 \\
1642\end{array}$ & 2712 & $319 t$ & 7236 & 1607 & $324 i$ & 3035 & 48.45 & 21.91 & 11.10 \\
\hline $\begin{array}{l}94.0 \\
95.0\end{array}$ & 6.7711 & 4279 & $\begin{array}{l}1642 \\
1623\end{array}$ & 26,47 & 1174 & $421 ?$ & $1 ; 44$ & $32.3 n$ & 3018 & 4818 & 21.79 & 11.04 \\
\hline $\begin{array}{c}95.0 \\
960\end{array}$ & 68067 & 9231 & $\begin{array}{l}1623 \\
16,23\end{array}$ & 2684 & 113 & 4189 & 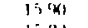 & 5212 & 3002 & 4791 & 21.68 & 10.99 \\
\hline 96.0 & 6.8067 & 4183 & $\begin{array}{l}16.25 \\
16.16\end{array}$ & $2 n, x+8$ & $31+11$ & $41+x_{2}$ & 1582 & 3195 & 2985 & 47.69 & 21.56 & 10.93 \\
\hline 97.0 & 6.8420 & 9183 & 1616 & 26,54 & 112 & $41+4$ & 157 & 3178 & 2970 & 4738 & 21.45 & 10.87 \\
\hline 98.0 & 6.8772 & 9136 & 1608 & $2 t,+4)$ & 3107 & 1123 & $15+\infty$ & 316,3 & 2954 & 4712 & 21.34 & 10.82 \\
\hline
\end{tabular}




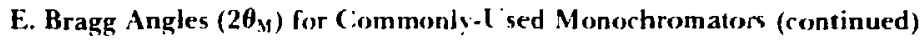

\begin{tabular}{|c|c|c|c|c|}
\hline & & d.spacing $(A)$ & $\begin{array}{l}3.2462727 \\
1.92366 ;\end{array}$ & $\begin{array}{l}3.16 n+18 \\
3.1+131\end{array}$ \\
\hline$E(m e V)$ & $\mathrm{k}\left(\boldsymbol{A} \boldsymbol{A}^{\prime}\right)$ & $\lambda(\mathrm{A})$ & (1111) & $\{2,21\})$ \\
\hline 1000 & $694 ; 0$ & 11.9444 & 15,12 & $2+11$ \\
\hline 10211 & $7016:$ & (1) 8495 & is & 28 \\
\hline 104.0 & 70244 & $11.80,4$ & $15+1$ & 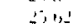 \\
\hline 106.0 & 7.1524 & (1).87, & Bis: & $\because 10$ \\
\hline 108.0 & 7.219 .5 & $0.87+14$ & 1531 & $\therefore, 1:$ \\
\hline 110.0 & 7.2861 & 08624 & $1 \div 1$ & $24|k|$ \\
\hline 1120 & 7.3520 & 0.854 & 1506 & $2+10^{-}$ \\
\hline 1140 & $=\$ 174$ & if 8471 & $i+41$, & $2+4$ \\
\hline 116.0 & $7.482 z$ & 0.8 .398 & $1+\div$ & $\therefore 14$ \\
\hline 118.0 & $7.5+64$ & (1) 8325 & $1+\ldots$ & 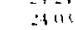 \\
\hline 1200 & 7.6101 & 1.82:3t & $1+3$ & $\because \mathrm{H}=$ \\
\hline 1220 & 767.32 & $\begin{array}{l}1103188 \\
118188\end{array}$ & $1+411$ & 260. \\
\hline 1240 & 7.7559 & 118122 & $1+234$ & $24+$ \\
\hline $12 \mathrm{~b} .0$ & 77980 & $11800^{\circ}$ & $1+17$ & $\therefore 124$ \\
\hline 128.0 & 78596 & $117 \% 94$ & $1+13$ & $2 \sin ^{2}$ \\
\hline $\begin{array}{l}1300 \\
1300\end{array}$ & $\begin{array}{l}78900 \\
7.900 \mathrm{H}\end{array}$ & (1) 7093 & $114 i$ & $\because 4$ \\
\hline 1320 & 7.9815 & 41872 & $168+$ & $\therefore 311$ \\
\hline 134.0 & yosi: & 07817 & 197 & $\therefore 54$ \\
\hline 1360 & 81015 & (1) itito & $130+$ & $\therefore 3$ \\
\hline 138.0 & 8. linkt & $11 ; x, 44_{4}$ & 13 is & $\because \cdots$ \\
\hline $1+00$ & 8.2198 & 11 intt & $11+4$ & $\therefore 0$ \\
\hline $1+2.0$ & 82783 & 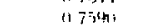 & 1334 & II 8 \\
\hline $1+4.0$ & $8.336+$ & 1756 & $19 \therefore$ & $21 \div$ \\
\hline $1+6.0$ & $8.39+1$ & $0 \div+85$ & 1110 & $\because 7$ \\
\hline 148.0 & 8.5514 & 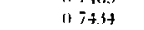 & $130^{\circ}$ & 214 \\
\hline 1500 & 8.5083 & 117385 & 1248 & 318 \\
\hline 152.01 & $8.56+9$ & $12-336$ & (i) un & 2116 \\
\hline 154.0 & 8.6210 & (1) 7288 & 281 & $\because\left(n_{1}\right.$ \\
\hline 156.09 & 8,7768 & $11 ; 2+1$ & 127 & (1) $8 \mathrm{rr}$ \\
\hline 158.10 & 87323 & $\left(1,719_{3}\right.$ & In & $30: 2$ \\
\hline 1600 & 7.7874 & 1770 & $12 \div$ & 24 \\
\hline 162.0 & 8.8421 & 07 7un & 12.4 & $30+t$ \\
\hline $16+0$ & 8.8965 & (1) $7(16$ : & $12+1$ & (1) 3 \\
\hline 106.0 & 8.9506 & (1) 7020 & 1237 & $20 \geq 1$ \\
\hline 168.0 & $900 \mathrm{nt}$ & 116788 & 1.2. 4 & $211 x_{1}$ \\
\hline 17100 & 0.0578 & 0169.37 & 1210 & 1007 \\
\hline 172.0 & 9.1100 & $41+6394$ & 212 & 19.85 \\
\hline 174.0 & 9.1637 & (1). $688^{7}$ & $\therefore 0$ & 97 \\
\hline 1760 & 9.2163 & 0.5818 & 1148 & 1402 \\
\hline 178.1 & 9.2685 & 1.6774 & 11 प1 & 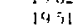 \\
\hline 1800 & 9.3204 & (1) 6741 & 1185 & {$[(s+4)$} \\
\hline 1820 & 9.3720 & 0.07124 & 1174 & 14311 \\
\hline 1840 & 94234 & 0 & 1172 & $14 ! 9$ \\
\hline 186. & $9+745$ & 0 & 1165 & 1408 \\
\hline 1898 & 4.525 .3 & 1) 6.596 & 1150 & 18.98 \\
\hline $1 * 0$ & 45758 & 0.6562 & 11.5 .5 & 1888 \\
\hline 1920 & 96261 & (1) 6522 & $114=$ & $18 \div 8$ \\
\hline 194.0 & 4.6761 & 1) $6+4+4$ & 1111 & 18 is \\
\hline 196.0 & $4.525 B$ & (1).trt(x) & 113 & 其 \\
\hline i 98.0 & $4,573,3$ & (i) $0+28$ & $\because 3$ & $18+4$ \\
\hline 2000 & 9.8246 & 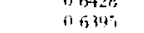 & 114 & $\ln t$ \\
\hline
\end{tabular}

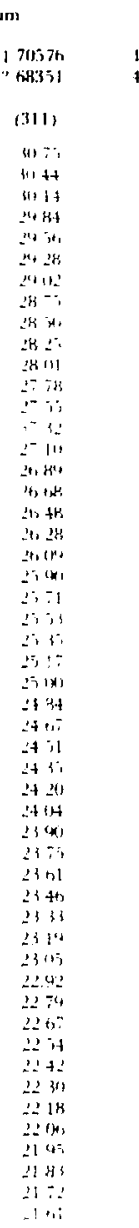

\begin{tabular}{|c|c|c|}
\hline \multirow[b]{2}{*}{ syras } & \multicolumn{2}{|c|}{ G, raphise } \\
\hline & $\begin{array}{l}835416 \\
1.8725\end{array}$ & 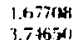 \\
\hline 13311 & $(\boldsymbol{N}) 2_{1}$ & (10H4) \\
\hline$H 1 . . \%$ & $\therefore \cdots$ & $\therefore=$ \\
\hline & $\ldots+$ & sin $10^{-}$ \\
\hline 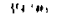 & $1: 14$ & $\{1, \cdots$, \\
\hline 14, & 1:11; & (11) ? \\
\hline$k+: H$ & $+4+1$ & H11ks \\
\hline 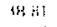 & $14^{-1}$ & $-2+48$ \\
\hline 34 & $1+i n$ & \\
\hline & $1+: 1$ & $n_{4}$ \\
\hline & 43 & יחיני \\
\hline $1-10$ & 110 & $\therefore$ \\
\hline$=x_{1}^{-1}+x_{1}$ & $1: 14$ & 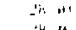 \\
\hline 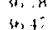 & $1+11-$ & $=4.4$ \\
\hline $\begin{array}{l}3,1 \\
1,1\end{array}$ & $6 a^{\prime \prime 1}$ & Hat \\
\hline$\because \mu^{-}$ & 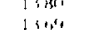 & $\therefore(\mu)$ \\
\hline$\therefore i 4$ & icin & $\therefore 3$ \\
\hline$\therefore: 1$ & $114 k$ & $\because 1$. \\
\hline ind & 1.19 & $2+1+4$ \\
\hline is & $13 \%$ & $2 n-1$ \\
\hline $4+i$ & $1 \mathrm{sin}$ & 24,1 \\
\hline $4+25$ & l sikt & $\therefore$ \\
\hline HA & $1: 40$ & $\therefore 11$ \\
\hline , & $121+1$ & $\therefore 4^{-}$ \\
\hline Bi: & $12 B 1$ & $\therefore \because$ \\
\hline $3 \leqslant$ & $12-1$ & $\therefore 1,1$ \\
\hline itr. & $1 \therefore \omega$ & $\therefore H$ \\
\hline 1294 & [2 it, & $\therefore$ \\
\hline$\because 2,1$ & 124 & $\therefore 11$ \\
\hline $2 z+1$ & $1 \leq \because 4$ & $24 \cdot 4$ \\
\hline $3 \leq 10$ & $\therefore 1$ & $\therefore 4$ \\
\hline (1) & 1224 & $24 \cdots$ \\
\hline 3: : : H & $12 n$ & $=4+$ \\
\hline is & $12 \mathrm{mr}$ & $24 ; 1$ \\
\hline i1 18 & {$[\leq 67$} & $2 \neq 1 \%$ \\
\hline i) 198 & $11 \cdot 4$ & -4101 \\
\hline (1 1 (x) & 1137 & $\therefore$ - \\
\hline 1) $\varepsilon$ & और & \\
\hline 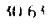 & $11: 3$ & 21,4 \\
\hline (1):": & $110^{-}$ & $\therefore \div$ \\
\hline 31 (1) 18 & $\| 16$ ind & $\therefore 3:$ \\
\hline 4) 16 & 11 it & $\therefore \mathrm{i}^{\prime \prime}$ \\
\hline 244 & 114 & 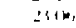 \\
\hline 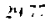 & 1111 & $2 \because+\mathrm{i}$ \\
\hline $24+6)$ & 113 & $\therefore A 1$ \\
\hline$x+4$ & 1124 & $22 \mathrm{n}^{4}$ \\
\hline 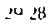 & 1123 & $\therefore$ \\
\hline$=9116$ & $111:$ & $\therefore+4$ \\
\hline 284 & $11: 1$ & $\because 3$ \\
\hline 48 & 1110 & $\because 2$ \\
\hline $28 n^{2}$ & $11|x|$ & $\because \because n$ \\
\hline
\end{tabular}

\begin{tabular}{|c|c|c|c|}
\hline \multicolumn{2}{|c|}{ inernllium } & \multirow{2}{*}{$\begin{array}{c}\text { Zint } \\
2.475 .5 \\
2.5+6.32\end{array}$} & \multirow{2}{*}{$\begin{array}{c}\text { Maknmin } \\
4.8470 \\
1.2963\end{array}$} \\
\hline $\begin{array}{l}.791601 \\
510702\end{array}$ & $\begin{array}{l}1.1+2849 \\
3 .+984(16)\end{array}$ & & \\
\hline (N) 2 , & (1111) & $(\mathbf{O N}(2)$ & (111) \\
\hline-4 & wh, & 2112 & III:I \\
\hline$\therefore$ & $4 n 14$ & 21:41 & $(i)+(x)$ \\
\hline 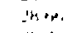 & 4,1, & (6) $\because 1$ & 1iin \\
\hline in & $\therefore:$ & $n \div 1$ & (11)+1 \\
\hline$\because 41:$ & Htif, & $2 n+31$ & 16311 \\
\hline$\therefore-n$ & $4+33$ & 2113 & 1021 \\
\hline$\therefore \cdots$ & $1: 4$ & 104.4 & (1) $1:$ \\
\hline$\because \vdots$ & +11 & $14 \div$ & (11) \\
\hline$\therefore 11$ & +111 & 1454 & 94.4 \\
\hline $2 x^{2}$ & $\{:-3$ & $1^{14}+45$ & 483 \\
\hline$\therefore \rightarrow, 4$ & 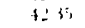 & 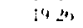 & 13 \\
\hline$\therefore 1:$ & 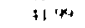 & $1 \% 10$ & $a b, 4$ \\
\hline$\therefore 211$ & $A i+3$ & $14+i$ & $+6,1$ \\
\hline$\because \cdots$ & $+1 \%$ & $18 x_{2}$ & 16 \\
\hline$\because \Rightarrow$ & Witi & lis ort & $6+4$ \\
\hline$\therefore \mathrm{H}$ & $+11+12$ & is: & 434 \\
\hline$\therefore 48$ & ti $n_{4}$ & is its & " : \\
\hline$\therefore \cdots$ & 34,645 & in $2:$ & 4 \\
\hline$\therefore N$ & $\langle i+t)^{-}$ & 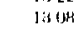 & $4+1 B$ \\
\hline$\therefore 4$ & (4) $\div$ & $1: 43$ & 411 \\
\hline $24 \ldots$ & सम & $1: 82$ & $40 \%$ \\
\hline$\therefore 4$ & 织 & $1 ; t^{4}$ & 4 \\
\hline$z+2 k$ & $3 i ;$ & $1: 3$ & $84:$ \\
\hline$\therefore+1$ & $6: 1$ & $i \geqslant 4$ & $48+2$ \\
\hline 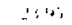 & 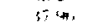 & 1) 39 & $B 86$ \\
\hline$\therefore \because \cdots$ & $1 ;$ & 13 & 874 \\
\hline$\therefore n$ & $\therefore H$ & i: 111 & $11+\$$ \\
\hline$\because 7^{\circ}$ & 311 & $1+\infty x_{4}$ & $u_{11}=$ \\
\hline 251 & in 44 & it $x y$ & $4 \div$ \\
\hline$\therefore \mathrm{i}^{\circ}$ & it $3 i$ & $1+\div$ & $4: 1$ \\
\hline$z i \mathrm{r}_{2}$ & $3 n+1$ & $\ln (x)$ & 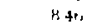 \\
\hline$\therefore$ & $4 n, 2:$ & 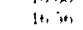 & $4 \$ 1$ \\
\hline$\because 2$ & itsint & $i n+\infty$ & 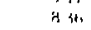 \\
\hline 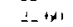 & 仿行 & It it th & \& 31 \\
\hline $2+4$ & $\vdots \vdots$ & $102 n$ & $82+1$ \\
\hline$\because 2: 1$ & $\therefore i 4$ & it, it, & 821 \\
\hline$\therefore 6$ & $\because \leqslant 12$ & mon & 80 \\
\hline$\therefore$, & 44 & $1 ; 4=$ & 811 \\
\hline$\therefore 4$ & is $: 1$ & 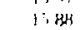 & $8: 1^{-}$ \\
\hline$\therefore 61$ & $4 ; 1$ & $11 \%$ & $4 i 12$ \\
\hline $21,3^{4}+$ & 3.4 it & 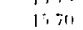 & 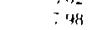 \\
\hline $21:-$ & $3: 11$ & $\therefore i$ & -40 \\
\hline$\because 4$ & $\therefore 4$ & $1 ; i ;$ & Ki \\
\hline$\therefore 13$ & an & 1it; & 8 \\
\hline 2122 & 13 is & $\therefore \mathrm{s}$, & 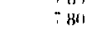 \\
\hline$\therefore 14$ & $3+3^{2}$ & $\therefore ;$ & -3 \\
\hline (2) $1 x_{4}$ & $\because 4$ & $\because 20$ & $\cdots$ \\
\hline 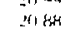 & inn & $\because \because 2$ & $=4$ \\
\hline$m$ & $3=34$ & $\because \because A+$ & $-n$ \\
\hline ?116- & $\therefore \ldots$ & $1+6=$ & - inl \\
\hline $2 ;$ & $\because 1$ & in. & $\because$ \\
\hline
\end{tabular}




\section{F. GAMMA-RAY ATTENLATION}

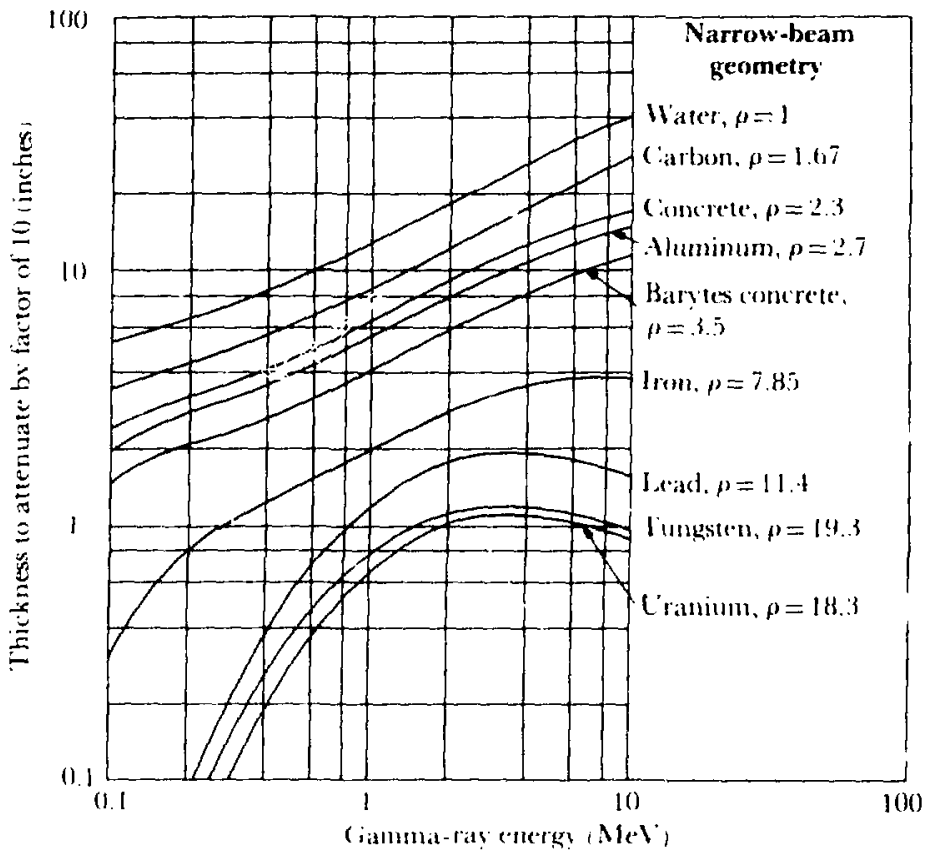

Thickness of 'ı, value layer for various gamma-ray shielding materials. Courfesy Mcciraw-Hill. 